Cardiology in the Young

cambridge.org/cty

\section{Original Article}

Cite this article: Shah MJ, Silka MJ, Silva JNA, Balaji S, Beach CM, Benjamin MN, Berul Cl, Cannon B, Cecchin F, Cohen MI, Dalal AS, Dechert BE, Foster A, Gebauer R, Gonzalez Corcia MC, Kannankeril PJ, Karpawich PP, Kim JJ, Krishna MR, Kubuš P, LaPage MJ, Mah DY, Malloy-Walton L, Miyazaki A, Motonaga KS, Niu MC, Olen M, Paul T, Rosenthal E, Saarel EV, Silvetti MS, Stephenson EA, Tan RB, Triedman J, Von Bergen NH, and Wackel PL (2021) 2021 PACES expert consensus statement on the indications and management of cardiovascular implantable electronic devices in pediatric patients. Cardiology in the Young 31: 1738-1769. doi: 10.1017/S1047951121003413

First published online: 2 August 2021

\section{Keywords:}

ambulatory ECG monitoring; antiarrhythmic drug therapy; antitachycardia pacing; arrhythmogenic cardiomyopathy; arrhythmogenic right ventricular cardiomyopathy; asystole; atrioventricular block; Bradycardia; Brugada syndrome; cardiac channelopathies; cardiac transplantation; cardiomyopathy; cardiovascular implantable electronic devices; catecholaminergic polymorphic ventricular tachycardia; children; congenital heart disease; coronary artery compression; ECG; echocardiography; endocardial lead; epicardial lead; expert consensus statement; genetic arrhythmias; heart block; heart failure; hypertrophic cardiomyopathy; implantable cardioverter defibrillator; insertable cardiac monitor; lead extraction; lead removal; Long QT syndrome; low- and middle-income countries; MR imaging; neuromuscular disease; pacemaker; PACES; pediatrics; postoperative; remote monitoring; shared decision-making; sick sinus syndrome; sports and physical activity; sudden cardiac arrest; sudden cardiac death; syncope; transvenous; ventricular fibrillation; ventricular tachycardia

\section{Abbreviations:}

ACM, arrhythmogenic cardiomyopathy; ARVC, arrhythmogenic right ventricular cardiomyopathy; $\mathrm{AV}$, atrioventricular; $\mathrm{BrS}$, Brugada syndrome; CCAVB, congenital complete atrioventricular block; CHD, congenital heart disease; CIED, cardiovascular implantable electronic device; COR, class of recommendation; CPVT,

catecholaminergic polymorphic ventricular tachycardia; ECG, electrocardiogram; HCM, hypertrophic cardiomyopathy; ICD, implantable cardioverter defibrillator; ICM, insertable cardiac monitor; IPE, in-person evaluation; LGE, late gadolinium enhancement; LVEF, left ventricular ejection fraction; LMIC, low- and middle-income countries; LOE, level of evidence; LQTS, long QT syndrome; MRI, magnetic resonance imaging; NIDCM, nonischemic dilated cardiomyopathy; RCT, randomized clinical trial; RIM, remote interrogation and monitoring; SCA, sudden cardiac arrest; $S C D$, sudden cardiac death; $S N D$, sinus node dysfunction; TTM, transtelephonic monitoring; VF, ventricular fibrillation; $\mathrm{VT}$, ventricular tachycardia

\title{
2021 PACES expert consensus statement on the indications and management of cardiovascular implantable electronic devices in pediatric patients
}

\section{Developed in collaboration with and endorsed by the Heart Rhythm Society (HRS), the American College of Cardiology (ACC), the American Heart Association (AHA), and the Association for European Paediatric and Congenital Cardiology (AEPC). Endorsed by the Asia Pacific Heart Rhythm Society (APHRS), the Indian Heart Rhythm Society (IHRS), and the Latin American Heart Rhythm Society (LAHRS).}

\section{Writing Committee Members ${ }^{\S}$}

Maully J. Shah" ${ }^{1, \wedge}$, Michael J. Silka ${ }^{2, \wedge}$, Jennifer N. Avari Silva ${ }^{3, \wedge}$, Seshadri Balaji Cheyenne M. Beach ${ }^{5}$, Monica N. Benjamin ${ }^{6}$, Charles I. Berul', Bryan Cannon ${ }^{8}$, Frank Cecchin ${ }^{9}$, Mitchell I. Cohen ${ }^{10}$, Aarti S. Dalal ${ }^{3}$, Brynn E. Dechert ${ }^{11}$, Anne Foster ${ }^{12}$,

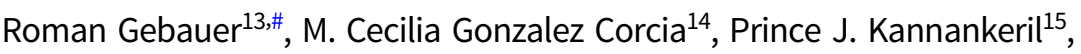
Peter P. Karpawich ${ }^{16}$, Jeffery J. Kim ${ }^{17}$, Mani Ram Krishna ${ }^{18}$, Peter Kubuš ${ }^{19}$, Martin J. LaPage ${ }^{11}$, Douglas Y. Mah ${ }^{20}$, Lindsey Malloy-Walton ${ }^{21}$, Aya Miyazaki ${ }^{22}$, Kara S. Motonaga ${ }^{23}$, Mary C. Niu $^{24}$, Melissa Olen ${ }^{25}$, Thomas Paul ${ }^{26}$, Eric Rosenthal ${ }^{27}$, Elizabeth V. Saarel ${ }^{28}$, Massimo Stefano Silvetti ${ }^{29}$, Elizabeth A. Stephenson ${ }^{30} \neq$, Reina B. $\operatorname{Tan}^{31}$, John Triedman ${ }^{20,4}$, Nicholas H. Von Bergen ${ }^{32}$ and Philip L. Wackel ${ }^{8}$

\section{Author for correspondence:}

Dr Maully J. Shah, Cardiac Center, Children's Hospital of Philadelphia, 3401 Civic Center Blvd, Philadelphia, PA 19104. E-mail: shahm@chop.edu; OR Dr Michael J. Silka, Division of Pediatric Cardiology, Children's Hospital Los Angeles, 4650 Sunset Blvd, Los Angeles, CA 90027. E-mail: msilka@chla.usc.edu.

"Representative of the Heart Rhythm Society (HRS)

*Representative of the American College of Cardiology (ACC)

\#Representative of the Association for European Paediatric and Congenital Cardiology (AEPC)

‡Representative of the American Heart Association (AHA)

${ }^{\wedge}$ Maully J. Shah, MBBS, FHRS, FACC, and Michael J. Silka, MD, FACC, FAHA, are co-first authors.

${ }^{\S}$ Writing committee members are required to recuse themselves from voting on sections to which their specific relationships with industry may apply; see Appendix 1 for detailed information.

(c) 2021 The Author(s). Published by Elsevier Inc. on behalf of the Heart Rhythm Society and the American College of Cardiology Foundation, by Elsevier B.V. on behalf of the Indian Heart Rhythm Society, and by Cambridge University Press. This is an open access article under the CC BY-NC-ND license (http://creativecommons.org/licenses/by-nc-nd/4.0/), which permits non-commercial re-use, distribution, and reproduction in any medium, provided the original work is unaltered and is properly cited. The written permission of Cambridge University Press must be obtained for commercial re-use or in order to create a derivative work.

\section{CAMBRIDGE UNIVERSITY PRESS}




\title{
Document Reviewers:
}

\section{Philip M. Chang, Fabrizio Drago, Anne M. Dubin, Susan P. Etheridge, Apichai Kongpatanayothin, Jose Manuel Moltedo,}

\section{Ashish A. Nabar and George F. Van Hare}

\begin{abstract}
${ }^{1}$ University of Pennsylvania Perelman School of Medicine, Philadelphia, Pennsylvania; ${ }^{2}$ University of Southern California Keck School of Medicine, Los Angeles, California; ${ }^{3}$ Washington University in St. Louis, St. Louis, Missouri; ${ }^{4}$ Oregon Health \& Science University, Portland, Oregon; ${ }^{5}$ Yale University School of Medicine, New Haven, Connecticut; ${ }^{6} \mathrm{Hospital}$ de Pediatría Juan P. Garrahan, Hospital El Cruce, Hospital Británico de Buenos Aires, Instituto Cardiovascular ICBA, Buenos Aires, Argentina; ${ }^{7}$ George Washington University, Washington, DC; ${ }^{8}$ Mayo Clinic, Rochester, Minnesota; ${ }^{9}$ New York University Grossman School of Medicine, New York, New York; ${ }^{10}$ Inova Children's Hospital, Fairfax, Virginia; ${ }^{11}$ University of Michigan, Ann Arbor, Michigan; ${ }^{12}$ Advocate Children's Heart Institute, Chicago, Illinois; ${ }^{13}$ Heart Centre Leipzig, University of Leipzig, Leipzig, Germany; ${ }^{14}$ Bristol Royal Hospital for Children, Bristol, UK; ${ }^{15}$ Vanderbilt University Medical Center, Nashville, Tennessee; ${ }^{16}$ University Pediatricians, Children's Hospital of Michigan, Detroit, Michigan; ${ }^{17}$ Baylor College of Medicine, Houston, Texas; ${ }^{18}$ Amrita Institute of Medical Sciences, Kochi, India; ${ }^{19} \mathrm{Children's} \mathrm{Heart} \mathrm{Center,} \mathrm{Charles} \mathrm{University} \mathrm{in} \mathrm{Prague} \mathrm{and} \mathrm{Motol} \mathrm{University} \mathrm{Hospital,} \mathrm{Prague,} \mathrm{Czech} \mathrm{Republic;}{ }^{20} \mathrm{Harvard}$ Medical School, Boston, Massachusetts; ${ }^{21}$ University of Missouri-Kansas City School of Medicine, Kansas City, Missouri; ${ }^{22}$ Shizuoka General Hospital and Mt. Fuji Shizuoka Children's Hospital, Shizuoka, Japan; ${ }^{23}$ Stanford University, Palo Alto, California; ${ }^{24}$ University of Utah Health Sciences Center, Salt Lake City, Utah; ${ }^{25}$ Nicklaus Children's Hospital, Miami, Florida; ${ }^{26}$ Georg-August-University Medical Center, Göttingen, Germany; ${ }^{27}$ Evelina London Children's Hospital and St Thomas' Hospital, Guy's \& St Thomas' NHS Foundation Trust, London, UK; ${ }^{28}$ St. Luke's Health System, Boise, Idaho; ${ }^{29}$ Bambino Gesù Children's Hospital IRCCS, Rome, Italy; ${ }^{30}$ The Hospital for Sick Children, Toronto, Canada; ${ }^{31} \mathrm{New}$ York University Langone Health, New York, New York and ${ }^{32}$ University of Wisconsin School of Medicine and Public Health, Madison, Wisconsin
\end{abstract}

\section{Abstract}

In view of the increasing complexity of both cardiovascular implantable electronic devices (CIEDs) and patients in the current era, practice guidelines, by necessity, have become increasingly specific. This document is an expert consensus statement that has been developed to update and further delineate indications and management of CIEDs in pediatric patients, defined as $\leq 21$ years of age, and is intended to focus primarily on the indications for CIEDs in the setting of specific disease categories. The document also highlights variations between previously published adult and pediatric CIED recommendations and provides rationale for underlying important differences. The document addresses some of the deterrents to CIED access in low- and middle-income countries and strategies to circumvent them. The document sections were divided up and drafted by the writing committee members according to their expertise. The recommendations represent the consensus opinion of the entire writing committee, graded by class of recommendation and level of evidence. Several questions addressed in this document either do not lend themselves to clinical trials or are rare disease entities, and in these instances recommendations are based on consensus expert opinion. Furthermore, specific recommendations, even when supported by substantial data, do not replace the need for clinical judgment and patient-specific decision-making. The recommendations were opened for public comment to Pediatric and Congenital Electrophysiology Society (PACES) members and underwent external review by the scientific and clinical document committee of the Heart Rhythm Society (HRS), the science advisory and coordinating committee of the American Heart Association (AHA), the American College of Cardiology (ACC), and the Association for European Paediatric and Congenital Cardiology (AEPC). The document received endorsement by all the collaborators and the Asia Pacific Heart Rhythm Society (APHRS), the Indian Heart Rhythm Society (IHRS), and the Latin American Heart Rhythm Society (LAHRS). This document is expected to provide support for clinicians and patients to allow for appropriate CIED use, appropriate CIED management, and appropriate CIED follow-up in pediatric patients.

\section{Table of Contents}

\section{Preamble}

\section{Introduction}

Methodology and Evidence Review

Organization of the Writing Committee

Document Review and Approval

Health Policy Objectives

Top 10 Take-Home Messages

\section{Permanent Pacemakers}

Introduction

Isolated Sinus Node Dysfunction

Isolated Congenital Complete Atrioventricular Block

Atrioventricular Block: Other Considerations

Postoperative Atrioventricular Block

Congenital Heart Disease: Specific Considerations

Post Cardiac Transplantation

Neuromuscular Diseases and Other

Progressive Conduction Diseases

Neurocardiogenic Syncope
Cardiac Channelopathies

Inflammation/Infection

\section{Implantable Cardioverter Defibrillators}

Introduction

General Recommendations for ICD Therapy

ICD Indications for Cardiac Channelopathies

Long QT Syndrome

Catecholaminergic Polymorphic Ventricular

Tachycardia

Brugada Syndrome

ICD Indications for Cardiomyopathies

Hypertrophic Cardiomyopathy

Restrictive Cardiomyopathy

Arrhythmogenic Cardiomyopathies

Nonischemic Dilated Cardiomyopathies

ICD indications for Congenital Heart Disease

Insertable Cardiac Monitors

CIED Lead Management

CIED Follow-up and Ancillary Testing

Special Considerations 
CIEDs and Magnetic Resonance Imaging

CIEDs and Sports Participation

CIEDs in Low- and Middle-Income Countries

Shared Decision-Making

Knowledge Gaps and Future Research

References

Appendix 1 Author Relationships With Industry

Appendix 2 Reviewer Relationships With Industry

This article has been copublished in Heart Rhythm, JACC: Clinical Electrophysiology, Indian Pacing and Electrophysiology Journal, and Cardiology in the Young.

\section{Preamble}

Guidelines for the implantation of cardiovascular implantable electronic devices (CIEDs) have evolved since the initial American College of Cardiology (ACC)/American Heart Association (AHA) pacemaker guidelines in $1984 .{ }^{1}$ CIEDs have evolved to include novel forms of cardiac pacing, the development of implantable cardioverter defibrillators (ICDs), and the introduction of devices for long-term monitoring of heart rhythm as well as other physiologic parameters. In view of the increasing complexity of both devices and patients in the current era, practice guidelines, by necessity, have become increasingly specific. One aspect of this evolution is the "2018 ACC/AHA/HRS Guideline on the Evaluation and Management of Patients With Bradycardia and Cardiac Conduction Delay," ${ }^{2}$ which included specific recommendations for patients $>18$ years of age. This age-specific threshold was established in view of the need for differing indications for CIEDs as well as size-specific technology factors in younger patients. Therefore, this document has been developed to update and further delineate indications for the use and management of CIEDs in pediatric patients, defined as $\leq 21$ years of age, in recognition that there is often overlap in the care of patents between 18 and 21 years of age.

This document is an expert consensus statement intended to focus primarily on the indications for CIEDs in the setting of specific disease/diagnostic categories. This consensus statement will also provide guidance regarding the management of CIEDs for rhythm disorders in pediatric patients and address some of the deterrents to CIED access in low- and middle-income countries and strategies to circumvent them.

Recommendations are presented in a modular or knowledge chunk format, in which each section includes a table of recommendations, a brief synopsis, and recommendation-specific supportive text. ${ }^{3}$ However, this document is not intended to provide an exhaustive review of all aspects of pacemakers, ICDs, and insertable cardiac monitors (ICMs), as this information is easily accessible in electronic searches or textbooks. Furthermore, specific recommendations, such as heart rate criteria for pacemaker implantation, even when supported by substantial data, do not replace the need for clinical judgment and patient-specific decision-making. As a final introductory comment, to avoid clinical overlap, the indications and management of cardiac resynchronization therapy and physiological pacing will be addressed in the anticipated "2022 HRS Expert Consensus Statement on Cardiac Physiological Pacing for the
Avoidance and Mitigation of Heart Failure," which will include a specific section on pediatric and congenital heart disease (CHD).

\section{Introduction}

Methodology and evidence review

The principles in the development of this document are 1) new recommendations and any changes to previous recommendations are based on data, when possible; 2) these recommendations are consistent with current ACC/AHA/Heart Rhythm Society (HRS) guidelines when reasonable; ${ }^{2-19}$ and 3) all recommendations are critically reviewed, initially by the writing committee and editors, followed by the Pediatric and Congenital Electrophysiology Society (PACES) executive committee, and subsequently by external HRS, ACC, AHA, and Association for European Paediatric and Congenital Cardiology (AEPC) representatives. Any revisions or additions to existing recommendations will require approval of at least $80 \%$ by the members of the PACES writing committee. Specific prior guidelines and consensus statements relevant to CIEDs that have been referenced as the basis for recommendations in this document are acknowledged below and recognized in the specific sections (Table 1).

These recommendations have been developed consistent with standard guideline methodology, i.e., with both a class of recommendation (COR) and a level of evidence (LOE) (Table 2). ${ }^{4}$ The class of the recommendation indicates the strength of recommendation, based on the estimated magnitude or certainty of benefit in proportion to risk. The level of evidence rates the quality of scientific evidence supporting the intervention on the basis of the type, quantity, and consistency of data from clinical trials and other sources. Due to the lack of randomized clinical trials (RCTs) in pediatric patients, these LOE recommendations will be limited to class B-NR (limited populations), class C-LD (very limited populations), or C-EO (consensus expert opinion, case studies, or standard of care). It is important to emphasize that a recommendation with a level of evidence C-EO does not imply that the recommendation is weak. Many of the questions addressed in this (and other) documents either do not lend themselves to clinical trials or are rare disease entities. ${ }^{5}$ However, there may be unequivocal expert consensus that a particular intervention is either effective or necessary. The final evidence tables for the recommendations are included in Supplemental Appendix 3 and summarize the evidence used by the writing committee to formulate these recommendations. References selected and published in this document are intended to be representative and not all-inclusive. Variations between previously published adult and pediatric CIED recommendations as well as new pediatric-specific recommendations are listed in Supplemental Appendix 4.

\section{Organization of the writing committee}

The writing committee consisted of members of PACES who were selected by the PACES executive committee. The writing committee members included junior and senior pediatric electrophysiologists as well as allied health professionals and represented diverse genders, countries, and cultures. The writing committee also included external representatives from the ACC, AHA, HRS, and AEPC. Prior to final publication, all committee members 
Table 1. Guidelines, expert consensus statements, and reports Cited

\begin{tabular}{|c|c|c|}
\hline Title & Organization & Year (reference) \\
\hline Guidelines for permanent pacemaker implantation & ACC/AHA & $1984^{1}$ \\
\hline Guidelines for the management of patients with bradycardia and cardiac conduction delay & ACC/AHA/HRS & $2019^{2}$ \\
\hline Report: Innovations, modifications, and evolution of clinical practice guidelines & $\mathrm{ACC} / \mathrm{AHA}$ & $2019^{3}$ \\
\hline Report: Evolution of the clinical practice guideline recommendation classification system & $\mathrm{ACC} / \mathrm{AHA}$ & $2016^{4}$ \\
\hline ECS: ICD therapy in patients who are not included or not well represented in clinical trials & $\mathrm{HRS} / \mathrm{ACC} / \mathrm{AHA}$ & $2014^{5}$ \\
\hline Guidelines for device-based therapy & ACC/AHA/HRS & $2008^{6}$ \\
\hline Update of the 2008 device-based therapy guidelines & $\mathrm{ACC} / \mathrm{AHA} / \mathrm{HRS}$ & $2012^{7}$ \\
\hline ECS: Arrhythmias in congenital heart disease & EHRA/AEPC/ESC & $2018^{8}$ \\
\hline ECS: Recognition and management of arrhythmias in adult congenital heart disease & PACES/HRS & $2014^{9}$ \\
\hline Guidelines on cardiac pacing and resynchronization & ESC & $2013^{10}$ \\
\hline Guidelines for the evaluation and management of patients with syncope & ACC/AHA/HRS & $2017^{11}$ \\
\hline Guidelines for management of patients with ventricular arrhythmias and the prevention of sudden cardiac death & $\mathrm{AHA} / \mathrm{ACC} / \mathrm{HRS}$ & $2018^{12}$ \\
\hline Guidelines for management of patients with ventricular arrhythmias and the prevention of sudden cardiac death & ESC & $2015^{13}$ \\
\hline ECS: The diagnosis and management of patients with inherited primary arrhythmia syndromes & HRS/EHRA/APHRS & $2013^{14}$ \\
\hline Guideline for the diagnosis and treatment of patients with hypertrophic cardiomyopathy & $\mathrm{AHA} / \mathrm{ACC}$ & $2020^{15}$ \\
\hline ECS: The evaluation, risk stratification, and management of arrhythmogenic cardiomyopathy & HRS & $2019^{16}$ \\
\hline Guidelines for the management for pediatric heart failure & HRS & $2015^{17}$ \\
\hline ECS: CIED lead management and extraction & HRS & $2017^{18}$ \\
\hline ECS: MRI and radiation exposure in patients with CIEDs & HRS & $2018^{19}$ \\
\hline
\end{tabular}

ECS = expert consensus statements; EHRA = European Heart Rhythm Association; ESC = European Society of Cardiology.

Table 2. Class of Recommendation and Level of Evidence Categories*

\begin{tabular}{|c|c|c|c|}
\hline Class I & Class IIa & Class IIb & Class III \\
\hline $\begin{array}{l}\text { Benefit }>>\text { Risk } \\
\text { Procedure/treatment SHOULD be } \\
\text { performed/is recommended }\end{array}$ & $\begin{array}{l}\text { Benefit }>>\text { Risk } \\
\text { IT IS REASONABLE to perform the } \\
\text { procedure/treatment }\end{array}$ & $\begin{array}{l}\text { Benefit } \geq \text { Risk } \\
\text { Procedure/treatment } \\
\text { MAY BE CONSIDERED/ } \\
\quad \text { effectiveness is uncertain }\end{array}$ & $\begin{array}{l}\text { Risk } \geq \text { Benefit } \\
\text { Procedure should NOT be } \\
\text { performed } \\
\text { IS NOT HELPFUL/MAY BE } \\
\text { HARMFUL }\end{array}$ \\
\hline \multicolumn{4}{|l|}{ Levels of Evidence } \\
\hline \multicolumn{4}{|c|}{ B-NR: Evidence from nonrandomized studies, observational studies, or registry studies } \\
\hline
\end{tabular}

*Adapted from Halperin, et al. ${ }^{4}$

were required to verify their specific contributions to this document. Appendix 1 lists writing committee members' relevant relationships with industry.

\section{Document review and approval}

Following internal review by the PACES executive committee, this document was then reviewed by the PACES writing committee. Following considerations of these comments and approval by an independent PACES reviewer, the recommendations were opened for public comment to PACES members. An official reviewer each nominated by HRS, ACC, AHA, and
AEPC provided independent external review. This document was then approved for publication by the PACES executive committee and endorsed by all collaborators and the Asia Pacific Heart Rhythm Society (APHRS), the Indian Heart Rhythm Society (IHRS), and the Latin American Heart Rhythm Society. Appendix 2 lists reviewers' relevant relationships with industry.

\section{Health policy objectives}

The purpose of this document is to provide guidance to clinicians for the management of pediatric patients who may require a CIED, 
with a primary focus on the indications for device implantation. The document will be useful to pediatric cardiologists, cardiac surgeons, cardiac intensivists, anesthesiologists, and arrhythmia specialists. This document supersedes the pediatric CIED recommendations made in "ACC/AHA/HRS 2008 Guidelines for Device-Based Therapy of Cardiac Rhythm Abnormalities"6 and "2012 ACCF/AHA/HRS Focused Update of the 2008 Guidelines for Device-Based Therapy of Cardiac Rhythm Abnormalities."7 This document is expected to provide support for clinicians and patients to allow for appropriate device use, appropriate device management, follow-up, and appropriate reimbursement in pediatric patients.

\section{Top 10 take-home messages}

1. In patients with isolated sinus node dysfunction (SND), there is no minimum heart rate or maximum pause duration where permanent pacing is absolutely recommended. Establishing a temporal correlation between symptoms and bradycardia is critical in the decision as to whether permanent pacing is indicated.

2. Young patients with impaired ventricular function or abnormal cardiovascular physiology may be symptomatic due to sinus bradycardia or the loss of atrioventricular (AV) synchrony at heart rates that do not produce symptoms in individuals with normal cardiovascular physiology.

3. Although the average ventricular rate in newborns and infants with congenital complete atrioventricular block (CCAVB) provides an objective measure regarding the decision for pacemaker implantation, additional factors may equally influence the decision/timing of pacemaker implant. These include birth weight (size), congenital heart defects, ventricular function, and other comorbidities.

4. In patients with postoperative AV block, a period of observation for at least 7-10 days before pacemaker implantation remains advised; in select cases, earlier pacemaker implantation may be considered if AV block is not expected to resolve due to extensive injury to the cardiac conduction system.

5. Atrial pacing with antitachycardia pacing capabilities is reasonable for CHD patients with recurrent intra-atrial reentrant tachycardia when medication and catheter ablation are not effective.

6. There is increased recognition of the need for pacemaker implantation in conditions such as Kearns-Sayre syndrome or certain neuromuscular disorders due to the unpredictable progression of conduction disease.

7. The cause of sudden cardiac arrest (SCA) remains undefined in nearly $50 \%$ of pediatric survivors. ICD implantation is recommended provided completely reversible causes have been excluded, other treatments that may be beneficial are considered, and meaningful survival is anticipated.

8. The decisions for implantation of an ICD for primary prevention in cardiac channelopathies or cardiomyopathies remain guided by limited and, at times, conflicting data. Consideration of patient-specific factors and shared decision-making are critically important.

9. In pediatric patients with nonischemic dilated cardiomyopathy (NIDCM), primary prevention ICD implantation for left ventricular ejection fraction (LVEF) 35\%, in the absence of other risk factors, is not clearly supported by published data.

10. In patients with indications for implantation of a CIED, shared decision-making and patient/family-centered care are endorsed and emphasized. Treatment decisions are based on the best available evidence and patient's preferences.

\section{Permanent pacemakers}

\section{Introduction}

The most common indications for permanent pacemaker implantation in children, adolescents, and patients with $\mathrm{CHD}$ may be classified as 1) symptomatic sinus bradycardia, 2) advanced second- or third-degree AV block, either congenital or acquired, and 3) pacing for the prevention or termination of tachyarrhythmias. ${ }^{6}$ In general, many of the indications for pacemaker implantation in children and adolescents (defined as $<19$ years of age) are similar to those in adults. ${ }^{2}$ However, there are several important differences in infants and children. These patients have faster heart rates, and therefore standards for what is considered normal are age-dependent variables; whereas a heart rate of $45 \mathrm{bpm}$ may be a normal in an adolescent, the same rate in a newborn or infant indicates profound bradycardia. In addition, young patients with impaired ventricular function or abnormal physiology may be symptomatic due to sinus bradycardia or loss of AV synchrony at heart rates that do not produce symptoms in individuals with normal cardiovascular physiology. ${ }^{8,9}$ Hence, the indications for pacemaker implantation in young patients need to be based on the correlation of symptoms with relative bradycardia rather than absolute heart rate criteria.

Significant technical challenges may complicate device and lead implantation in small patients or those with abnormalities of venous or intracardiac anatomy. Epicardial pacemaker lead placement and use of device technology in innovative ways often need to be considered to provide pacing in the youngest patients. ${ }^{20-22}$ Any pacemaker system used in a young patient may need to be utilized for multiple decades, and consideration of the long-term consequences from device and lead failure plays a role in implantation of pediatric devices.

Bradycardia and associated symptoms in children are often transient (e.g., breath-holding spells) and therefore may not require permanent pacemaker therapy. Conversely, there are other conduction system disorders that may rapidly progress (e.g., neuromuscular disorders) that may require prophylactic pacemaker implantation for disease-specific indications. In addition, as risk factors for cardiac conditions such as the channelopathies are better defined, the indications for device placement in these patients may evolve rapidly.

The goal of this section is to provide an update regarding the indications for permanent pacemaker implantation in pediatric patients. A summary of the recent literature is provided as a framework for clinicians to make individual decisions about pacing in these patients. As the pediatric and CHD populations represent unique groups of patients, clinical judgment and patient-specific decision-making are of the highest importance. 
Isolated sinus node dysfunction

\begin{tabular}{|c|c|c|c|}
\hline \multirow[b]{2}{*}{ COR } & Recommendations & \multirow[b]{2}{*}{ LOE } & \multirow[b]{2}{*}{ References } \\
\hline & Isolated Sinus Node Dysfunction & & \\
\hline 1 & $\begin{array}{l}\text { Permanent atrial or dual- } \\
\text { chamber pacemaker } \\
\text { implantation is indicated for } \\
\text { SND when there is correlation of } \\
\text { symptoms with age- } \\
\text { inappropriate bradycardia. }\end{array}$ & B-NR & $23-26$ \\
\hline । & $\begin{array}{l}\text { Permanent pacemaker } \\
\text { implantation is indicated in } \\
\text { patients with symptomatic SND } \\
\text { secondary to chronic medical } \\
\text { therapy for which there is no } \\
\text { alternative treatment. }\end{array}$ & C-EO & \\
\hline Ila & $\begin{array}{l}\text { Permanent pacemaker } \\
\text { implantation (with rate- } \\
\text { responsive programming) is } \\
\text { reasonable in patients with } \\
\text { symptoms temporally associated } \\
\text { with observed chronotropic } \\
\text { incompetence. }\end{array}$ & C-LD & 27,28 \\
\hline IIb & $\begin{array}{l}\text { Permanent pacemaker } \\
\text { implantation may be considered } \\
\text { in patients with SND and } \\
\text { symptoms that are likely } \\
\text { attributable to bradycardia or } \\
\text { prolonged pauses without } \\
\text { conclusive evidence correlating } \\
\text { the symptoms with bradycardia } \\
\text { following a thorough } \\
\text { investigation. }\end{array}$ & C-EO & \\
\hline $\begin{array}{l}\text { III } \\
\text { No Benefit }\end{array}$ & $\begin{array}{l}\text { Permanent pacemaker } \\
\text { implantation is not indicated in } \\
\text { patients with asymptomatic } \\
\text { SND. }\end{array}$ & C-EO & \\
\hline $\begin{array}{l}\text { III } \\
\text { Harm }\end{array}$ & $\begin{array}{l}\text { Permanent pacemaker } \\
\text { implantation is not indicated in } \\
\text { patients with symptomatic SND } \\
\text { due to a reversible cause. }\end{array}$ & C-EO & \\
\hline
\end{tabular}

Recommendation-specific supportive text

SND refers to physiologically inappropriate atrial rates, due to either sustained bradycardia or abrupt pauses in the intrinsic cardiac rhythm. In patients with isolated sinus bradycardia without symptoms due to cerebral or systemic hypoperfusion, there is no minimum heart rate or maximum pause duration where permanent pacing is recommended. Establishing a temporal correlation between symptoms and age-related bradycardia is of paramount importance when determining whether permanent pacing is needed.

Nonrandomized studies in both children and adults have demonstrated that pacing can provide symptomatic improvement when symptoms, particularly syncope and pre-syncope, are clearly attributable to SND. ${ }^{23-26}$ However, there is no clear evidence that pacing in the setting of isolated SND without symptoms improves outcomes.

In symptomatic patients with SND, atrial-based pacing is generally recommended over single-chamber ventricular pacing.,28 Furthermore, the decisions regarding pacemaker implantation for SND in patients with CHD or channelopathies should be made on an individualized basis and are discussed further in the corresponding sections. ${ }^{29}$
Isolated congenital complete

Atrioventricular block

\begin{tabular}{|c|c|c|c|}
\hline & Recommendations & & \\
\hline COR & $\begin{array}{l}\text { Isolated Congenital Complete } \\
\text { Atrioventricular Block }\end{array}$ & LOE & References \\
\hline 1 & $\begin{array}{l}\text { Permanent pacemaker implantation is } \\
\text { indicated for patients with CCAVB with } \\
\text { symptomatic bradycardia. }\end{array}$ & B-NR & $30-33$ \\
\hline I & $\begin{array}{l}\text { Permanent pacemaker implantation is } \\
\text { indicated for patients with CCAVB with } \\
\text { a wide QRS escape rhythm, complex } \\
\text { ventricular ectopy, or ventricular } \\
\text { dysfunction. }\end{array}$ & B-NR & $34-36$ \\
\hline 1 & $\begin{array}{l}\text { Permanent pacemaker implantation is } \\
\text { indicated for CCAVB in asymptomatic } \\
\text { neonates or infants when the mean } \\
\text { ventricular rate is } \leq 50 \mathrm{bpm} \text {. } \\
\text { Ventricular rate alone should not be } \\
\text { used as implant criteria, as symptoms } \\
\text { due to low cardiac output may occur } \\
\text { at faster heart rates. }\end{array}$ & C-LD & $30,34,37$ \\
\hline Ila & $\begin{array}{l}\text { Permanent pacemaker implantation is } \\
\text { reasonable for asymptomatic CCAVB } \\
\text { beyond the first year of life when the } \\
\text { mean ventricular rate is }<50 \mathrm{bpm} \text { or } \\
\text { there are prolonged pauses in } \\
\text { ventricular rate. }\end{array}$ & B-NR & $36,38,39$ \\
\hline Ila & $\begin{array}{l}\text { Permanent pacemaker implantation is } \\
\text { reasonable for CCAVB with left } \\
\text { ventricular dilation }(z \text { score } \geq 3) \\
\text { associated with significant mitral } \\
\text { insufficiency or systolic dysfunction. }\end{array}$ & C-LD & 40,41 \\
\hline $\mathrm{llb}$ & $\begin{array}{l}\text { Permanent pacemaker implantation } \\
\text { may be considered for CCAVB in } \\
\text { asymptomatic adolescents with an } \\
\text { acceptable ventricular rate, a narrow } \\
\text { QRS complex, and normal ventricular } \\
\text { function, based on an individualized } \\
\text { consideration of the risk/benefit ratio. }\end{array}$ & C-LD & 2,33 \\
\hline
\end{tabular}

Recommendation-Specific Supportive Text

Although the average ventricular rate in newborns ( $\leq 30$ days old) and infants ( $\leq 12$ months old) with isolated CCAVB provides an objective measure regarding the decision for pacemaker implantation, additional factors may equally influence the decision/timing of pacemaker implant. These include birth weight (size), ventricular dysfunction, and other comorbidities. ${ }^{42}$ Furthermore, although symptoms such as poor feeding or tachypnea in the neonate may be due to multiple causes, they may be indicative of low cardiac output secondary to bradycardia. Therefore, a lower limit heart rate of $50 \mathrm{bpm}$ is recommended for pacemaker implantation when overt symptoms related to low cardiac output do not appear to be present. One additional point of emphasis is that use of heart rate criteria for newborn or infant pacing should be based on heart rate consistency rather than a single measurement in time. ${ }^{34,37}$

Beyond the first year of life, permanent pacemaker implantation is generally indicated in symptomatic patients. Contemporary studies suggest that approximately $66 \%$ of neonates and infants diagnosed with isolated CCAVB will undergo pacemaker implantation during their first year of life and that $90 \%$ of patients with CCAVB will undergo pacemaker implantation by 20 years of age. ${ }^{30}$ 
Long-term natural history studies have demonstrated progressive left ventricular dysfunction and mitral insufficiency with cardiovascular mortality in the fourth or fifth decade of life in patients with CCAVB who did not undergo pacemaker implantation. ${ }^{33,34,43}$ On the other hand, some patients with CCAVB will develop left ventricular cardiomyopathy despite pacing due to either antibody-mediated myocarditis or pacing-induced dyssynchrony. ${ }^{43,44}$

\section{Atrioventricular block: other considerations}

\begin{tabular}{|c|c|c|c|}
\hline \multirow[b]{2}{*}{ COR } & Recommendations & \multirow[b]{2}{*}{ LOE } & \multirow[b]{2}{*}{ Reference } \\
\hline & $\begin{array}{l}\text { Atrioventricular Block: Other } \\
\text { Considerations }\end{array}$ & & \\
\hline I & $\begin{array}{l}\text { Permanent pacemaker implantation } \\
\text { is indicated in patients with clinically } \\
\text { significant VT that is pause } \\
\text { dependent or associated with severe } \\
\text { bradycardia; ICD implantation may } \\
\text { be considered as a reasonable } \\
\text { alternative. }\end{array}$ & C-LD & 45,46 \\
\hline 1 & $\begin{array}{l}\text { Permanent pacing is indicated in } \\
\text { symptomatic patients with idiopathic } \\
\text { advanced second- or third-degree AV } \\
\text { block not attributable to reversible } \\
\text { causes. }\end{array}$ & C-LD & $2,6,7$ \\
\hline Ila & $\begin{array}{l}\text { Permanent pacemaker implantation } \\
\text { is reasonable for any degree of } A V \\
\text { block that progresses to advanced } \\
\text { second- or third-degree with exercise } \\
\text { in the absence of reversible causes. }\end{array}$ & C-LD & 47,48 \\
\hline $\mathrm{llb}$ & $\begin{array}{l}\text { Permanent pacemaker implantation } \\
\text { may be considered for patients with } \\
\text { intermittent advanced second- or } \\
\text { third-degree AV block not } \\
\text { attributable to reversible causes and } \\
\text { associated with minimal symptoms } \\
\text { that are otherwise unexplained. }\end{array}$ & C-LD & 49 \\
\hline $\begin{array}{l}\text { III } \\
\text { Harm }\end{array}$ & $\begin{array}{l}\text { Permanent pacemaker implantation } \\
\text { is not indicated for asymptomatic } \\
\text { first-degree AV block or } \\
\text { asymptomatic second-degree Mobitz } \\
\text { type I. }\end{array}$ & C-LD & 2,7 \\
\hline
\end{tabular}

Recommendation-specific supportive text

The diagnosis of advanced AV block during late childhood or adolescence is an uncommon but well-recognized phenomena. Advanced AV block may be congenital, may be related to infiltrative diseases, or may remain idiopathic. At times, late-onset AV block may be paroxysmal and quite difficult to document. ${ }^{49}$

Exercise stress testing can be useful to detect the site and significance of AV block. Generally, supra-His block resolves with exercise by increased sympathetic tone. When second- and third-degree degree AV block are observed during exercise, conduction disturbance within the His-Purkinje system is suspected. Although progression to advanced second- and third-degree AV block during exercise is rare, it is associated with a poor prognosis in the absence of a pacemaker. ${ }^{47,48}$

With the exception of infiltrative or inflammatory causes of advanced AV block, the criteria for pacemaker implantation are similar to those for CCAVB. Permanent pacemaker implantation may be considered for advanced idiopathic AV block in adolescents with an acceptable ventricular rate, a narrow QRS complex, and normal ventricular function, based on an individualized consideration of symptoms and the risk/benefit ratio.

\section{Postoperative atrioventricular block}

\begin{tabular}{|c|c|c|c|}
\hline & Recommendations & & \\
\hline COR & Postoperative Atrioventricular Block & LOE & References \\
\hline I & $\begin{array}{l}\text { Permanent pacemaker implantation is } \\
\text { indicated for postoperative advanced } \\
\text { second- or third-degree AV block that } \\
\text { persists for at least } 7-10 \text { days after } \\
\text { cardiac surgery. }\end{array}$ & B-NR & 50-53 \\
\hline 1 & $\begin{array}{l}\text { Permanent pacemaker implantation is } \\
\text { indicated for late-onset advanced } \\
\text { second- or third-degree AV block } \\
\text { especially when there is a prior history } \\
\text { of transient postoperative AV block. }\end{array}$ & C-LD & $52,54,55$ \\
\hline IIb & $\begin{array}{l}\text { Permanent pacemaker implantation } \\
\text { may be considered for unexplained } \\
\text { syncope in patients with a history of } \\
\text { transient postoperative advanced } \\
\text { second- or third-degree AV block. }\end{array}$ & C-LD & 54,55 \\
\hline Ilb & $\begin{array}{l}\text { Permanent pacemaker implantation } \\
\text { may be considered at }<7 \\
\text { postoperative days when advanced } \\
\text { second- or third-degree AV block is not } \\
\text { expected to resolve due to extensive } \\
\text { injury to the cardiac conduction } \\
\text { system. }\end{array}$ & C-EO & \\
\hline $\mathrm{Ilb}$ & $\begin{array}{l}\text { Permanent pacemaker implantation } \\
\text { may be considered in select patients } \\
\text { with transient postoperative advanced } \\
\text { second- or third-degree AV block who } \\
\text { are predisposed to progressive } \\
\text { conduction abnormalities (see text). }\end{array}$ & C-EO & \\
\hline
\end{tabular}

\section{Recommendation-specific supportive text}

Postoperative AV block complicates 3-8\% of congenital heart surgeries, with $1-3 \%$ of patients requiring permanent pacemaker implantation for persistent postoperative AV block. ${ }^{56-58}$ A very poor prognosis has been established for $\mathrm{CHD}$ patients with permanent postoperative AV block who do not receive permanent pacemakers. ${ }^{54,55}$ Among patients who do regain AV conduction following a period of transient $\mathrm{AV}$ block, $\geq 85 \%$ have recovery of AV conduction by postoperative day 7 and $\geq 95 \%$ AV conduction by postoperative day $10 .^{50,51}$ Although patients who spontaneously regain AV conduction have a favorable prognosis, ${ }^{7}$ there is a small but definite risk of late-onset complete AV block in transient postoperative AV block patients, with onset occurring as early as months, to as late as decades, following surgery. ${ }^{52,54,55}$ Limited data suggest that some patients with a history of transient postoperative advanced second- or third-degree AV block may be at risk for lateonset AV block or sudden cardiac death (SCD) if they have postoperative bifascicular block on the electrocardiogram (ECG) that was not present preoperatively. ${ }^{54,55}$ Permanent pacemaker implantation may also be considered for transient postoperative third-degree AV block that reverts to intact AV node conduction when there is concern about the late development of AV block in patients with forms of CHD associated with progressive conduction abnormalities such as discordant AV connections, AV septal defects, and heterotaxy syndromes. ${ }^{59,60}$ 
Congenital heart disease: specific considerations

\begin{tabular}{ll}
\hline COR & Recommendations \\
\hline Congenital Heart Disease & LOE $\quad$ References \\
\hline & $\begin{array}{l}\text { All the recommendations in children } \\
\text { with a structurally normal heart apply, } \\
\text { but in addition: }\end{array}$ \\
\hline Permanent pacemaker implantation \\
is indicated for CCAVB in neonates or \\
infants with complex CHD when \\
bradycardia is associated with \\
hemodynamic compromise or when \\
the mean ventricular rate is <60- \\
70 bpm.
\end{tabular}

Recommendation-specific supportive text

Patients with CHD often have important structural and functional lesions, ${ }^{70}$ which influence both the indications for pacing as well as the type of pacing lead(s) utilized. ${ }^{42}$ Therefore, pacemaker implantation in these patients should not be viewed as an isolated procedure. The loss of vascular access or direct access to cardiac chambers and/or persistent right-to-left shunting require utilization of epicardial pacing leads (with concomitant sternotomy or thoracotomy), ${ }^{74}$ although novel hybrid approaches to lead placement are being developed. ${ }^{75,76}$
Bradycardia and scar-related tachycardias are common following surgery, and in the absence of high-grade AV block, atrial pacing is preferred to avoid pacing-induced ventricular dysfunction. ${ }^{67,68}$ Permanent pacemaker and/or lead implantation may be considered prophylactically in patients with evidence of conduction disease and heart defects with a known natural progression to advanced heart block (e.g., discordant AV connections, heterotaxy syndrome) at the time of cardiac surgery. ${ }^{59,60,77}$

Similarly, in single-ventricle patients undergoing Fontan conversion, prophylactic antitachycardia pacemakers have been used. ${ }^{67}$ There may be a role for pacing in improving the hemodynamic status in patients with plastic bronchitis and protein-losing enteropathy without conventional pacing indications. ${ }^{78}$

The decisions regarding pacemaker implantation should also consider the complexity of the patient's anatomy and hemodynamic status, with complex defined as patients with palliative repairs or impaired ventricular function or circulatory physiology. ${ }^{70}$

\section{Post cardiac transplantation}

\begin{tabular}{|c|c|c|c|}
\hline \multirow[b]{2}{*}{ COR } & \multicolumn{2}{|l|}{ Recommendations } & \multirow[b]{2}{*}{ References } \\
\hline & Post Cardiac Transplantation & LOE & \\
\hline 1 & $\begin{array}{l}\text { Permanent pacing is indicated for } \\
\text { persistent symptomatic bradycardia } \\
\text { that is not expected to resolve and for } \\
\text { other class I indications for permanent } \\
\text { pacing. }\end{array}$ & C-LD & $6,79-82$ \\
\hline Ila & $\begin{array}{l}\text { Permanent pacing is reasonable for } \\
\text { marked chronotropic incompetence } \\
\text { impairing the quality of life late in the } \\
\text { post-transplant period. }\end{array}$ & C-LD & $79-82$ \\
\hline $\mathrm{Ilb}$ & $\begin{array}{l}\text { Permanent pacing may be considered } \\
\text { when relative bradycardia is } \\
\text { prolonged, recurrent, or limits } \\
\text { rehabilitation or discharge after } \\
\text { postoperative recovery from cardiac } \\
\text { transplantation. }\end{array}$ & C-LD & $6,81,83$ \\
\hline IIb & $\begin{array}{l}\text { Permanent pacing may be considered } \\
\text { for any degree of AV block considered } \\
\text { to be due to graft vasculopathy. }\end{array}$ & C-LD & 79,84 \\
\hline
\end{tabular}

\section{Recommendation-specific supportive text}

Transient sinus bradycardia is relatively common immediately after transplantation and frequently resolves spontaneously. In rare cases, sinus bradycardia may persist and pacemaker implantation may be needed, but at least a week should be allowed for spontaneous recovery of sinus node function. Early post-transplant AV block has been reported in pediatric patients to be more frequent than in the adult population and may be related to donor age. ${ }^{79,80}$ An analysis of the United Network for Organ Sharing (UNOS) database reported that between 1994 and 2014, $1 \%$ of cardiac transplant patients $<18$ years of age required a pacemaker in the acute post-transplant interval. Factors associated with need for pacemaker implant were biatrial anastomosis, older donor age, and antiarrhythmic drug use. ${ }^{80}$

Late-onset conduction disorders (sinus node or AV node dysfunction) may be related to cardiac allograft vasculopathy or allograft rejection. Patients should be evaluated for the presence or development of transplant coronary artery disease, as late-onset bradycardia may be the first manifestation. ${ }^{79,84}$ Microvascular angiopathy that may not be seen during conventional angiography may also cause significant ventricular dysfunction and subsequent graft failure with an added risk for conduction abnormalities. ${ }^{85}$ 
The role of prophylactic ICD implantation is not well established but may be considered in patients who require pacemakers. Risk factors to consider are coronary artery vasculopathy and left ventricular dysfunction, which may present as ventricular arrhythmias and have been associated with SCD. ${ }^{86,87}$

\section{Neuromuscular diseases and other}

Progressive cardiac conduction diseases

\begin{tabular}{|c|c|c|c|}
\hline \multirow[b]{2}{*}{ COR } & Recommendations & \multirow[b]{2}{*}{ LOE } & \multirow[b]{2}{*}{ Reference } \\
\hline & $\begin{array}{l}\text { Neuromuscular Diseases and Other } \\
\text { Progressive Cardiac Conduction } \\
\text { Diseases }\end{array}$ & & \\
\hline 1 & $\begin{array}{l}\text { Permanent pacemaker implantation is } \\
\text { indicated in patients with } \\
\text { neuromuscular diseases with } \\
\text { symptomatic bradycardia due to SND } \\
\text { or any degree of AV block. }\end{array}$ & B-NR & $2,88-95$ \\
\hline I & $\begin{array}{l}\text { Permanent pacemaker implantation is } \\
\text { indicated in Kearns-Sayre syndrome } \\
\text { for any degree of AV block (including } \\
\text { first-degree AV block) and/or } \\
\text { conduction abnormality because of } \\
\text { unpredictable progression of } \\
\text { conduction disease. }\end{array}$ & C-LD & $2,95-98$ \\
\hline Ila & $\begin{array}{l}\text { Permanent pacemaker implantation is } \\
\text { reasonable in patients with myotonic } \\
\text { dystrophy type } 1 \text { for marked first- } \\
\text { degree AV block (PR interval }>240 \mathrm{~ms} \text { ) } \\
\text { or intraventricular conduction delay } \\
\text { (native QRS duration }>120 \mathrm{~ms} \text { ). } \\
\text { Additional defibrillator capability may } \\
\text { be considered. }\end{array}$ & B-NR & $2,88,90,91$ \\
\hline Ila & $\begin{array}{l}\text { Permanent pacemaker implantation is } \\
\text { reasonable in patients with lamin A/C } \\
\text { gene mutations, including limb-girdle } \\
\text { and Emery-Dreifuss muscular } \\
\text { dystrophies with a PR interval }>240 \text { ms } \\
\text { and/or left bundle branch block. } \\
\text { Additional defibrillator capability may } \\
\text { be considered. }\end{array}$ & C-LD & $2,94,99$ \\
\hline $\mathrm{Ilb}$ & $\begin{array}{l}\text { Permanent pacemaker implantation } \\
\text { may be considered for any patient } \\
\text { with any progressive cardiac } \\
\text { conduction disease with potential for } \\
\text { rapid deterioration of AV nodal } \\
\text { function, even in the presence of } \\
\text { normal AV conduction after taking into } \\
\text { consideration patient age, size, and } \\
\text { other individual risk factors. }\end{array}$ & C-LD & $2,88,90,91,100$ \\
\hline
\end{tabular}

Conditions include Duchenne muscular dystrophy, Becker muscular dystrophy, myotonic dystrophy type 1, Friedreich ataxia, Emery-Dreifuss muscular dystrophy, facioscapulohumeral muscular dystrophy, Barth syndrome, Kearns-Sayre syndrome, lamin A/C mutations, and desmin-related myopathies.

\section{Recommendation-specific supportive text}

Progressive cardiac conduction diseases often involve genetic disorders with progressive deterioration of the conduction system occurring either in isolation or in conjunction with other cardiac and metabolic diseases including neuromuscular and mitochondrial diseases.

The severity and onset of cardiac complications differ among the diseases. Conduction disturbances are commonly observed in myotonic dystrophy type 1 and Emery-Dreifuss muscular dystrophy. ${ }^{81}$ Variable degrees of conduction abnormalities may occur, ranging from first-degree AV block to complete AV block with unpredictable progression. Laminopathy caused by mutations in the LMNA gene is a wide-spectrum disorder exhibiting peripheral neuropathy, skeletal muscle disorders, progerias, and dilated cardiomyopathy. Cardiac conduction abnormalities, such as sinus bradycardia, AV block, atrial fibrillation, atrial standstill, and ventricular tachycardia (VT), are common and are often observed before the onset of heart failure symptoms. ${ }^{87,92}$ In a meta-analysis, arrhythmias were observed in $36 \%$ of patients before 20 years of age, with heart failure observed in $10 \%$ before 30 years of age. ${ }^{87}$ A prolonged $\mathrm{PR}$ interval $>240 \mathrm{~ms}$ in adults is reported to be a predictor of progressive AV block and/or ventricular arrhythmias in patients with myotonic dystrophy and in patients with laminopathy. ${ }^{91,92,94,99}$

Among the mitochondrial diseases, patients with Kearns-Sayre syndrome, characterized by progressive external ophthalmoplegia and myopathy with an onset before the age of 20 years, are known to carry a high risk for AV block and SCD. ${ }^{88-91}$ Currently, an HRS expert consensus statement on the evaluation and management of arrhythmic risk in neuromuscular disorders is under development. Therefore, the above recommendations may be subject to modification as newer data become available.

Neurocardiogenic syncope

\begin{tabular}{|c|c|c|c|}
\hline & Recommendations & & \\
\hline $\mathrm{COR}$ & Neurocardiogenic Syncope & LOE & References \\
\hline Ila & $\begin{array}{l}\text { Permanent pacemaker } \\
\text { implantation is reasonable with } \\
\text { severe recurrent breath-holding } \\
\text { spells with documentation of } \\
\text { cardioinhibitory response on } \\
\text { ECG monitoring and } \\
\text { complicated by prolonged } \\
\text { syncope, prolonged postanoxic } \\
\text { convulsions, and other } \\
\text { bradycardia-induced symptoms. }\end{array}$ & B-NR & $101-103$ \\
\hline $\mathrm{IIb}$ & $\begin{array}{l}\text { Permanent pacing may be } \\
\text { considered for recurrent } \\
\text { symptomatic neurocardiogenic } \\
\text { syncope associated with } \\
\text { documented spontaneous } \\
\text { bradycardia or asystole in } \\
\text { patients who have failed other } \\
\text { medical treatments. }\end{array}$ & C-LD & 104-106 \\
\hline $\mathrm{IIb}$ & $\begin{array}{l}\text { Permanent pacemaker } \\
\text { implantation may be considered } \\
\text { in patients with epilepsy } \\
\text { associated with severe } \\
\text { symptomatic bradycardia (ictal } \\
\text { induced) who have failed to } \\
\text { improve with antiepileptic } \\
\text { medical therapy. }\end{array}$ & C-LD & 107,108 \\
\hline $\begin{array}{l}\text { III } \\
\text { No benefit }\end{array}$ & $\begin{array}{l}\text { Permanent pacing is not } \\
\text { indicated for neurocardiogenic } \\
\text { syncope solely on the basis of a } \\
\text { positive cardioinhibitory tilt } \\
\text { response. }\end{array}$ & C-EO & \\
\hline $\begin{array}{l}\text { III } \\
\text { Harm }\end{array}$ & $\begin{array}{l}\text { Permanent pacing is not } \\
\text { indicated for neurocardiogenic } \\
\text { syncope with hypotension as } \\
\text { the major or significant } \\
\text { component of the symptoms. }\end{array}$ & C-EO & \\
\hline
\end{tabular}




\section{Recommendation-specific supportive text}

In the vast majority of cases, neurocardiogenic syncope is a limited disease and pacemaker implantation is not required. In some patients, however, recurrent syncopal events may significantly impair quality of life and may result in traumatic injury, particularly when the dominant feature of reflex syncope is cardioinhibitory. ${ }^{101-104,108}$ Therefore, in a highly select group of patients who fail more conservative treatment options, pacemaker therapy may be useful by preventing profound bradycardia or prolonged asystole. Because the efficacy of pacing depends on the clinical setting, a clear relationship between symptoms and bradycardia should be established prior to pacemaker implantation. Bradycardia or asystole should be observed during episodes of clinical syncope, ideally on more than one occasion. ${ }^{105}$ Event monitors and ICMs have been effective for documenting this relationship.

In pallid breath-holding spells, studies of predominantly infants and toddlers have demonstrated either complete resolution or a significant reduction in the number of syncopal events in $86 \%$ patients with pacing. ${ }^{101,102}$ Single-chamber pacing with hysteresis appears as effective as dual-chamber pacing with rate drop response for the prevention of syncope and seizures. Pacemaker settings may be optimized to prevent sustained bradycardia by programming a relatively fast pacing rate at the time of the vasovagal reflex to augment cardiac output.

Attributed to vagal storm in the setting of epilepsy, ictalinduced bradyarrhythmia or asystole can impair both cerebral perfusion and cortical function and contribute to transient loss of consciousness and injury. ${ }^{106,107}$ While conventional antiepileptic medications and epilepsy surgery are the mainstay treatments for ictal-induced bradycardia, pacemaker implantation may be reasonable as an adjunct for reducing the severity of symptoms.

\section{Cardiac channelopathies}

\begin{tabular}{|c|c|c|c|}
\hline \multirow[b]{2}{*}{ COR } & \multicolumn{2}{|l|}{ Recommendations } & \multirow[b]{2}{*}{ References } \\
\hline & Cardiac Channelopathies & LOE & \\
\hline 1 & $\begin{array}{l}\text { Permanent pacemaker } \\
\text { implantation is indicated in } \\
\text { channelopathy patients with } \\
\text { pause-dependent, clinically } \\
\text { significant VT; ICD implantation } \\
\text { may be considered as a } \\
\text { reasonable alternative. }\end{array}$ & C-LD & 109-111 \\
\hline IIb & $\begin{array}{l}\text { Permanent pacemaker } \\
\text { implantation may be considered } \\
\text { as adjunctive therapy in patients } \\
\text { with long QT syndrome and } \\
\text { functional 2:1 AV block. }\end{array}$ & C-LD & 112 \\
\hline IIb & $\begin{array}{l}\text { Permanent pacemaker } \\
\text { implantation may be considered } \\
\text { as adjunctive therapy in patients } \\
\text { with long QT syndrome or other } \\
\text { channelopathies where a faster } \\
\text { heart rate may decrease the } \\
\text { arrhythmia burden or symptoms } \\
\text { due to bradycardia. }\end{array}$ & C-LD & $109,113,114$ \\
\hline $\begin{array}{l}\text { III } \\
\text { No benefit }\end{array}$ & $\begin{array}{l}\text { Atrial pacing alone is not } \\
\text { indicated in patients with } \\
\text { complete atrial standstill due to } \\
\text { the high potential for } \\
\text { noncapture of the myocardium. }\end{array}$ & C-LD & 115,116 \\
\hline
\end{tabular}

Recommendation-specific supportive text

The utility of pacing as adjunctive therapy in the various channelopathies is not well defined. Most data are based on observational reports of pacing in the context of long QT syndrome (LQTS). In certain high-risk patients with LQTS, permanent pacemaker implantation may provide a benefit to decrease bradycardiarelated or pause-related initiation of ventricular tachyarrhythmias or so-called short-long-short episodes. ${ }^{109-111}$ In infants with prolonged QT-related functional 2:1 AV block, one observational study reported that pacing in combination with other therapies resulted in favorable outcomes with no mortality. ${ }^{112}$ Additionally, in some patients with LQTS, atrial pacing faster than the intrinsic rate has been shown to shorten the QT interval and reduce the rate of recurrent syncopal events in high-risk LQTS patients. ${ }^{109,114}$ When SND and/or AV block are present in the setting of a channelopathy or as the result of antiarrhythmic medications needed for treatment of a channelopathy, the indications for permanent pacing detailed in the respective section on SND and/or AV block apply. In the setting of atrial standstill secondary to a channelopathy or laminopathy, single-chamber atrial pacemaker placement alone is not recommended due to the high probability of atrial noncapture. ${ }^{115,116}$

\section{Inflammation/infection}

\begin{tabular}{|c|c|c|c|}
\hline \multirow[b]{2}{*}{ COR } & \multicolumn{2}{|l|}{ Recommendations } & \multirow[b]{2}{*}{ References } \\
\hline & Inflammation/Infection & LOE & \\
\hline 1 & $\begin{array}{l}\text { Permanent pacing is indicated } \\
\text { in patients with high-grade or } \\
\text { symptomatic AV block } \\
\text { attributable to a known } \\
\text { potentially reversible cause } \\
\text { when AV block does not resolve } \\
\text { despite treatment of the } \\
\text { underlying cause. }\end{array}$ & C-LD & 117,118 \\
\hline Ila & $\begin{array}{l}\text { Pacemaker implantation is } \\
\text { reasonable in Chagas disease and } \\
\text { advanced second- or third-degree } \\
\text { AV block, as spontaneous } \\
\text { resolution is unlikely. ICD } \\
\text { implantation may be a } \\
\text { reasonable alternative. }\end{array}$ & C-LD & $117-120$ \\
\hline $\begin{array}{l}\text { III } \\
\text { No benefit }\end{array}$ & $\begin{array}{l}\text { Permanent pacing should not } \\
\text { be performed in patients who } \\
\text { had acute AV block attributable } \\
\text { to a known reversible cause, } \\
\text { when there is recovery of } \\
\text { normal AV conduction. }\end{array}$ & C-EO & \\
\hline
\end{tabular}

\section{Recommendation-specific supportive text}

Systemic infections may cause myocardial inflammation or infiltration presenting with bradycardia or complete AV block. Known causes are Lyme disease (Borrelia burgdorferi), Chagas disease in individuals from Trypanosoma cruziendemic areas in Central and South America, and rarely from diphtheria myocarditis. Other etiologies include infectious mononucleosis (Epstein-Barr virus), bacterial endocarditis, viral myocarditis with perivalvular abscess, rheumatic fever, and sarcoidosis.

In symptomatic AV block associated with Lyme disease, approximately $40 \%$ of patients may require temporary pacing, although AV block is typically reversible with antibiotic 
therapy. ${ }^{117,118}$ Chronic Chagas disease can present with different degrees of conduction defects. Advanced heart block in Chagas is permanent, and pacemaker implantation is indicated. ${ }^{119,120}$ An ICD should be considered in Chagas cardiomyopathy in the presence of significant left ventricular dysfunction or ventricular arrhythmias. ${ }^{120}$ More recently, there have been reports of transient $\mathrm{AV}$ conduction abnormalities associated with the COVID-19-related multisystem inflammatory syndrome in children (MIS-C) with ventricular dysfunction. ${ }^{121}$ Medical-directed therapy for the underlying condition should be maximized (including antibiotic therapy, steroids, intravenous immunoglobulins), and if tolerated, a waiting period of up to several months is warranted prior to pacemaker implantation to provide sufficient opportunity for spontaneous recovery of AV conduction.

Recovery of AV conduction in patients with complete heart block due to acute myocarditis has been reported to occur in $67 \%$ of young patients within 7 days of the onset of AV block. ${ }^{122}$ Late monitoring for possible recurrence of symptoms or unrecognized recurrences of AV block or other arrhythmias is advised in these patients.

\section{Implantable cardioverter defibrillators}

\section{Introduction}

The process of CIED guideline development has evolved over the past few decades, with initial recommendations based on observational clinical experience and refined based on controlled clinical studies and advances in device technology. Although the development of pediatric CIED recommendations has been limited by the lack of RCTs and small patient numbers, pacemaker recommendations have been established based on clearly defined diagnoses and five decades of clinical experience. Conversely, pediatric recommendations for ICD implantation have been primarily based on adult data and, with some modifications, applied to younger patients. Adult ICD guidelines are based on a specific diagnosis as the defined cause or presumed risk factor for a sudden cardiac event, such as ischemia, cardiomyopathy, or genetic cardiovascular disease. ${ }^{6,7,12,13}$ In contrast, recent studies of pediatric SCA survivors have continued to demonstrate that in approximately $50 \%$ of cases, the cause of the event remains undefined despite an extensive and systematic evaluation. ${ }^{123,124}$ Furthermore, in young patients with diagnoses such as catecholaminergic polymorphic ventricular tachycardia (CPVT) or Brugada syndrome, SCA is often the presenting symptom of the disease. ${ }^{125,126}$ Therefore, while development of pediatric ICD recommendations based on specific cardiovascular diagnoses would be intuitively preferable, the following discussion of ICD indications will begin with general considerations for the young patient with an unexplained SCA, followed by a more nuanced series of recommendations for ICD implantation when a specific cause of SCA or defined risk factor has been identified. Furthermore, there remain extensive "gaps" in current ICD recommendations, irrespective of age, for many of the diseases associated with SCD in pediatrics. ${ }^{127,128}$ The recommendations that follow are largely based on limited clinical data or expert opinion and consensus and require the application of case-specific clinical judgment and a shared-decision approach.
General recommendations for implantable cardioverter defibrillator therapy

\begin{tabular}{|c|c|c|c|}
\hline & Recommendations & & \\
\hline COR & $\begin{array}{l}\text { General Recommendations for } \\
\text { Implantable Cardioverter Defibrillator } \\
\text { Therapy }\end{array}$ & LOE & References \\
\hline 1 & $\begin{array}{l}\text { ICD implantation is indicated for } \\
\text { survivors of SCA due to VT/VF if } \\
\text { completely reversible causes have } \\
\text { been excluded and an ICD is } \\
\text { considered to be more beneficial } \\
\text { than alternative treatments that may } \\
\text { significantly reduce the risk of SCA. }\end{array}$ & B-NR & $\begin{array}{l}6,7,12,13,129- \\
132\end{array}$ \\
\hline IIb & $\begin{array}{l}\text { ICD implantation may be considered } \\
\text { for patients with sustained VT that } \\
\text { cannot be adequately controlled with } \\
\text { medication and/or catheter ablation. }\end{array}$ & C-EO & \\
\hline Ilb & $\begin{array}{l}\text { ICD therapy may be considered for } \\
\text { primary prevention of SCD in patients } \\
\text { with genetic cardiovascular diseases } \\
\text { and risk factors for SCA or } \\
\text { pathogenic mutations and family } \\
\text { history of recurrent SCA. }\end{array}$ & C-EO & \\
\hline $\begin{array}{l}\text { III } \\
\text { Harm }\end{array}$ & $\begin{array}{l}\text { ICD therapy is not indicated for } \\
\text { patients with incessant ventricular } \\
\text { tachyarrhythmias due to risk of ICD } \\
\text { storm. }\end{array}$ & C-EO & \\
\hline $\begin{array}{l}\text { III } \\
\text { Harm }\end{array}$ & $\begin{array}{l}\text { ICD therapy is not indicated for } \\
\text { patients with ventricular arrhythmias } \\
\text { that are adequately treated with } \\
\text { medication and/or catheter ablation. }\end{array}$ & C-LD & $133-136$ \\
\hline $\begin{array}{l}\text { III } \\
\text { Harm }\end{array}$ & $\begin{array}{l}\text { ICD therapy is not indicated for } \\
\text { patients who have an expected } \\
\text { survival }<1 \text { year, even if they meet } \\
\text { ICD implantation criteria specified in } \\
\text { the above recommendations. }\end{array}$ & C-EO & \\
\hline $\begin{array}{l}\text { III } \\
\text { Harm }\end{array}$ & $\begin{array}{l}\text { Endocardial leads should be avoided } \\
\text { in patients with intracardiac shunts } \\
\text { except in select cases, when there } \\
\text { should be an individualized } \\
\text { consideration of the risk/benefit } \\
\text { ratio. In these exceptional cases } \\
\text { anticoagulation is mandatory, but } \\
\text { thromboembolism remains a risk. }\end{array}$ & B-NR & $71-73$ \\
\hline
\end{tabular}

Recommendation-specific supportive text

ICD guidelines specific to pediatrics must consider the unique aspects of device implantation and follow-up in children as well as the pathogenesis of the disease, which may evolve over time. A pediatric cardiologist should be involved in the decision to implant an ICD in pediatric patients, and the procedure should be performed by a cardiologist or cardiothoracic surgeon with special training and/or experience in CIED implantation in the pediatric age-group. ICD implantation should be a shared decision between the patient, family, and physician considering specific pediatric characteristics including age, size of the patient, need for an epicardial device, religious/cultural beliefs, and patient quality of life. This includes the physical as well as the psychological impact of an ICD on the patient's well-being. ${ }^{137}$ In addition, all ICD recommendations are based on the premise that meaningful survival of $>1$ year is expected; meaningful survival means that a 
patient has a reasonable quality of life and functional status. ${ }^{11}$ It is further recommended that the indications for an individual patient's ICD be reconsidered at each reintervention with respect to current guidelines, especially after a period of nonuse, as discontinuation of device therapy may be considered in select cases. ${ }^{138}$

\section{ICD indications for cardiac channelopathies}

\section{Long QT syndrome}

\begin{tabular}{|c|c|c|c|}
\hline \multirow[b]{2}{*}{ COR } & Recommendations & \multirow[b]{2}{*}{ LOE } & \multirow[b]{2}{*}{ References } \\
\hline & Long QT Syndrome & & \\
\hline 1 & $\begin{array}{l}\text { ICD implantation along with the } \\
\text { use of beta-blockade is indicated } \\
\text { for patients with a diagnosis of } \\
\text { LQTS who are survivors of SCA. In } \\
\text { select LQTS patients, medical } \\
\text { therapy and/or cardiac } \\
\text { sympathetic denervation may be } \\
\text { considered as an alternative. }\end{array}$ & B-NR & $12-14,139,140$ \\
\hline 1 & $\begin{array}{l}\text { ICD implantation is indicated in } \\
\text { LQTS patients with symptoms } \\
\text { (arrhythmic syncope or VT) in } \\
\text { whom beta-blockade is either } \\
\text { ineffective or not tolerated and } \\
\text { cardiac sympathetic denervation } \\
\text { or other medications are not } \\
\text { considered effective alternatives. }\end{array}$ & B-NR & $12-14,141-147$ \\
\hline IIb & $\begin{array}{l}\text { ICD therapy may be considered } \\
\text { for primary prevention in LQTS } \\
\text { patients with established clinical } \\
\text { risk factors and/or pathogenic } \\
\text { mutations (see text). }\end{array}$ & C-LD & 148-154 \\
\hline $\begin{array}{l}\text { III } \\
\text { Harm }\end{array}$ & $\begin{array}{l}\text { ICD implantation is not indicated } \\
\text { in asymptomatic LQTS patients } \\
\text { who are deemed to be at low risk } \\
\text { of SCA and have not been tried } \\
\text { on beta-blocker therapy. }\end{array}$ & C-LD & $13,14,139$ \\
\hline
\end{tabular}

\section{Recommendation-specific supportive text}

Congenital LQTS refers to genetically heterogeneous disorders characterized by the phenotypes of QTc prolongation on the ECG and risk of potentially life-threatening cardiac arrhythmias. Both phenotypic and genotypic characteristics are used to guide risk stratification of patients with LQTS and consideration for ICD. ${ }^{153}$ Phenotypic risk factors include the onset of symptoms at age $<10$ years, prior SCA, or recurrent syncope. ${ }^{143-146,153}$ Additional high risk factors include a QTc $\geq 550 \mathrm{~ms}$ regardless of genotype, QTc $\geq 500 \mathrm{~ms}$ with LQT1 genotype, females with LQT2 genotype, and males with LQT3 genotype. ${ }^{141,150}$

Patients with rare conditions such as the Jervell and LangeNielson syndrome, Timothy syndrome, or calmodulinopathies may be at highest risk for SCA or SCD. ${ }^{150-152}$ Infants presenting with bradycardia, functional 2:1 AV block, or cardiac arrest are also at significant risk. ${ }^{155}$

Nonselective beta-blockers are considered first-line therapy and can significantly decrease subsequent cardiac events in patients, especially in those with KCNQ1 mutations. ${ }^{14,140}$ In addition, beta-blockers and cardiac sympathetic denervation without ICD may be appropriate alternatives in carefully selected patients. ${ }^{14,142,143}$
In highest-risk patients, observational studies support effectiveness of the ICD in preventing SCD, with consideration of left cardiac sympathetic denervation to reduce the frequency of ICD shocks. ${ }^{139,142,143}$ However, implantation of an ICD in asymptomatic low-risk patient with LQTS for a positive family history of LQTS-related SCD is not clearly supported by published data, and individual decision-making is important. ${ }^{14}$

Catecholaminergic polymorphic ventricular tachycardia

\begin{tabular}{|c|c|c|c|}
\hline & Recommendations & & \\
\hline COR & $\begin{array}{l}\text { Catecholaminergic Polymorphic } \\
\text { Ventricular Tachycardia }\end{array}$ & LOE & References \\
\hline I & $\begin{array}{l}\text { ICD implantation is indicated in } \\
\text { patients with a diagnosis of CPVT } \\
\text { who experience cardiac arrest or } \\
\text { arrhythmic syncope despite } \\
\text { maximally tolerated beta-blocker } \\
\text { plus flecainide and/or cardiac } \\
\text { sympathetic denervation. }\end{array}$ & C-LD & $\begin{array}{c}13,14,126,156- \\
162\end{array}$ \\
\hline Ila & $\begin{array}{l}\text { ICD implantation is reasonable in } \\
\text { combination with pharmacologic } \\
\text { therapy with or without cardiac } \\
\text { sympathetic denervation when } \\
\text { aborted SCA is the initial } \\
\text { presentation of CPVT. Pharmacologic } \\
\text { therapy and/or cardiac sympathetic } \\
\text { denervation without ICD may be } \\
\text { considered as an alternative. }\end{array}$ & C-LD & 126 \\
\hline $\mathrm{IIb}$ & $\begin{array}{l}\text { ICD implantation may be considered } \\
\text { in CPVT patients with polymorphic/ } \\
\text { bidirectional VT despite optimal } \\
\text { pharmacologic therapy with or } \\
\text { without cardiac sympathetic } \\
\text { denervation. }\end{array}$ & C-LD & 157 \\
\hline $\begin{array}{l}\text { III } \\
\text { Harm }\end{array}$ & $\begin{array}{l}\text { ICD implantation is not indicated in } \\
\text { asymptomatic patients with a } \\
\text { diagnosis of CPVT. }\end{array}$ & C-EO & \\
\hline
\end{tabular}

Recommendation-specific supportive text

CPVT is characterized by exertion-related polymorphic or bidirectional VT and is associated with syncope and SCA. SCA/SCD is reported in $3-13 \%$ of CPVT patients. ${ }^{158}$ High risk factors include male sex, previous history of cardiac arrest, multiple genetic variants, and younger age at diagnosis. ${ }^{158,159}$ Continued complex ventricular ectopy on exercise testing despite optimal medical therapy is also associated with worse outcome. ${ }^{160}$ Studies evaluating CPVT patients with $>2$ genetic variants suggest that these patients may also be at higher risk for SCA. ${ }^{159}$

Treatment with nonselective beta-blockers is associated with a reduction in adverse cardiac events. ${ }^{13,14,158}$ The addition of flecainide to refractory patients in addition to maximally tolerated betablocker may suppress ventricular ectopy by as much as $85 \%{ }^{161}$

In general, ICD implantation should be reserved for CPVT patients with prior SCA or with arrhythmogenic syncope on combination medical therapy and/or cardiac sympathetic denervation. $^{13,14,126,157}$ Inappropriate shocks are reported in $20-30 \%$ of CPVT patients with ICDs. ${ }^{157,163,164}$ Device programming in patients with CPVT should be optimized to deliver therapy for ventricular fibrillation (VF) and to minimize inappropriate shocks and the risk of potentially fatal electrical storms. ${ }^{157,164}$ 
Cardiac sympathetic denervation is recommended in patients who continue to have syncope or significant arrhythmias despite optimal medical therapy, are intolerant of medical therapy, or experience recurrent ICD shocks. ${ }^{162}$ In selected patients with aborted SCA as the initial presentation of CPVT, pharmacologic therapy and/or cardiac sympathetic denervation without ICD may be considered as a possible alternative. ${ }^{14,126}$

\section{Brugada syndrome}

\begin{tabular}{|c|c|c|c|}
\hline & Recommendations & & \\
\hline COR & Brugada Syndrome & LOE & References \\
\hline 1 & $\begin{array}{l}\text { ICD implantation is indicated in } \\
\text { patients with a diagnosis of BrS } \\
\text { who are survivors of SCA or } \\
\text { have documented spontaneous } \\
\text { sustained VT. }\end{array}$ & B-NR & $12-14,165-171$ \\
\hline Ila & $\begin{array}{l}\text { ICD implantation is reasonable } \\
\text { for patients with BrS with a } \\
\text { spontaneous type I Brugada } \\
\text { ECG pattern and recent syncope } \\
\text { presumed due to ventricular } \\
\text { arrhythmias. }\end{array}$ & B-NR & $165-169$ \\
\hline $\mathrm{IIb}$ & $\begin{array}{l}\text { ICD implantation may be } \\
\text { considered in patients with } \\
\text { syncope presumed due to } \\
\text { ventricular arrhythmias with a } \\
\text { type I Brugada ECG pattern only } \\
\text { with provocative medications. }\end{array}$ & C-EO & \\
\hline $\begin{array}{l}\text { III } \\
\text { No benefit }\end{array}$ & $\begin{array}{l}\text { ICD implantation is not } \\
\text { indicated in asymptomatic BrS } \\
\text { patients in the absence of risk } \\
\text { factors. }\end{array}$ & C-EO & \\
\hline
\end{tabular}

\section{Recommendation-specific supportive text}

Brugada syndrome (BrS) is an inherited arrhythmogenic disorder characterized by a coved-type ST-segment elevation in the right precordial ECG leads and an increased risk of SCD. ${ }^{12-14,165}$ The phenotypic expression of the disease spans from patients who are completely asymptomatic to those who experience a lethal arrhythmia. ${ }^{165,166}$ The syndrome presents typically in the fourth to fifth decade, but in rare cases may have an early onset during childhood. ${ }^{155}$ Pediatric cases are rare but can express as a rapidly progressive form and lead to life-threatening arrhythmias. ${ }^{128,166-169}$

The placement of an ICD remains the only therapy with proven efficacy for the management of ventricular arrhythmias and prevention of SCD in patients with BrS. ${ }^{170}$ Adult recommendations for risk stratification including ventricular stimulation have been established but have not been validated in pediatrics. ${ }^{12-14}$ Findings associated with high risk of ventricular arrhythmias and SCD in children include, in order of relevance: the presence of symptoms (SCD or arrhythmogenic syncope), spontaneous coved-type ST elevation (type I pattern) ECG, atrial arrhythmias and/or SND, and conduction abnormalities (AV block or intraventricular conduction delay). ${ }^{165}$ Although attempts have been made to create a noninvasive risk stratification scoring system, ${ }^{167}$ such recommendations are based on small cohorts. Patients with a type I ECG pattern and a history of syncope or SCD have a class I indication for an ICD implantation. ${ }^{160}$ In this study, 9 of $35(26 \%)$ BrS patients with an ICD implanted at age $<20$ years received an appropriate therapy during a median follow-up of 7.3 years. ${ }^{160}$ Conversely, implantation of an ICD is not indicated in asymptomatic patients in the absence of risk factors. Large multicentric studies are necessary to further characterize risk factors and support primary prevention indications for $\mathrm{BrS}$ in pediatric patients.

\section{ICD indications for cardiomyopathies}

\section{Hypertrophic cardiomyopathy}

\begin{tabular}{|c|c|c|c|}
\hline & Recommendations & & \\
\hline COR & Hypertrophic Cardiomyopathy & LOE & References \\
\hline 1 & $\begin{array}{l}\text { ICD implantation is indicated in } \\
\text { patients with HCM who are survivors } \\
\text { of SCA or have spontaneous } \\
\text { sustained VT. }\end{array}$ & B-NR & $\begin{array}{c}12,13,15,172- \\
175\end{array}$ \\
\hline Ila & $\begin{array}{l}\text { For children with HCM who have } \geq 1 \\
\text { primary risk factors, including } \\
\text { unexplained syncope, massive left } \\
\text { ventricular hypertrophy, } \\
\text { nonsustained VT, or family history of } \\
\text { early HCM-related SCD, ICD } \\
\text { placement is reasonable after } \\
\text { considering the potential } \\
\text { complications of long-term ICD } \\
\text { placement. }\end{array}$ & B-NR & 15,172-179 \\
\hline IIb & $\begin{array}{l}\text { ICD implantation may be considered } \\
\text { in patients with HCM without the } \\
\text { above risk factors but with secondary } \\
\text { risk factors for SCA such extensive } \\
\text { LGE on cardiac MRI or systolic } \\
\text { dysfunction. }\end{array}$ & B-NR & $15,179-182$ \\
\hline $\begin{array}{l}\text { III } \\
\text { Harm }\end{array}$ & $\begin{array}{l}\text { ICD implantation is not indicated in } \\
\text { patients with an identified HCM } \\
\text { genotype in the absence of known } \\
\text { pediatric SCA risk factors. }\end{array}$ & C-LD & 177 \\
\hline
\end{tabular}

\section{Recommendation-specific supportive text}

Hypertrophic cardiomyopathy (HCM) is a genetic cardiovascular condition manifested by pathologic left ventricular hypertrophy in the absence of loading conditions. The phenotypic expression of HCM is variable, resulting in a diverse clinical course and highly variable long-term prognosis. Estimates for SCD rates in childhood HCM vary widely, with recent epidemiologic studies that have reported rates of between 1 and $7.2 \%$ per year. ${ }^{172,174}$ While ICDs have improved the outcomes for patients with HCM resuscitated from SCA, the accurate identification of risk factors for SCD to guide primary prevention ICD implantation remains a challenge, particularly given the potential progression of the disease process over time. ${ }^{172-175}$ A multicenter pediatric HCM registry study reported the 5-year risk of SCA was $9 \% .{ }^{174}$ Primary and secondary prevention ICDs were implanted in 18 and $4 \%$ of the cohort, respectively. Only $2.5 \%$ of the patients with a primary prevention ICD received an appropriate discharge at 5 years' follow-up, highlighting the major gaps in knowledge for accurate prediction of SCD risk in pediatric HCM patients. ${ }^{174}$

Previously published clinical practice guidelines define high risk for SCD in HCM by the presence of $\geq 1$ clinical risk factors based on primarily adult data. ${ }^{6,7,14}$ Recent studies, however, suggest that the significance of the various risk factors may differ in children compared to adults. ${ }^{174-177}$ Conventional risk factors include survival from an SCA, spontaneous sustained VT, 
unexplained syncope, nonsustained VT, family history of early HCM-related SCD, and massive left ventricular hypertrophy. ${ }^{14,173}$ While a left ventricular wall thickness $\geq 30 \mathrm{~mm}$ is considered a risk factor in adults, left ventricular hypertrophy is determined relative to age and body size and therefore should be converted to a $\mathrm{z}$ score when evaluating this as a risk factor in smaller children. ${ }^{174,177} \mathrm{~A}$ multicenter pediatric study showed that a left ventricular posterior wall thickness $\mathrm{z}$ score $\geq 5$ was associated with VT/VF or SCA, while a meta-analysis of pediatric studies reported a maximum left ventricular wall thickness $\geq 30 \mathrm{~mm}$ or a $\mathrm{z}$ score $\geq 6$ associated with an increased risk of SCD. ${ }^{175,176}$

Other secondary risk factors for SCD, such as late gadolinium enhancement (LGE) on cardiac magnetic resonance imaging (MRI), have been investigated, but the predictive value of LGE for SCD in children is still unclear. ${ }^{179,180}$ The evolving role of genetic testing for specific "malignant" sarcomere mutations remains debated and requires further investigation before inclusion as specific risk factors for SCD in pediatric patients with HCM. ${ }^{181,183}$

\section{Restrictive cardiomyopathy}

There are limited data regarding the use of ICDs in patients with restrictive cardiomyopathy. ${ }^{184,185}$ The underlying cause of the restrictive cardiomyopathy is most commonly due to abnormalities in the sarcomeric genes, resulting in overlap with the HCM phenotype as well as risk for both tachyarrhythmias and conduction block. ${ }^{185}$ Given the overlap with HCM, ICD recommendations for patients with restrictive cardiomyopathy are included under the HCM and general guidelines. However, these patients do require unique consideration as, in comparison to those with HCM, patients with purely restrictive cardiomyopathy may not display the typical risk factors such as thickening of the intraventricular septum but do appear to be at higher risk for SCD, SCA, and cardiac transplant. ${ }^{186,187}$ Given this, ICD implantation may be appropriate in patients with a restrictive cardiomyopathy who present with heart failure or unexplained syncope when transplant is not an immediate option. ${ }^{188}$

\section{Arrhythmogenic cardiomyopathies}

\begin{tabular}{|c|c|c|c|}
\hline & Recommendations & & \\
\hline COR & Arrhythmogenic Cardiomyopathies & LOE & References \\
\hline I & $\begin{array}{l}\text { ICD implantation is indicated in } \\
\text { patients with ACM who have been } \\
\text { resuscitated from SCA or sustained VT } \\
\text { that is not hemodynamically tolerated. }\end{array}$ & B-NR & $\begin{array}{c}12,13,16,189- \\
191\end{array}$ \\
\hline Ila & $\begin{array}{l}\text { ICD implantation is reasonable in } \\
\text { patients with ACM with } \\
\text { hemodynamically tolerated sustained } \\
\text { VT, syncope presumed due to } \\
\text { ventricular arrhythmia, or an } \\
\text { LVEF } \leq 35 \% \text {. }\end{array}$ & B-NR & 192 \\
\hline $\mathrm{Ilb}$ & $\begin{array}{l}\text { ICD implantation may be considered in } \\
\text { patients with inherited ACM associated } \\
\text { with increased risk of SCD based on } \\
\text { an assessment of additional risk } \\
\text { factors. }\end{array}$ & C-LD & 192,193 \\
\hline
\end{tabular}

\section{Recommendation-specific supportive text}

Arrhythmogenic cardiomyopathy (ACM) encompasses a spectrum of disorders of the myocardium with the distinguishing feature of presentation with sustained arrhythmias. ${ }^{16}$ It includes, but is not limited to, genetic disorders such as arrhythmogenic right/left ventricular cardiomyopathy, lamin A/C, filamin-C, phospholamban, and cardiac amyloidosis. ${ }^{16}$ Under this definition, infectious processes such as myocarditis and Chagas disease and inflammatory disorders such as sarcoidosis may also be classified. Most of these entities are infrequent before puberty and often overlap with other cardiomyopathies in presentation, particularly dilated cardiomyopathy. ${ }^{16}$

The diagnosis of ACM requires a high degree of suspicion. The initial evaluation should include clinical history, physical examination, detailed family history, 12-lead ECG, echocardiography, ambulatory electrocardiography monitoring, exercise testing, and cardiac MRI. Additional testing includes signal-averaged ECG and genetic testing. ${ }^{16,189}$

The most frequent form of ACM in the pediatric age-group is arrhythmogenic right ventricular cardiomyopathy (ARVC). ${ }^{189}$ ARVC is characterized by predominant right ventricular involvement with fibro-fatty replacement of the myocardium resulting in conduction abnormalities and ventricular arrhythmias. Biventricular disease is associated with younger age of onset. ${ }^{190,191}$ ARVC is either de novo or inherited in an autosomal dominant pattern involving variances in desmosomal genes or desmosome-associated proteins. ${ }^{16,193}$ Syncope is reported in 16$40 \%$ of ARVC patients at the time of diagnosis, is frequently exercise related, and has been associated with high arrhythmic risk. ${ }^{16,191}$ In adult ARVC cohorts, risk factors for SCD include syncope presumed due to ventricular arrhythmia, sustained or nonsustained VT, and severe right ventricular and/or left ventricular systolic dysfunction. ${ }^{12,16}$ Due to the relatively low prevalence of manifest ARVC in the young, there is a paucity of data regarding risk stratification for SCD in pediatric patients with ARVC.

Overall, SCD affects $2-15 \%$ of young patients with ACM. ${ }^{189,191}$ Patients presenting with SCD and/or sustained ventricular arrhythmias have a class I indication for an ICD implantation. ${ }^{12,16}$ The limited available data on risk stratification in the young hamper the indication for a primary prevention ICD in this population. However, ICD implantation is reasonable in patients with ACM with hemodynamically tolerated sustained VT, syncope presumed due to ventricular arrhythmia, or an LVEF $\leq 35 \%$. Candidacy and timing of cardiac transplantation and whether a wearable external defibrillator is a reasonable alternative should be taken into consideration on an individual basis for those patients with advanced heart failure. ${ }^{5}$

\section{Nonischemic dilated cardiomyopathy}

\begin{tabular}{lllll}
\hline & \multicolumn{2}{l}{ Recommendations } & & \\
\cline { 2 - 3 } COR & $\begin{array}{l}\text { Nonischemic Dilated } \\
\text { Cardiomyopathy }\end{array}$ & LOE & References \\
\hline I & $\begin{array}{l}\text { ICD implantation is } \\
\text { indicated in patients with } \\
\text { NIDCM who either survive } \\
\text { SCA or experience } \\
\text { sustained VT not due to } \\
\text { completely reversible } \\
\text { causes. }\end{array}$ & & \\
\end{tabular}


(Continued)

\begin{tabular}{|c|c|c|c|}
\hline \multirow[b]{2}{*}{ COR } & Recommendations & \multirow[b]{2}{*}{ LOE } & \multirow[b]{2}{*}{ References } \\
\hline & $\begin{array}{l}\text { Nonischemic Dilated } \\
\text { Cardiomyopathy }\end{array}$ & & \\
\hline IIb & $\begin{array}{l}\text { ICD implantation may be } \\
\text { considered in patients with } \\
\text { NIDCM and syncope or an } \\
\text { LVEF } \leq 35 \% \text {, despite } \\
\text { optimal medical therapy. }\end{array}$ & C-LD & 194-197 \\
\hline $\begin{array}{l}\text { III } \\
\text { Harm }\end{array}$ & $\begin{array}{l}\text { ICD implantation is NOT } \\
\text { recommended in patients } \\
\text { with medication-refractory } \\
\text { advanced heart failure who } \\
\text { are not cardiac } \\
\text { transplantation or left } \\
\text { ventricular assist device } \\
\text { candidates. }\end{array}$ & C-EO & \\
\hline $\begin{array}{l}\text { III } \\
\text { No benefit }\end{array}$ & $\begin{array}{l}\text { ICD therapy is not } \\
\text { indicated for patients with } \\
\text { advanced heart failure who } \\
\text { are urgently listed for } \\
\text { cardiac transplantation } \\
\text { and will remain in the } \\
\text { hospital until } \\
\text { transplantation, even if } \\
\text { they meet ICD } \\
\text { implantation criteria } \\
\text { specified in the above } \\
\text { recommendations. }\end{array}$ & C-EO & \\
\hline
\end{tabular}

Recommendation-specific supportive text

The incidence of SCD in pediatric patients with idiopathic/ NIDCM is only $1-5 \%$, which is significantly less than that in adult patients. ${ }^{195,196}$ Although studies have shown some ICD survival benefit for secondary prevention in pediatric dilated cardiomyopathy, the low incidence of SCD has made it quite difficult to establish risk factors to guide recommendations for primary prevention ICD implantation. ${ }^{195}$ In contrast to some studies of adult patients with NIDCM and LVEF $\leq 35 \%,{ }^{198}$ there is no clear evidence that ICDs implanted for primary prevention improve survival for pediatric patients with NICDM. ${ }^{199,200}$ However, primary prevention ICDs may be considered for patients with syncope or severe impairment of left ventricular function despite optimal medical therapy (betablockers and afterload reduction) and after careful consideration of device-related complication risks, candidacy and timing of cardiac transplantation, and whether a wearable external defibrillator is a reasonable alternative. ${ }^{5,17,194,197}$

The phenotype of NIDCM may overlap with other types of pediatric cardiomyopathies resulting in variable risks of SCD. For example, the Sudden Death in Childhood Cardiomyopathy study showed that the risk of SCD varied according to cardiomyopathy phenotype. ${ }^{195}$ The cumulative incidence of SCD at 15 years was $5 \%$ for idiopathic dilated cardiomyopathy compared to $23 \%$ for left ventricular noncompaction. Myocardial dysfunction and/ or a history of clinically significant arrhythmias are strongly associated with mortality in left ventricular noncompaction. ${ }^{201,202}$ Therefore, factors that may influence the decision regarding implantation of a primary prevention ICD include the underlying etiology of the NIDCM, the cardiomyopathy phenotype, the degree of ventricular dysfunction, and the presence of cardiac arrhythmias. $^{203}$
ICD indications for congenital heart disease

\begin{tabular}{|c|c|c|c|}
\hline \multirow[b]{2}{*}{ COR } & Recommendations & \multirow[b]{2}{*}{ LOE } & \multirow[b]{2}{*}{ References } \\
\hline & Congenital Heart Disease & & \\
\hline 1 & $\begin{array}{l}\text { ICD implantation is indicated for } \\
\text { CHD patients who are survivors of } \\
\text { SCA after evaluation to define the } \\
\text { cause of the event and exclude any } \\
\text { completely reversible causes. }\end{array}$ & B-NR & $\begin{array}{c}9,12,13,129,131,204- \\
206\end{array}$ \\
\hline 1 & $\begin{array}{l}\text { ICD implantation is indicated for } \\
\text { CHD patients with } \\
\text { hemodynamically unstable } \\
\text { sustained VT who have undergone } \\
\text { hemodynamic and } \\
\text { electrophysiologic evaluation. } \\
\text { Catheter ablation or surgical repair } \\
\text { may be possible alternatives in } \\
\text { carefully selected patients. }\end{array}$ & C-LD & $131,204,207,208$ \\
\hline Ila & $\begin{array}{l}\text { ICD implantation is reasonable for } \\
\text { CHD patients with systemic } \\
\text { LVEF }<35 \% \text { and sustained VT or } \\
\text { presumed arrhythmogenic syncope. }\end{array}$ & C-LD & $9,12,13,204,209,210$ \\
\hline IIb & $\begin{array}{l}\text { ICD implantation may be } \\
\text { considered for CHD patients with } \\
\text { spontaneous hemodynamically } \\
\text { stable sustained VT who have } \\
\text { undergone hemodynamic and } \\
\text { electrophysiologic evaluation. } \\
\text { Catheter ablation or surgical repair } \\
\text { may be possible alternatives in } \\
\text { carefully selected patients. }\end{array}$ & C-EO & \\
\hline IIb & $\begin{array}{l}\text { ICD implantation may be } \\
\text { considered for CHD patients with } \\
\text { unexplained syncope in the } \\
\text { presence of ventricular dysfunction, } \\
\text { nonsustained VT, or inducible } \\
\text { ventricular arrhythmias at } \\
\text { electrophysiologic study. }\end{array}$ & C-LD & $9,210,211$ \\
\hline Ilb & $\begin{array}{l}\text { ICD implantation may be } \\
\text { considered for CHD patients with a } \\
\text { single or systemic right ventricular } \\
\text { ejection fraction } \leq 35 \% \text {, particularly } \\
\text { in the presence of additional risk } \\
\text { factors such as VT, arrhythmic } \\
\text { syncope, or severe systemic AV } \\
\text { valve insufficiency. }\end{array}$ & C-EO & \\
\hline
\end{tabular}

Recommendation-specific supportive text

The association between CHD and arrhythmias has been well established. First demonstrated in repaired Tetralogy of Fallot, multiple studies since have identified risk factors for VT or SCD including residual cardiac defects, alterations in hemodynamics, and scars from prior interventions/surgeries. ${ }^{204-206}$ Correction of residual abnormalities or ablation of arrhythmogenic substrate may improve ventricular function and reduce symptoms. However, this may be inadequate to prevent the risk of subsequent VT or SCA in all but a select group of patients. ${ }^{207,208}$ ICD placement may therefore be appropriate in patients with, or at high risk of, potentially life-threatening arrhythmias. ${ }^{9,12,13}$

While ICDs are commonly placed for both primary and secondary prevention in patients with CHD, those with CHD appear to have an increased risk of inappropriate shocks compared to those with ICDs and without CHD. ${ }^{130,131,211-213}$ Appropriate ICD shock rates of 3-6\% per year have been shown with an increased frequency 
of appropriate shocks for secondary prevention indications. ${ }^{204}$ Antitachycardia pacing has been shown to be effective in VT termination and reducing ICD shocks. ${ }^{214}$ Patients with CHD receiving an ICD have an increased rate of complications as high as $26-45 \%$, as well a high rate of inappropriate shocks. ${ }^{130,131,212,213}$ The role of programmed stimulation and presence and degree of ventricular dysfunction as risk factors for SCD in CHD and thus primary prevention ICDs continues to be debated. ${ }^{215-217}$ ICD implantation can be especially challenging in patients with $\mathrm{CHD}$ due to anatomic complexity, intracardiac shunts, or limited vascular access. This may require nonstandard approaches such as epicardial leads, nontransvenous defibrillation coils or a subcutaneous ICD. ${ }^{218,219}$

\section{Insertable cardiac monitors}

Syncope and palpitations are common symptoms in children and adolescents. ICMs (also referred to as implantable loop recorders) are subcutaneously implanted devices that provide long-term rhythm surveillance and documentation during a patient's symptomatic event. Rhythm tracings during events are either patienttriggered recordings or stored automatically by predefined criteria. Long-term ECG monitoring using an ICM is recommended in symptomatic cases when the personal history, physical examination, and noninvasive investigations have been inconclusive, especially due to the low frequency of clinical events and/or limited feasibility of a complete diagnostic protocol. ${ }^{220-224}$ A remote monitoring program with immediate wireless data transfer capability and daily diagnostic data availability has overcome the prior problem of limited device storage capacity and has facilitated early diagnosis. ICMs, along with Holter monitoring, external loop recorders, and remote at-home telemetry, are reported to provide a diagnostic yield of $43-50 \%$ at 2 years and $80 \%$ at 4 years. ${ }^{221-226}$

\begin{tabular}{|c|c|c|c|}
\hline & Recommendations & & \\
\hline COR & Insertable Cardiac Monitors & LOE & References \\
\hline 1 & $\begin{array}{l}\text { Noninvasive cardiac rhythm } \\
\text { monitoring is indicated in all patients } \\
\text { prior to placement of an ICM. }\end{array}$ & B-NR & $11,220-223$ \\
\hline I & $\begin{array}{l}\text { ICM is indicated in syncopal patients } \\
\text { with high-risk criteria when } \\
\text { comprehensive evaluation does not } \\
\text { define a cause of syncope or lead to a } \\
\text { specific treatment, and who do not } \\
\text { have conventional indications for a } \\
\text { pacemaker or ICD. }\end{array}$ & B-NR & $8,220,225-229$ \\
\hline Ila & $\begin{array}{l}\text { ICM is reasonable in the evaluation of } \\
\text { patients with recurrent syncope of } \\
\text { uncertain origin but not a high risk of } \\
\text { SCD. }\end{array}$ & B-NR & $8,11,223-234$ \\
\hline Ila & $\begin{array}{l}\text { ICM is reasonable in patients with } \\
\text { infrequent symptoms ( }>30 \text {-day } \\
\text { intervals) suspected to be due to an } \\
\text { arrhythmia, when the initial } \\
\text { noninvasive evaluation is } \\
\text { nondiagnostic. }\end{array}$ & C-LD & 2 \\
\hline Ila & $\begin{array}{l}\text { ICM implantation is reasonable for } \\
\text { guiding the management of patients } \\
\text { with cardiac channelopathies or } \\
\text { structural heart diseases associated } \\
\text { with significant rhythm abnormalities. }\end{array}$ & C-LD & $12,226,227$ \\
\hline
\end{tabular}

(Continued)
(Continued)

\begin{tabular}{|c|c|c|c|}
\hline \multirow[b]{2}{*}{ COR } & Recommendations & \multirow[b]{2}{*}{ LOE } & \multirow[b]{2}{*}{ References } \\
\hline & Insertable Cardiac Monitors & & \\
\hline IIb & $\begin{array}{l}\text { ICM may be considered in patients } \\
\text { with suspected reflex syncope } \\
\text { presenting with frequent or severe } \\
\text { syncopal episodes. }\end{array}$ & C-LD & $8,230,231$ \\
\hline IIb & $\begin{array}{l}\text { ICM may be considered in carefully } \\
\text { selected patients with suspected } \\
\text { epilepsy in whom anticonvulsive } \\
\text { treatment has proven ineffective. }\end{array}$ & C-LD & 235 \\
\hline Ilb & $\begin{array}{l}\text { ICM may be considered in patients } \\
\text { with severe but infrequent palpitations } \\
\text { when other monitoring methods have } \\
\text { failed to document an underlying } \\
\text { cause. }\end{array}$ & C-LD & $\begin{array}{c}223,224,231- \\
233\end{array}$ \\
\hline Ilb & $\begin{array}{l}\text { ICM implantation may be considered } \\
\text { for detecting subclinical arrhythmias } \\
\text { in patients with cardiac } \\
\text { channelopathies or other diseases } \\
\text { associated with significant rhythm } \\
\text { abnormalities. }\end{array}$ & C-EO & \\
\hline
\end{tabular}

Recommendation-specific supportive text

Several observational studies have demonstrated a benefit of ICM in establishing a diagnosis for recurrent symptoms of unclear etiology when other monitoring methods have failed to document an underlying cause.

- Syncope: Cardiac or undefined syncope may be present in up to $8 \%$ of syncopal events in children and adolescents. ${ }^{8}$ In adults, monitoring with an ICM has been shown to be more cost-effective for establishing a diagnosis than other methods of rhythm monitoring and should be the method of choice when arrhythmogenic syncope is suspected but not proven. ${ }^{223,226}$

- Palpitations: ICM implantation should be considered on an individual basis, taking into account each patient's underlying cardiac condition, the severity of symptoms, and age- and developmentrelated monitoring limitations. ${ }^{233,234}$

- Bradyarrhythmias: ICM may be useful in the monitoring of bradyarrhythmias and their correlation with clinical symptoms. ICM may also be useful for patients at risk for intermittent or progressive AV block including patients with neuromuscular diseases, progressive cardiac conduction diseases, and Kearns-Sayre syndrome. ${ }^{91,98}$

- Other conditions: ICM may be useful for occult arrhythmia detection in asymptomatic children with potentially lethal cardiac diseases (e.g., inherited primary arrhythmia syndromes, cardiomyopathies) and may identify events that warrant changes in patient management. ${ }^{226,230-232}$ Furthermore, monitoring with an ICM may provide psychological reassurance for parents of children at risk for malignant arrhythmias. ${ }^{233}$

\section{CIED lead management}

Lead management remains a vitally important issue in children, both with and without CHD. Updated consensus statements regarding lead management and extraction were put forth in $2017^{18}$ and 2018. ${ }^{236}$ The following recommendations are complementary to these existing guidelines with a nuanced perspective focusing on pediatrics and patients with CHD.

The definitions used related to lead management in this document are similar to those explained in the 2017 statement. ${ }^{18}$ The general category of "lead removal" includes "lead explant" that is performed 
using a simple traction technique and "lead extraction" that refers to removal of a lead that has been implanted for $>1$ year or requiring the assistance of specialized equipment regardless of implant duration. ${ }^{18}$ The most common indications for transvenous lead extraction in children remain lead failure (76\%) and venous occlusion. ${ }^{237-243}$ Pediatric patients are more likely to outlive the functionality of their leads, amplifying the importance of lead durability, longevity of venous access, and long-term risks of lead dysfunction. Coupled with studies in children indicating that older lead age is an independent predictor of need for advanced extraction techniques and added complexity, greater emphasis should be given to the potential risks of lead abandonment in this population. ${ }^{240,241}$

Available extraction tools in children are similar to those in the adult population, as there are no special tools designed specifically for children or patients with CHD. These include locking stylets, telescoping sheaths, femoral snares, and mechanical, laser, or radiofrequencypowered sheaths. ${ }^{243,244}$ Extractors should be appropriately trained, and the entire team must have working knowledge of these tools and techniques. Additionally, expertise in pediatrics, CHD, and surgically corrected anatomy is mandatory, as the methods and potential complications may be specific to both size and anatomy. Unusual lead position and foreign material such as prosthetic valves, conduits, and baffles may necessitate adjustments in approach. ${ }^{242}$ Younger patients are also more likely to require the use of femoral extraction tools. ${ }^{245}$ Lastly, the presence of epicardial leads may require surgical access as a component of the procedure. ${ }^{241}$

The environment for lead extractions in the pediatric population warrants careful patient-centered assessment for optimal preparedness (Table S1 in Supplemental Appendix 3). As in adults, major complications are relatively rare, but significant potential for life-threatening events exists. ${ }^{236,238,239}$ The contribution of complex CHD to the likelihood of successful extraction has varied, ranging from 74 to $94 \%$ for complete removal. The rates of major complications, however, have been found to be consistent between 3 and $4 \% .^{239,240,242}$ Specific complications may be more prevalent based on anatomy and size, such as increased subpulmonary AV valve regurgitation in transposition of the great arteries, or increased risk of tricuspid or pulmonary valve involvement related to excess lead slack left for growth in smaller children. ${ }^{243-248}$ Additionally, although patient age and size have not been shown to predict venous occlusion, more vigorous fibrous adhesions have been implicated in younger patients. ${ }^{249}$

Due to the complexities and potential for serious events in this population, lead extractions should only be performed in centers with an institutional commitment to the development and maintenance of a collaborative team. This includes a need for appropriate facilities, necessary equipment, trained personnel, and the ability to manage all complications. A multidisciplinary team familiar with nuances related to $\mathrm{CHD}$ is vital to maximizing procedural safety and efficacy (Table S1 in Supplemental Appendix 3). In particular, it is essential that the cardiac surgeon and surgical team be readily available to immediately provide open-chest surgical repair. Based on congenital anatomy and previous surgeries, emergent surgical approach via thoracotomy (versus sternotomy) may be preferred in certain scenarios, and focused pre-procedure imaging and planning is critical.

It must be recognized that several gaps in knowledge persist in relationship to lead management in children and patients with CHD. ${ }^{250}$ This includes limited data in the very young, as well as the impact of multiple extractions over a lifetime on vascular integrity and valvular function. There also continues to be lack of clarity regarding prophylactic lead extractions at the time of generator change, ${ }^{251}$ and long-term prospective studies on abandonment versus extraction in the young do not exist.
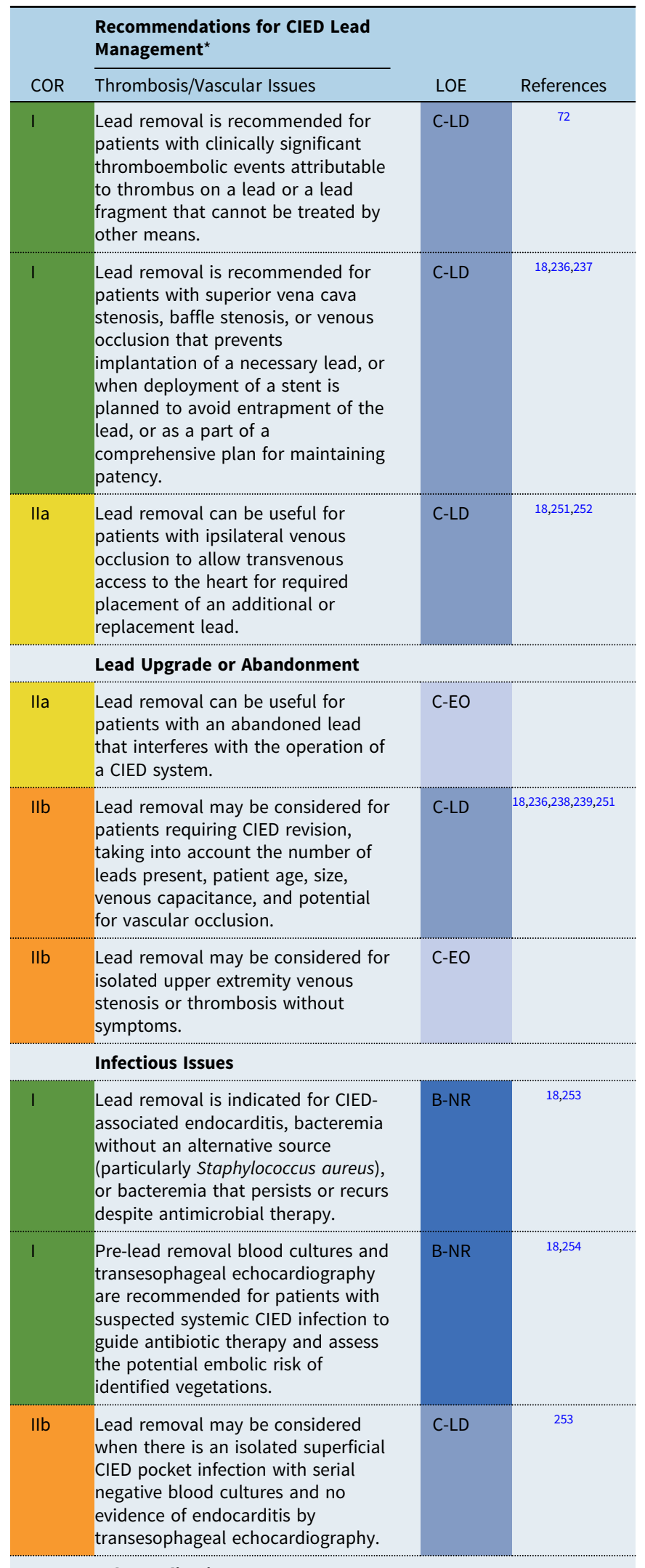

\section{Other Indications}

Lead removal is recommended for
patients with life-threatening
arrhythmias secondary to retained
leads.

(Continued) 
(Continued)

\begin{tabular}{|c|c|c|c|}
\hline \multirow{3}{*}{$\begin{array}{l}\text { COR } \\
\text { Ila }\end{array}$} & $\begin{array}{l}\text { Recommendations for CIED Lead } \\
\text { Management }{ }^{\star}\end{array}$ & \multirow{3}{*}{$\begin{array}{l}\text { LOE } \\
\text { C-EO }\end{array}$} & \multirow{3}{*}{ References } \\
\hline & & & \\
\hline & $\begin{array}{l}\text { Device and/or lead removal can be } \\
\text { useful for patients with severe } \\
\text { chronic pain at the device or lead } \\
\text { insertion site or believed to be } \\
\text { secondary to the device, for which } \\
\text { there is no acceptable alternative. }\end{array}$ & & \\
\hline \multirow[t]{2}{*}{$\mathrm{IIb}$} & $\begin{array}{l}\text { Lead removal may be considered for } \\
\text { patients with leads that, due to } \\
\text { their design or their failure, pose a } \\
\text { potential future threat to patients if } \\
\text { left in place. }\end{array}$ & C-LD & $250,254,255$ \\
\hline & \multicolumn{3}{|l|}{ Epicardial Leads } \\
\hline 1 & $\begin{array}{l}\text { Epicardial lead removal is } \\
\text { recommended for patients where } \\
\text { the lead is shown to be associated } \\
\text { with coronary artery compression } \\
\text { and evidence of myocardial injury. }\end{array}$ & C-LD & 241 \\
\hline 1 & $\begin{array}{l}\text { Complete removal of epicardial } \\
\text { lead(s) and patches is } \\
\text { recommended for all patients with } \\
\text { confirmed infection surrounding the } \\
\text { intrathoracic portion of the lead. }\end{array}$ & C-EO & \\
\hline Ilb & $\begin{array}{l}\text { Epicardial lead removal may be } \\
\text { considered for patients with leads } \\
\text { that are thought to be at risk for } \\
\text { causing coronary artery } \\
\text { compression, valve impingement, or } \\
\text { cardiac strangulation. }\end{array}$ & C-EO & \\
\hline $\mathrm{IIb}$ & $\begin{array}{l}\text { Epicardial lead removal may be } \\
\text { considered at the time of epicardial } \\
\text { lead replacement in the presence of } \\
\text { a damaged or nonfunctional lead, } \\
\text { taking into account the procedural } \\
\text { risk and benefit. }\end{array}$ & C-EO & \\
\hline
\end{tabular}

*Based on adult lead management guidelines. ${ }^{18,236}$

\section{Recommendation-specific supportive text}

The most common indications for lead removal are infection, venous occlusion, advisory or recall as a result of potential lead malfunction, or mechanical lead failure. ${ }^{18,250-256}$ Lead management involves the assessment of risks and benefits of whether or not to remove the lead based on the individual clinical condition of the patient as well as lead characteristics. ${ }^{18,236,253}$

Upper extremity venous thrombosis and venous stenosis are not absolute indications for lead removal. However, instances in which a thrombosis causes significant symptoms (e.g., superior vena cava syndrome, ongoing thromboembolic events), or in which stenosis/occlusion impedes upgrade of an existing device, are generally considered appropriate circumstances to remove an existing lead. ${ }^{236-238}$

Infections, which can result in CIED device and lead removal, can generally be grouped into major categories: isolated pocket infection, CIED-associated endocarditis, bacteremia without an alternative source (particularly Staphylococcus aureus), or bacteremia that persists or recurs despite appropriate antimicrobial therapy. ${ }^{18,236}$ These situations are associated with challenging management decisions and often require CIED device and lead removal when the infection is more than superficial cellulitis. ${ }^{253,254}$
Advisory/recall: The decision to remove an apparently normally functioning lead or leads in response to a manufacturer's or regulatory body's recall or warning is complex and should be performed in close consultation with an electrophysiologist with consideration for the patient's overall clinical status. ${ }^{255,256}$

Recommendations for CIED follow-up and ancillary testing

\begin{tabular}{|c|c|c|c|}
\hline & Recommendations & & \\
\hline COR & $\begin{array}{l}\text { CIED Follow-up } \\
\text { Recommendations }\end{array}$ & LOE & References $^{257,258}$ \\
\hline 1 & $\begin{array}{l}\text { In-person evaluation (IPE) and } \\
\text { the establishment of remote } \\
\text { interrogation and monitoring } \\
\text { (RIM) are recommended within } \\
\text { 2-4 weeks post CIED } \\
\text { implantation. }\end{array}$ & C-EO & \\
\hline 1 & $\begin{array}{l}\text { At least one annual IPE of all } \\
\text { CIEDs is recommended. }\end{array}$ & C-EO & \\
\hline 1 & $\begin{array}{l}\text { RIM is recommended for all } \\
\text { patients with a CIED that has } \\
\text { been recalled or has an advisory } \\
\text { to enable early detection of } \\
\text { actionable events and confirm } \\
\text { proper device function. }\end{array}$ & C-EO & \\
\hline 1 & $\begin{array}{l}\text { RIM of CIEDs is recommended } \\
\text { every } 3-12 \text { months for } \\
\text { pacemakers and } 3-6 \text { months for } \\
\text { ICDs. Frequency should be } \\
\text { increased (every } 1-3 \text { months) for } \\
\text { CIEDs approaching elective } \\
\text { replacement indicators. }\end{array}$ & C-EO & \\
\hline \multirow[t]{2}{*}{1} & $\begin{array}{l}\text { It is recommended that allied } \\
\text { health care professionals possess } \\
\text { International Board of Heart } \\
\text { Rhythm Examiners certification } \\
\text { or equivalent experience if they } \\
\text { provide RIM and are involved in } \\
\text { patient management decisions. }\end{array}$ & C-EO & \\
\hline & $\begin{array}{l}\text { CIED Ancillary Testing } \\
\text { Recommendations }\end{array}$ & & \\
\hline 1 & $\begin{array}{l}\text { Evaluation of the intrinsic cardiac } \\
\text { rhythm evaluation is } \\
\text { recommended during CIED } \\
\text { interrogation at the annual IPE. }\end{array}$ & C-EO & \\
\hline Ila & $\begin{array}{l}\text { A standard } 12 \text {-lead ECG is } \\
\text { reasonable at annual in-person } \\
\text { evaluation. }\end{array}$ & C-EO & \\
\hline Ila & $\begin{array}{l}\text { Two-view chest X-ray is } \\
\text { reasonable at the first post- } \\
\text { implant IPE and every } 1-3 \text { years } \\
\text { based on patient-specific } \\
\text { considerations. }\end{array}$ & C-EO & \\
\hline Ila & $\begin{array}{l}\text { An echocardiogram is reasonable } \\
\text { for assessment of ventricular } \\
\text { function in patients who have } \\
>40 \% \text { ventricular paced rhythm } \\
\text { every } 1-3 \text { years. }\end{array}$ & C-LD & $259-263$ \\
\hline $\mathrm{IIb}$ & $\begin{array}{l}\text { Exercise stress testing and } \\
\text { ambulatory ECG monitoring may } \\
\text { be considered in patients with } \\
\text { symptoms suggesting possible } \\
\text { device malfunction or to assist } \\
\text { with device programming. }\end{array}$ & C-LD & $264-267$ \\
\hline
\end{tabular}




\section{Recommendation-specific supportive text}

Cardiovascular implantable electronic devices (CIEDs) that are currently amenable to remote interrogation and monitoring (RIM) include pacemakers, ICDs, and ICMs. The benefits of routine RIM are extensively validated and maximize the opportunity for prolongation of battery life as well as early detection and intervention of CIED malfunctions, arrhythmic issues, and adverse events. ${ }^{268-272}$ Remote evaluation of CIEDs began with transtelephonic monitoring (TTM), an analog-based technology that delivered limited data on pacemaker function via transmission over a telephone landline. RIM technologies, which are now incorporated in all CIEDs, are recommended over TTM because of the additional diagnostic data they provide, but TTM is still in use with older devices that do not have RIM capability. At present, there are no established guidelines for CIED follow-up in the pediatric population with resultant variability in monitoring of pediatric CIEDs. ${ }^{273,274}$

Several device, lead, and pocket complications can be seen within the first few days to weeks after CIED implantation, and an in-person evaluation (IPE) is useful in the early postimplant phase. Although specific patient care guidelines for IPE and RIM for children have not been established, the Centers for Medicare \& Medicaid Services has established reimbursement guidelines for IPE and RIM for patients with pacemakers.

In addition to monitoring the CIED itself, it is equally important to evaluate the impact of CIED-related consequences on the patient with ancillary testing. Ancillary testing may consist of but is not limited to 12-lead ECG, echocardiogram, ambulatory rhythm monitoring, chest X-ray, and exercise stress testing. The annual IPE should include evaluation of the patient's underlying rhythm. In patients who have $>40 \%$ paced ventricular rhythm, it is reasonable to assess systemic ventricular function by echocardiogram every 1-3 years for early recognition of pacemaker-induced cardiomyopathy or lead-related valve regurgitation. ${ }^{259-263}$ Ambulatory rhythm monitoring and/or exercise stress testing may be useful in patients with arrhythmia concerns or symptoms related to activity and to assist with device optimization. ${ }^{264-267,275-277}$ It is reasonable to consider lead surveillance with chest $\mathrm{X}$-ray in the acute post-implant period and to consider repeating every $1-3$ years according to growth. ${ }^{241,247}$

\section{Special considerations}

CIEDs and magnetic resonance imaging

\begin{tabular}{|c|c|c|c|}
\hline \multirow[b]{2}{*}{ COR } & Recommendations & \multirow[b]{2}{*}{ LOE } & \multirow[b]{2}{*}{ References } \\
\hline & Magnetic Resonance Imaging & & \\
\hline 1 & $\begin{array}{l}\text { MRI in all patients with conditional or } \\
\text { nonconditional CIEDs should be } \\
\text { performed in the context of a defined } \\
\text { institutional protocol. }\end{array}$ & $C-L D$ & 19 \\
\hline Ila & $\begin{array}{l}\text { MRI is reasonable in patients with } \\
\text { nonconditional transvenous CIEDs if } \\
\text { there are no fractured, epicardial, or } \\
\text { abandoned leads. }\end{array}$ & B-NR & $278-280$ \\
\hline IIb & $\begin{array}{l}\text { MRI may be considered in patients } \\
\text { with epicardial or abandoned leads } \\
\text { based on an individualized } \\
\text { consideration of the risk/benefit ratio. }\end{array}$ & C-LD & $279,281,282$ \\
\hline
\end{tabular}

Recommendation-specific supportive text

The 2017 MRI and Radiation Exposure in Patients with CIEDs Consensus Statement provides comprehensive recommendations for individuals with both conditional and nonconditional transvenous devices. ${ }^{19}$ With MRI, there is potential risk for heating of the lead, increase in pacing thresholds, sudden battery depletion, and inappropriate sensing/pacing. The consensus statement also provides guidance for CIED programming and evaluation pre-, during, and post-MRI along with a protocol of testing and patientspecific considerations. However, these recommendations are not specific for patients with abandoned or epicardial CIED leads and make no specific recommendations for MRI in these cases. ${ }^{283,284}$

Regarding epicardial lead considerations, younger patients and those with CHD have a greater likelihood of requiring epicardial leads. Additionally, as there are no MRI conditional epicardial leads, even when used with a conditional device, the system is considered nonconditional. The 2017 recommendations suggest a possible contraindication to MRI, and in the pediatric section no recommendations regarding epicardial leads are made. However, when attached to a device, the limited data show only a small increase in risk for substantial alterations of the pacing threshold or changes in sensing after MRI. ${ }^{279-281,285,286}$

Regarding abandoned leads, in vitro data suggest that epicardial leads are more likely to generate heat than transvenous leads; however, small studies evaluating MRIs in patients with both epicardial and transvenous abandoned leads suggest that it can be done safely in the majority of cases. ${ }^{282,283,287-289}$ Even so, these studies do not imply lack of an effect on the myocardium underlying the abandoned lead. In summary, the data on MRI use in epicardial or abandoned leads are inadequate to provide specific recommendations or an absolute contraindication.

Acknowledging the sparsity of data, but also appreciating the importance of MRI for diagnosis, prognosis, and surgical planning, individualized consideration of the risk/benefit ratio of MRI in young patients must be made on a "case-by-case basis."19

\section{CIEDs and sports participation}

\begin{tabular}{|c|c|c|c|}
\hline & Recommendations & & \\
\hline COR & Sports Participation & LOE & References \\
\hline 1 & $\begin{array}{l}\text { For patients with CIEDs, } \\
\text { decisions regarding } \\
\text { participation in sports or } \\
\text { exercise are primarily based on } \\
\text { considerations of the patient's } \\
\text { diagnosis and physiology rather } \\
\text { than the presence of the device. }\end{array}$ & C-EO & \\
\hline Ila & $\begin{array}{l}\text { For patients with pacemakers } \\
\text { and ICDs, participation in } \\
\text { competitive sports or intense } \\
\text { recreational exercise is } \\
\text { reasonable after shared } \\
\text { decision-making that involves a } \\
\text { provider who conveys the } \\
\text { estimated risk and also includes } \\
\text { coaches, schools, communities, } \\
\text { or teams. }\end{array}$ & C-LD & $290-296$ \\
\hline $\begin{array}{l}\text { III } \\
\text { No benefit }\end{array}$ & $\begin{array}{l}\text { ICD placement for the sole } \\
\text { purpose of participation in } \\
\text { competitive athletics should not } \\
\text { be performed. }\end{array}$ & B-NR & $290-296$ \\
\hline
\end{tabular}




\section{Recommendation-specific supportive text}

The safety of sports participation for patients with CIEDs remained fundamentally unstudied until the past decade. Despite a dearth of research, initial published guidelines recommended against strenuous competitive sports participation (greater than class Ia) for patients with pacemakers or ICDs. ${ }^{295-298}$ Subsequent to publication of guidelines in 2005 , evidence emerged suggesting that risks of sports participation for athletes with CIEDs may be lower than hypothesized. ${ }^{290-293}$

Surveys from HRS (2006) and PACES (2013) suggested that many patients with pacemakers and ICDs had participated in sports without adverse events. ${ }^{290,298}$ Thus, an international ICD Sports Registry was initiated and reported in 2013-2018..$^{292,293}$ The registry consisted of 129 patients <21 years of age including varsity high school and college athletes. While shocks occurred during sports, there were no deaths, no resuscitated arrests, and no arrhythmia-related injuries during sports. In addition, the rate of lead malfunction was similar to previously reported rates in unselected populations. ${ }^{292}$ The conclusion was made that despite the potential for exercise to be arrhythmogenic, some young patients with ICDs can participate in sports without injury or failure to terminate the arrhythmia.

When questions arise about sports participation in youth with CIEDs, it is now standard practice to counsel patients and families about the risks, including potential for increased rate of ventricular tachyarrhythmias and damage to the pacemaker or ICD system. Counseling is patient specific; the underlying cardiac disease, type of device, indication for implant, position of leads and pulse generators, underlying heart rhythm, patient age, and type of athletic activity are considered when estimating risk. ${ }^{298,299}$ Shared decision-making processes that include the patient, family, coach, school, team, and other community members should be utilized to determine the best course of pursuit for individuals with CIEDs and sporting endeavors.

\section{CIEDs in low- and middle-income countries}

A quote often used by doctors dealing with cardiac rhythm problems in resource limited settings (or indeed any branch of medicine) is the Italian proverb "Il meglio è l'inimico del bene," which translates to "better is the enemy of good." Lowand middle-income countries (LMIC) are defined as those designated by the World Bank based on per capita income. ${ }^{300}$ They represent a heterogenous community including countries where the primary deterrent to the use of implantable devices is the cost of the device (India and most countries in Asia and Southern Africa) and those in which the deterrent is both the cost and the availability (sub-Saharan Africa) ${ }^{301}$ These problems have been alleviated to a small extent by philanthropic measures initiated by the Western world as well as universal health care policies announced by various governments in recent years. Pediatric cardiologists in these countries circumvent these problems by using two primary strategies:

1. Patient-specific strategy. Most centers in LMIC tailor the indications of the device to an individual patient instead of following standard guidelines. This is based on available evidence and is not anecdotal, as is widely believed. In postoperative heart block, it has been shown that $95 \%$ of AV conduction recovery happens by the 10th postoperative day. ${ }^{50,51}$ Children with intermittent AV conduction on telemetry as well as an accelerated junctional rhythm have been shown to have a much higher recovery rate. ${ }^{302,303}$ Hence, many centers prefer to wait till the 10th postoperative day before placement of a permanent pacemaker. In children (and young adults) who have intermittent AV conduction and those with a reasonably fast narrow complex escape rhythm, centers may choose to wait even longer for recovery of AV conduction so as to avoid the use of a permanent pacemaker. Late recovery of surgically induced AV block has also been reported. ${ }^{303,304}$ Occasionally patients have been discharged home before return of AV conduction, and spontaneous recovery was documented on follow-up. ${ }^{305}$ In patients with corrected $\mathrm{CHD}$ and normal ventricular function, a single-chamber pacemaker is used in most centers, while a dual-chamber pacemaker is reserved for children with palliated hearts and more than mild ventricular systolic dysfunction.

2. The use of explanted devices. Devices explanted from deceased patients with a battery life of $>50 \%$ of a new device have been used in patients from a resource-limited setting. ${ }^{306} \mathrm{~A}$ hypothetical increased risk of infection from an explanted device has been a major deterrent for this approach. However, a recent metaanalysis of 18 studies involving 2270 patients in whom a reused pacemaker was placed revealed no significant increase in the risk of surgical site infection compared to a new device and a small increase in the risk of device malfunction. ${ }^{307}$ Even this small risk was shown to be predominantly technical and did not endanger the life of the patient. Standard guidelines on device reuse in India have been published. ${ }^{308}$

While most centers have used such inventive strategies to implant a device in children, follow-up interrogation of the device is often challenging. Most pediatric cardiac centers in LMIC are located in a few urban centers with a very large referral area. Frequent travel for device interrogation is often impossible for families because of the costs involved as well as the loss of livelihood. There is no published literature on the gravity of this problem, as most centers lack the resources to follow patients meticulously. Although remote monitoring is ideally suited for these patients, the added cost of the device makes it less attractive. The recent launch of mobile-based remote monitoring pacemakers using Bluetooth technology has immense potential in LMIC if such devices can be priced affordably. ${ }^{309}$

\section{Shared decision-making}

\begin{tabular}{|c|c|c|c|}
\hline \multirow[b]{2}{*}{ COR } & Recommendation & & \\
\hline & Shared Decision-Making & LOE & References \\
\hline 1 & $\begin{array}{l}\text { Shared decision-making between the } \\
\text { patient, their family, the provider, and } \\
\text { other stakeholders is recommended } \\
\text { prior to making care plans. This } \\
\text { includes discussion of risks, benefits, } \\
\text { alternatives, and expected outcomes } \\
\text { for patients requiring CIEDs for their } \\
\text { pre- and post-implant care. }\end{array}$ & B-NR & $310-312$ \\
\hline
\end{tabular}

\section{Recommendation-specific supportive text}

Shared decision-making is a process whereby patients, families, and providers exchange information and dialogue about medical diagnostic and treatment options. ${ }^{310}$ The goal is for patients and their families to reach evidence-informed and value-congruent medical decisions collaboratively with their clinicians. This modern model for health care decision-making has superseded 
paternalism, a previous model whereby providers made medical decisions on behalf of their patients using the ethical principal of beneficence. A shared decision-making approach, combining the ethical principles of professional beneficence and patient autonomy, has been shown to improve patient outcomes. ${ }^{311,312}$

The use of shared decision-making should occur prior to all CIED implantation procedures. Clinicians must estimate and clearly describe the potential benefits and risks for the patient and their family. Some decisions will be relatively straightforward; for example, the decision to implant a permanent pacemaker to treat postoperative surgical complete heart block in a patient who is pacemaker dependent will be largely uncontestable. However, other treatment decisions, such as implantation of an ICD for primary prevention of SCD, are more complex and nuanced and include choice of ICD system, device location, and personalized estimation of risk of life-threatening arrhythmia for the particular patient over time.

Finally, the shared decision-making process is also important and applicable to post-implant diagnostic and treatment decisions for our patients with CIEDs including genetic testing, MRI, sports participation, pregnancy, cardiac surgery, and device reprogramming, removal, or revision.

\section{Knowledge gaps and future research}

There have been no RCTs involving CIEDs in children. Therefore, the recommendations put forth in this guideline are based on data from observational studies in children, clinical trials in adults, and expert opinion. Clinical trials, especially RCTs, remain challenging in pediatric populations because of low overall event rates in specific diseases and variations in disease progression from birth to adulthood. $^{313}$

Critical knowledge gaps exist is several areas. ${ }^{314}$ One example is the use of ICDs for the primary prevention of SCD. With reduction in size and the development of novel lead configurations, ICD use in pediatrics has increased dramatically while the age at implant has decreased significantly. ${ }^{130,315}$ However, the accurate identification of patients at increased risk remains perplexing.

Several other important knowledge gaps include but are not limited to the optimal timing of pacemaker implantation after postoperative AV block, contemporary outcomes of patients with isolated CCAVB who do not undergo pacing, risk factors for pacemaker-induced cardiomyopathy, optimal age and body size for transvenous lead implantation, and safety of MRI with abandoned or epicardial leads.

With continuing technological innovations, future research is needed to develop pediatric-specific criteria for application of these new technologies. These include subcutaneous ICDs, leadless pacemakers, and conduction system pacing. ${ }^{219,316,317}$ Multicenter prospective registries as well as high-quality retrospective data are necessary to provide real-world evidence for new and existing CIED technologies. Future research should be conducted in collaboration with PACES, other relevant scientific societies, the U.S. Food and Drug Administration, and industry partners for development of pediatric "appropriate" CIEDs and device algorithms to specifically benefit young patients and improve their long-term outcomes.

Supplementary data. Supplementary data (Appendices 3 and 4) associated with this article can be found in the online version at https://doi.org/10. 1017/S1047951121003413.

\section{References}

1. Frye RL, Collins JJ, DeSanctis RW, et al. Guidelines for permanent pacemaker implantation, 1984. A report of the Joint American College of Cardiology/American Heart Association Task Force on Assessment of Cardiovascular Procedures (Subcommittee on Pacemaker Implantation). Circulation 1984; 70: 331A-339A.

2. Kusumoto FM, Schoenfeld MH, Barrett C, et al. 2018 ACC/AHA/HRS guideline on the evaluation and management of patients with bradycardia and cardiac conduction delay: a report of the American College of Cardiology/American Heart Association Task Force on Clinical Practice Guidelines, and the Heart Rhythm Society. J Am Coll Cardiol 2019; 74: 932-987.

3. Levine GN, O'Gara PT, Beckman JA, et al. Recent innovations, modifications, and evolution of ACC/AHA clinical practice guidelines: an update for our constituencies: a report of the American College of Cardiology/ American Heart Association Task Force on Clinical Practice Guidelines. Circulation 2019; 139: e879-e886.

4. Halperin JL, Levine GN, Al-Khatib SM, et al. Further evolution of the ACC/ AHA clinical practice guideline recommendation classification system: a report of the American College of Cardiology/American Heart Association Task Force on Clinical Practice Guidelines. J Am Coll Cardiol 2016; 67: 1572-1574.

5. Kusumoto FM, Calkins H, Boehmer J, et al. HRS/ACC/AHA expert consensus statement on the use of implantable cardioverter-defibrillator therapy in patients who are not included or not well represented in clinical trials. Circulation 2014; 130: 94-125.

6. Epstein AE, Dimarco JP, Ellenbogen KA, et al. ACC/AHA/HRS 2008 guidelines for device-based therapy of cardiac rhythm abnormalities. Heart Rhythm 2008; 5: 934-955.

7. Tracy CM, Epstein AE, Darbar D, et al. 2012 ACCF/AHA/HRS focused update of the 2008 guidelines for device-based therapy of cardiac rhythm abnormalities. Heart Rhythm 2012; 9: 1737-1753.

8. Hernández-Madrid A, Paul T, Abrams D, et al. Arrhythmias in congenital heart disease. A position paper of the European Heart Rhythm Association, Association for European Paediatric and Congenital Cardiology (AEPC), and the European Society of Cardiology (ESC) Working Group on Grownup Congenital Heart Disease. Europace 2018; 20: 1719-1753.

9. Khairy P, Van Hare GF, Balaji S, et al. 2014 PACES/HRS expert consensus statement on the recognition and management of arrhythmias in adult congenital heart disease. Heart Rhythm 2014; 11: e102-e165.

10. Brignole M, Auricchio A, Baron-Esquivias G, et al. 2013 ESC Guidelines on cardiac pacing and cardiac resynchronization therapy: the Task Force on cardiac pacing and resynchronization therapy of the European Society of Cardiology (ESC). Developed in collaboration with the European Heart Rhythm Association (EHRA). Europace 2013; 15: 1070-1118.

11. Shen WK, Sheldon RS, Benditt DG, et al. 2017 ACC/AHA/HRS guidelines for the evaluation and management of patients with syncope. Circulation 2017; 136: e60-e122.

12. Al-Khatib SM, Stevenson WG, Ackerman MJ, et al. 2017 AHA/ACC/HRS guideline for management of patients with ventricular arrhythmias and the prevention of sudden cardiac death. J Am Coll Cardiol 2018; 72: 1677-1749.

13. Priori SG, Blomström-Lundqvist C, Mazzanti A, et al. 2015 ESC guidelines for the management of patients with ventricular arrhythmias and the prevention of sudden cardiac death. Eur Heart J 2015; 36: 2793-2867.

14. Priori SG, Wilde AA, Horie M, et al. 2013 HRS/EHRA/APHRS expert consensus statement on the diagnosis and management of patients with inherited primary arrhythmia syndromes. Heart Rhythm 2013; 10: 1932-1963.

15. Ommen SR, Mital S, Burke MA, et al. 2020 AHA/ACC guideline for the diagnosis and treatment of patients with hypertrophic cardiomyopathy: a report of the American College of Cardiology/American Heart Association Joint Committee on Clinical Practice Guidelines. Circulation 2020; 142: e558-e631.

16. Towbin JA, McKenna WJ, Abrams DJ, et al. 2019 HRS expert consensus statement on evaluation, risk stratification, and management of arrhythmogenic cardiomyopathy. Heart Rhythm 2019; 16: e301-e372. 
17. Kirk R, Dipchand AI, Rosenthal DN, et al. 2014 The International Society for Heart and Lung Transplantation guidelines for the management for pediatric heart failure. J Heart Lung Transplant 2014; 33: 888-909.

18. Kusumoto FM, Schoenfeld MH, Wilkoff BL, et al. 2017 HRS expert consensus statement on cardiovascular implantable electronic device lead management and extraction. Heart Rhythm 2017; 14: e503-e551.

19. Indik JH, Gimbel JR, Abe H, et al. 2017 HRS expert consensus statement on magnetic resonance imaging and radiation exposure in patients with cardiovascular implantable electronic devices. Heart Rhythm 2017; 14: e97-e153.

20. Chang PM, Carter C, Bar-Cohen Y. Indications for permanent pacing, device and lead selection. In: Shah M, Rhodes L, Kaltman J (eds). Cardiac Pacing and Defibrillation in Pediatric and Congenital Heart Disease. John Wiley and Sons Ltd, West Sussex, UK, 2017: 37-61.

21. Weindling S, Saul J, Triedman J, et al. Staged pacing therapy for congenital complete heart block in premature infants. Am J Cardiol 1994; 74: 412-413.

22. Moore JP, Shannon KM. Transpulmonary atrial pacing: an approach to transvenous pacemaker implantation after extracardiac conduit Fontan surgery. J Cardiovasc Electrophysiol 2014; 25: 1028-1031.

23. Breivik K, Ohm OJ, Segadal L. Sick sinus syndrome treated with permanent pacemaker in 109 patients: a follow-up study. Acta Med Scand 1979; 206: 153-159.

24. Albin G, Hayes DL, Holmes Jr. DR. Sinus node dysfunction in pediatric and young adult patients: treatment by implantation of a permanent pacemaker in 39 cases. Mayo Clin Proc 1985; 60: 667-672.

25. Gillette PC, Shannon C, Garson Jr. A, et al. Pacemaker treatment of sick sinus syndrome in children. J Am Coll Cardiol 1983; 1: 1325-1329.

26. Chiu SN, Lin LY, Wang JK, et al. Long-term outcomes of pediatric sinus bradycardia. J Pediatr 2013; 163: 885-889.

27. Reybrouck T, Vangesselen S, Gewillig M. Impaired chronotropic response to exercise in children with repaired cyanotic congenital heart disease. Acta Cardiol 2009; 64: 723-727.

28. Kardelen F, Celiker A, Ozer S, Ozme S, Oto A. Sinus node dysfunction in children and adolescent: treatment by placement of a permanent pacemaker in 26 patients. Turk J Pediatr 2002; 44: 312-316.

29. Gillette PC, Wampler DR, Shannon C, et al. Use of atrial pacing in a young population. Pacing Clin Electrophysiol 1985; 8: 94-100.

30. Jaeggi ET, Hamilton RM, Silverman ED, et al. Outcome of children with fetal, neonatal or childhood diagnosis of isolated congenital atrioventricular block. J Am Coll Cardiol 2002; 39: 130-137.

31. Baruteau AE, Fouchard S, Behaghel A, et al. Characteristics and long-term outcome of non-immune isolated atrioventricular block diagnosed in utero or early childhood: a multicentre study. Eur Heart J 2012; 33: 622-629.

32. Balmer $C$, Fasnacht $M$, Rahn $M$, et al. Long-term follow up of children with congenital complete atrioventricular block and the impact of pacemaker therapy. Europace 2002; 4: 345-349.

33. Michaëlsson M, Engle MA. Isolated congenital complete atrioventricular block in adult life. Circulation 1995; 92: 442-449.

34. Michaëlsson M, Engle MA. Congenital complete heart block; an international study of the natural history. Cardiovasc Clin 1972; 4: 85-101.

35. Winkler RB, Freed MD, Nadas AS. Exercise induced ventricular ectopy in children and young adults with complete heart block. Am Heart J 1980; 9: 87-92.

36. Karpawich PP, Gillette PC, Garson Jr. A, et al. Congenital complete atrioventricular block: clinical and electrophysiologic predictors of need for pacemaker insertion. Am J Cardiol 1981; 48: 1098-1102.

37. Pinsky WW, Gillette PC, Garson A, et al. Diagnosis, management, and long-term results of patients with congenital complete atrioventricular block. Pediatrics 1982; 69: 728-733.

38. Dewey RC, Capeless MA, Levy AM. Use of ambulatory electrocardiographic monitoring to identify high-risk patients with congenital complete heart block. N Engl J Med 1987; 316: 835-839.

39. Benson DW, Spach MS, Edwards SB, et al. Heart block in children. Evaluation of subsidiary ventricular pacemaker recovery times and ECG tape recordings. Pediatr Cardiol 1982; 2: 39-45.

40. Sholler GF, Walsh EP. Congenital complete heart block in patients without anatomic cardiac defects. Am Heart J 1989; 118: 1193-1198.
41. Kertesz NJ, Friedman RA, Colan SD, et al. Left ventricular mechanics and geometry in patients with congenital complete atrioventricular block. Circulation 1997; 96: 3430-3435.

42. Glatz AC, Rhodes LA, Gayno JW, et al. Outcome of high-risk neonates with congenital complete heart block paced in the first 24 hours after birth. J Thorac Cardiovasc Surg 2008; 136: 767-773.

43. Moak JP, Barron KS, Hougen TJ, et al. Congenital heart block: development of late-onset cardiomyopathy, a previously underappreciated sequela. J Am Coll Cardiol 2001; 37: 238-242.

44. Janoušek, van Geldorp IE, Krupičková S, et al. Permanent cardiac pacing in children: Choosing the optimal pacing site: a multicenter study. Circulation 2013; 127: 613-623.

45. Gladman G, Davis AM, Fogelman R, Hamilton RM, Gow RM. Torsade de pointes, acquired complete heart block and inappropriately long QT in childhood. Can J Cardiol 1996; 12: 683-685.

46. Strasberg B, Kusniec J, Erdman S, et al. Polymorphous ventricular tachycardia and atrioventricular block. Pacing Clin Electrophysiol 1986; 9: 522-526.

47. Yandrapalli S, Harikrishnan P, Ojo A, Vuddanda VLK, Jain D. Exercise induced complete atrioventricular block: utility of exercise stress test. J Electrocardiol 2018; 51: 153-155.

48. Bonikowske AR, Barout A, Fortin-Gamero S, Lara MIB, Kapa S, Allison TG. Frequency and characteristics of exercise-induced second-degree atrioventricular block in patients undergoing stress testing. J Electrocardiol 2019; 54: 54-60.

49. Silver ES, Pass RH, Hordof A, Liberman. Paroxysmal AV block in children with normal cardiac anatomy as a cause of syncope. Pacing Clin Electrophysiol 2008; 31: 322-326.

\section{Postoperative atrioventricular block}

50. Weindling SN, Saul PJ, Gamble WJ, et al. Duration of complete atrioventricular block after congenital heart disease surgery. Am J Cardiol 1998; 82: 525-527.

51. Romer AJ, Tabbutt S, Etheridge SP, et al. Atrioventricular block after congenital heart surgery: analysis from the Pediatric Cardiac Critical Care Consortium. J Thorac Cardiovasc Surg 2019; 157: 1168-1177.

52. Aziz PF, Serwer GA, Bradley DJ, et al. Pattern of recovery for transient complete heart block after open heart surgery for congenital heart disease: duration alone predicts risk of late complete heart block. Pediatric Cardiol 2012; 34: 999-1005.

53. Gross GJ, Chiu CC, Hamilton RM, et al. Natural history of postoperative heart block in congenital heart disease: implications for pacing intervention. Heart Rhythm 2006; 3: 601-604.

54. Krongrad E. Prognosis for patients with congenital heart disease and postoperative intraventricular conduction defects. Circulation 1978; 57: 867-870.

55. Villain E, Ouarda F, Beyler C, et al. Predictive factors for late complete atrio-ventricular block after surgical treatment for congenital cardiomyopathy. Arch Mal Coeur Vaiss 2003; 96: 495-498.

56. Anderson JB, Czosek RJ, Knilans TK, et al. Postoperative heart block in children with common forms of congenital heart disease: results from the KID Database. J Cardiovasc Electrophysiol 2012; 23: 1349-1354.

57. Ayyildiz P, Kasar T, Ozturk E, et al. Evaluation of permanent or transient complete heart block after open heart surgery for congenital heart disease. Pacing Clin Electrophysiol 2016; 9: 160-165.

58. Liberman L, Pass RH, Hordof AJ, et al. Incidence and characteristics of heart block after heart surgery in pediatric patients: A multicenter study. J Thorac Cardiovasc Surg 2016; 152: 197-202.

59. Huhta JC, Maloney JD, Ritter DG, et al. Complete atrioventricular block in patients with atrioventricular discordance. Circulation 1983; 67: 1374-1377.

60. Moore JP, Aboulhosn JA. Introduction to the congenital heart defects: anatomy of the conduction system. Cardiac Electrophysiol Clin 2017; 9: $167-175$. 


\section{Congenital heart disease: specific considerations}

61. Jaeggi ET, Hornberger LK, Smallhorn JF, et al. Prenatal diagnosis of complete atrioventricular block associated with structural heart disease: combined experience of two tertiary care centers and review of the literature. Ultrasound Obstet Gynecol 2005; 26: 16-21.

62. Lopes LM, Tavares GM, Damiano AP, et al. Perinatal outcome of fetal atrioventricular block: one-hundred-sixteen cases from a single institution. Circulation 2008; 118: 1268-1275.

63. Silka MJ, Manwill JR, Kron J, et al. Bradycardia-mediated tachyarrhythmias in congenital heart disease and responses to chronic pacing at physiologic rates. Am J Cardiol 1990; 65: 488-493.

64. Rhodes LA, Walsh EP, Gamble WJ, et al. Benefits and potential risks of atrial antitachycardia pacing after repair of congenital heart disease. Pacing Clin Electrophysiol 1995; 18: 1005-1016.

65. Kramer CC, Maldonado JR, Olson MD, et al. Safety and efficacy of atrial antitachycardia pacing in congenital heart disease. Heart Rhythm 2018; 15 : 543-547.

66. Stephenson EA, Casavant D, Tuzi J, et al. Efficacy of atrial antitachycardia pacing using the Medtronic AT500 pacemaker in patients with congenital heart disease. Am J Cardiol 2003; 92: 871-876.

67. Tsao S, Deal BJ, Backer CL, et al. Device management of arrhythmias after Fontan conversion. J Thorac Cardiovasc Surg 2009; 138: 937-940.

68. Barber BJ, Batra AS, Burch GH, et al. Acute hemodynamic effects of pacing in patients with Fontan physiology: a prospective study. J Am Coll Cardiol 2005; 46: 1937-1942.

69. Drago F, Silvetti MS, Grutter G, et al. Use of DDDRP pacing device in prevention and treatment of tachy-brady syndrome after Mustard procedure. Pacing Clin Electrophysiol 2004; 27: 530-532.

70. Stout KK, Daniels CJ, Aboulhosn JA, et al. 2018 AHA/ACC guideline for the management of adults with congenital heart disease: A report of the American College of Cardiology/American Heart Association Task Force on Clinical Practice Guidelines. Circulation 2019; 139: e698-e800.

71. Khairy P, Landzberg M, Gatzoulis MA, et al. Epicardial versus ENdocardial pacing and Thromboembolic events (EVENT) Investigators. Transvenous pacing leads and systemic thromboemboli in patients with intracardiac shunts: A multicenter study. Circulation 2006; 113: 2391-2397.

72. DeSimone CV, Friedman PA, Noheria A, et al. Stroke or transient ischemic attack in patients with transvenous pacemaker or defibrillator and echocardiographically detected patent foramen ovale. Circulation 2013; 128: 14331441.

73. Supple GE, Ren J-F, Zado ES, Marchlinski FE. Mobile thrombus on device leads in patients undergoing ablation. Circulation 2011; 124: 772-778.

74. Lau KC, Gaynor JW, Fuller SM, et al. Long term atrial and ventricular epicardial pacemaker lead survival after cardiac operations in pediatric patients with congenital heart disease. Heart Rhythm 2015; 12: 566-573.

75. Termosesov S, Kulbachinskaya E, Polyakava E, et al. Video-assisted thoracoscopic pacemaker lead placement in children with atrioventricular block. Ann Pediatr Cardiol 2021; 14: 67-71.

76. Clark B, Kumthekar R, Mass P, et al. Chronic performance of subxiphoid minimally invasive pericardial Model 20066 pacemaker lead insertion in an infant animal model. J Interv Card Electrophysiol 2020; 59: 13-19.

77. Cohen MI, Rhodes LA, Spray TL. Efficacy of prophylactic epicardial pacing leads in children and young adults. Ann Thorac Surg 2004; 78: 197-203.

78. Rychik J, Atz AM, Celermajer DS, Deal BJ, et al. Evaluation and management of the child and adult with Fontan circulation: A scientific statement from the American Heart Association. Circulation 2019; 140: e234-e284.

\section{Post cardiac transplantation}

79. Kertesz NJ, Towbin JA, Clunie S, et al. Long-term follow-up of arrhythmias in pediatric orthotopic heart transplant recipients: incidence and correlation with rejection. J Heart Lung Transplant 2003; 22: 889-893.

80. El-Assaad I, Al-Kindi SG, Oliveira GH, et al. Pacemaker implantation in pediatric heart transplant recipients: predictors, outcomes, and impact on survival. Heart Rhythm 2015; 12: 1776-1781.

81. Jones DG, Mortsell DH, Rajaruthnam D, et al. Permanent pacemaker implantation early and late after heart transplantation: clinical indication, risk factors and prognostic implications. J Heart Lung Transplant 2011; 30: 1257-1265.

82. Mahmood A, Andrews R, Fenton M, et al. Permanent pacemaker implantation after pediatric heart transplantation: risk factors, indications, and outcomes. Clin Transplant 2019; 33: e13503.

83. Luebbert JJ, Lee FA, Rosenfeld LE. Pacemaker therapy for early and late sinus node dysfunction in orthotopic heart transplant recipients: a single-center experience. Pacing Clin Electrophysiol 2008; 31: 1108-1112.

84. Cannon BC, Denfeld SW, Friedman RA, et al. Late pacemaker requirement after pediatric orthotopic heart transplantation may predict the presence of transplant coronary artery disease. J Heart Lung Transplant 2004;23:67-71.

85. Chang AC, Hruban RH, Levin HR, et al. Comparison of rejection in the atrioventricular node and bundles with the working myocardium in transplanted hearts. J Heart Lung Transplant 1991; 10: 915-920.

86. Daly KP, Chakravarti SB, Tresler M, et al. Sudden death after pediatric heart transplantation: analysis of data from the Pediatric Heart Transplant Study Group. J Heart Lung Transplant 2011; 30: 1395-1402.

87. Carboni MP. Sudden cardiac death after heart transplantation: can ICD prevent SCD? Heart Rhythm 2014; 11: 1691-1692.

\section{Neuromuscular diseases and other progressive conduction} diseases

88. Feingold B, Mahle WT, Auerbach S, et al. Management of cardiac involvement associated with neuromuscular diseases: A scientific statement from the American Heart Association. Circulation 2017; 136: e200-e231.

89. Bhakta D, Shen C, Kron J, et al. Pacemaker and implantable cardioverterdefibrillator use in a us myotonic dystrophy type 1 population. J Cardiovasc Electrophysiol 2011; 22: 1369-1375.

90. Lund M, Diaz KJ, Ranthe MF, et al. Cardiac involvement in myotonic dystrophy: A nationwide cohort study. Eur Heart J 2014; 35: 2158-2164.

91. Ha AH, Tarnopolsky MA, Bergstra TG, et al. Predictors of atrio-ventricular conduction disease, long-term outcomes in patients with myotonic dystrophy types I and II. Pacing Clin Electrophysiol 2012; 35: 1262-1269.

92. Groh WJ, Groh MR, Saha C, et al. Electrocardiographic abnormalities and sudden death in myotonic dystrophy type 1. N Engl J Med 2008; 358: 2688 2697.

93. Wahbi K, Meune C, Porcher R, et al. Electrophysiological study with prophylactic pacing and survival in adults with myotonic dystrophy and conduction system disease. JAMA 2012; 307: 1292-1301.

94. Van Berlo JH, de Voogt WG, van der Kooi AJ, et al. Meta-analysis of clinical characteristics of 299 carriers of LMNA gene mutations: Do lamin A/C mutations portend a high risk of sudden death? J Mol Med 2005; 83: 79-83.

95. Polak PE, Zijlstra F, Roelandt JR. Indications for pacemaker implantation in the Kearns-Sayre syndrome. Eur Heart J 1989; 10: 281-282.

96. Kabunga P, Lau AK, Phan K, et al. Systematic review of cardiac electrical disease in Kearns-Sayre syndrome and mitochondrial cytopathy. Int J Cardiol 2015; 181: 303-310.

97. Khambatta S, Nguyen DL, Beckman TJ, et al. Kearns-Sayre syndrome: A case series of 35 adults and children. Int J Gen Med 2014; 7: 325-332.

98. Di Mambro C, Tamborrino PP, Silvetti MS, et al. Progressive involvement of cardiac conduction system in paediatric patients with Kearns-Sayre syndrome: how to predict occurrence of complete heart block and sudden cardiac death? Europace 2021; 6: 948-957.

99. Hasselberg NE, Edvardsen T, Petri H, Berge KE, et al. Risk prediction of ventricular arrhythmias and myocardial function in Lamin A/C mutation positive subjects. Europace 2014; 16: 563-571.

100. Asatryan B, Medeiros-Domingo A. Molecular and genetic insights into progressive cardiac conduction disease. Europace 2019; 21: 1145-1158.

\section{Neurocardiogenic syncope}

101. Kolterer B, Gebauer RA, Janousek J, Dähnert I, Riede FT, Paech C. Improved quality of life after treatment of prolonged asystole during breath holding spells with a cardiac pacemaker. Ann Pediatr Cardiol 2015; 8: 113-117. 
102. McLeod KA, Wilson N, Hewitt J, Norrie J, Stephenson JB. Cardiac pacing for severe childhood neurally mediated syncope with reflex anoxic seizures. Heart 1999; 82: 721-725.

103. Kelly AM, Porter CJ, McGoon MD, Espinosa RE, Osborn MJ, Hayes DL. Breath-holding spells associated with significant bradycardia: successful treatment with permanent pacemaker implantation. Pediatrics 2001; 108: 698-702.

104. Brignole M, Menozzi C, Moya A, et al. Pacemaker therapy in patients with neurally mediated syncope and documented asystole: third International Study on Syncope of Uncertain Etiology (ISSUE-3): a randomized trial. Circulation 2012; 125: 2566-2571.

105. Paech C, Wagner F, Mensch S, Antonin Gebauer R. Cardiac pacing in cardioinhibitory syncope in children. Congenit Heart Dis 2018; 13: 1064 1068.

106. Sutton R, de Jong JSY, Stewart JM, et al. Pacing in vasovagal syncope: physiology, pacemaker sensors, and recent clinical trials-Precise patient selection and measurable benefit. Heart Rhythm 2020; 17: 821-828.

107. Benditt DG, van Dijk G, Thijs RD. Ictal asystole: life-threatening vagal storm or a benign seizure self-termination mechanism? Circ Arrhythm Electrophysiol 2015; 8: 11-14.

108. Bestawros M, Darbar D, Arain A, Abou-Khalil B, Plummer D, Dupont WD, Rah SR. Ictal Asystole and Ictal Syncope: insights into Clinical Management. Circ Arrhythm Electrophysiol 2015; 8: 159-164.

\section{Cardiac channelopathies}

109. Moss AJ, Liu JE, Gottlieb S, et al. Efficacy of permanent pacing in the management of high-risk patients with long QT syndrome. Circulation 1991; 84: 1524-1529.

110. Eldar M, Griffin JC, Van Hare GF, et al. Combined use of beta-adrenergic blocking agents and long-term cardiac pacing for patients with the long QT syndrome. J Am Coll Cardiol 1992; 20: 830-837.

111. Viskin S, Fish R, Zeltser D, et al. Arrhythmias in the congenital long QT syndrome: how often is torsade de pointes pause dependent? Heart 2000; 83: 661-666.

112. Aziz PF, Tanel RE, Zelster IJ, et al. Congenital long QT syndrome and 2:1 atrioventricular block: an optimistic outcome in the current era. Heart Rhythm 2010; 7: 781-785.

113. Eldar M, Griffin JC, Abbott JA, et al. Permanent cardiac pacing in patients with the long QT syndrome. J Am Coll Cardiol 1987; 10: 600-607.

114. Kowlgi GN, Giudicessi JR, Brake W, et al. Efficacy of intentional permanent atrial pacing in the long-term management of congenital long QT syndrome. J Cardiovasc Electrophysiol 2021; 32: 782-789.

115. Bellmann B, Roser M, Muntean B, et al. Atrial standstill in sinus node disease due to extensive atrial fibrosis: impact on dual chamber pacemaker implantation. Europace 2016; 18: 238-245.

116. Ishikawa T, Tsuji Y, Makita N. Inherited bradyarrhythmia: a diverse genetic background. J Arrhythm 2016; 32: 352-358.

\section{Inflammation/Infection}

117. McAlister HF, Klementowicz PT, Andrews C, et al. Lyme carditis: an important cause of reversible heart block. Ann Intern Med 1989; 110: 339-345.

118. Forrester JD, Mead P. Third-degree heart block associated with lyme carditis: review of published cases. Clin Infect Dis 2014; 59: 996-1000.

119. Nunes MCP, Beaton A, Acquatella H, et al. Chagas cardiomyopathy: an update of current clinical knowledge and management: a scientific statement from the American Heart Association. Circulation 2018; 138: 33-41.

120. Bocchi EA, Bestetti RB, Scanavacca MI, et al. Chronic Chagas heart disease management: from etiology to cardiomyopathy treatment. J Am Coll Cardiol 2017; 70: 1510-1524.

121. Dionne A, Mah D, Son MF, et al. Atrio-ventricular block in children with multisystem inflammatory syndrome. Pediatrics 2020; 146: e2020009704.

122. Batra AS, Epstein D, Silka MJ. The clinical course of acquired complete heart block in children with acute myocarditis. Pediatr Cardiol 2003; 24 : 495-497.

\section{Implantable cardioverter defibrillators: introduction}

123. Cunningham T, Roston TM, Franciosi S, et al. Initially unexplained cardiac arrest in children and adolescents: a national experience from the Canadian Pediatric Heart Rhythm Network. Heart Rhythm 2020; 17: 975-981.

124. Rucinski C, Winbo A, Marcondes L, et al. A population-based registry of patients with inherited cardiac conditions and resuscitated cardiac arrest. J Am Coll Cardiol 2020; 75: 2698-2707.

125. Silka MJ, Kobayashi RL, Hill AC, et al. Pediatric survivors of out-of-hospital ventricular fibrillation: etiologies and outcomes. Heart Rhythm 2018; 15: $116-121$.

126. van der Werf C, Lieve KV, Bos JM, et al. Implantable cardioverter-defibrillators in previously undiagnosed patients with catecholaminergic polymorphic ventricular tachycardia resuscitated from sudden cardiac arrest. Eur Heart J 2019; 40: 2953-2961.

127. Cohen MI, Etheridge SP. Indications for implantable cardioverter defibrillator therapy, device and lead selection. In: Shah M, Rhodes L, Kaltman J (eds). Cardiac Pacing and Defibrillation in Pediatric and Congenital Heart Disease. John Wiley and Sons Ltd, West Sussex, UK, 2017: 62-90.

128. Minier M, Probst V, Berthome P, et al. Age at diagnosis of Brugada syndrome: influence on clinical characteristics and risk of arrhythmia. Heart Rhythm 2020; 17: 743-749.

129. Silka MJ, Kron J, Dunnigan A, Dick 2nd M. Sudden cardiac death and the use of implantable cardioverter-defibrillators in pediatric patients. The Pediatric Electrophysiology Society. Circulation 1993; 87: 800-807.

130. Berul CI, Van Hare GF, Kertesz NJ, et al. Results of a multicenter retrospective implantable cardioverter-defibrillator registry of pediatric and congenital heart disease patients. J Am Coll Cardiol 2008; 51: 1685-1691.

131. Von Bergen NH, Atkins DL, Dick 2nd M, et al. Multicenter study of the effectiveness of implantable cardioverter defibrillators in children and young adults with heart disease. Pediatr Cardiol 2011; 32: 399-405.

132. Baskar S, Bao H, Minges KE, Spar DS, et al. Characteristics and outcomes of pediatric patients who undergo placement of implantable cardioverter defibrillators: insights from the National Cardiovascular data registry. Circ Arrhythm Electrophysiol 2018; 11: e006542.

133. Collins KK, Schaffer MS, Liberman L, et al. Fascicular and nonfascicular left ventricular tachycardias in the young: an international multicenter study. J Cardiovasc Electrophysiol 2013; 24: 640-648.

134. Roggen A, Pavlovic M, Pfammatter JP. Frequency of spontaneous ventricular tachycardia in a pediatric population. Am J Cardiol 2008; 101: 852-854.

135. Wu J, Chen Y, Ji W, Gu B, et al. Catheter ablation of ventricular tachycardia in the pediatric patients: a single-center experience. Pacing Clin Electrophysiol 2020; 43: 37-46.

136. Li XM, Jiang H, Li YH, Zhang Y, et al. Effectiveness of Radiofrequency Catheter ablation of outflow tract ventricular arrhythmias in children and adolescents. Pediatr Cardiol 2016; 37: 1475-1481.

137. Sears SF, Hazelton AG, St Amant J. Quality of life in pediatric patients with implantable cardioverter defibrillators. Am J Cardiol 2011; 107: 10231027.

138. Kini V, Soufi MK, Deo R, et al. Appropriateness of primary prevention implantable cardioverter-defibrillators at the time of generator replacement: are indications still met? J Am Coll Cardiol 2014; 63: 2388-2394.

139. Schwartz PJ, Spazzolini C, Priori SG, et al. Who are the long-QT syndrome patients who receive an implantable cardioverter-defibrillator and what happens to them?: data from the European Long-QT Syndrome Implantable Cardioverter-Defibrillator (LQTS ICD) Registry. Circulation 2010; 122: 1272-1282.

140. Vincent GM, Schwartz PJ, Denjoy I, et al. High efficacy of beta-blockers in long-QT syndrome type 1: contribution of noncompliance and QT-prolonging drugs to the occurrence of beta-blocker treatment "failures". Circulation 2009; 119: 215-221.

141. Wedekind H, Burde D, Zumhagen S, et al. QT interval prolongation and risk for cardiac events in genotyped LQTS-index children. Eur J Pediatr 2009; 168: 1107-1115.

142. Schwartz PJ, Priori SG, Cerrone M, et al. Left cardiac sympathetic denervation in the management of high-risk patients affected by the long-QT syndrome. Circulation 2004; 109: 1826-1833. 
143. Bos JM, Bos KM, Johnson JN, et al. Left cardiac sympathetic denervation in long QT syndrome: analysis of therapeutic nonresponders. Circ Arrhythm Electrophysiol 2013; 6: 705-711.

144. Garson Jr. A, Dick 2nd M, Fournier A, et al. The long QT syndrome in children. An international study of 287 patients. Circulation 1993; 87: 1866-1872.

145. Spazzolini C, Mullally J, Moss AJ, et al. Clinical implications for patients with long QT syndrome who experience a cardiac event during infancy. J Am Coll Cardiol 2009; 54: 832-837.

146. Biton Y, Rosero S, Moss AJ, et al. Primary prevention with the implantable cardioverter-defibrillator in high-risk long-QT syndrome patients. Europace 2019; 21: 339-346.

147. Moss AJ, Zareba W, Hall WJ, et al. Effectiveness and limitations of betablocker therapy in congenital long-QT syndrome. Circulation 2000; 101: 616-623.

148. Liu JF, Jons C, Moss AJ, et al. Risk factors for recurrent syncope and subsequent fatal or near-fatal events in children and adolescents with long QT syndrome. J Am Coll Cardiol 2011; 57: 941-950.

149. Goldenberg I, Moss AJ, Peterson DR, et al. Risk factors for aborted cardiac arrest and sudden cardiac death in children with the congenital long-QT syndrome. Circulation 2008; 117: 2184-2191.

150. Giudicessi JR, Ackerman MJ. Genotype- and phenotype-guided management of congenital long QT syndrome. Curr Probl Cardiol 2013; 38: 417-455.

151. Dufendach KA, Timothy K, Ackerman MJ, et al. Clinical outcomes and modes of death in Timothy syndrome: a multicenter international study of a rare disorder. JACC Clin Electrophysiol 2018; 4: 459-466.

152. Crotti L, Spazzolini C, Tester DJ, et al. Calmodulin mutations and life-threatening cardiac arrhythmias: insights from the International Calmodulinopathy registry. Eur Heart J 2019; 40: 2964-2975.

153. Mazzanti A, Maragna R, Vacanti, et al. Interplay between genetic substrate, QTc duration, and arrhythmia risk in patients with long QT syndrome. J Am Coll Cardiol 2018; 71: 1663-1671.

154. Etheridge SP, Sanatani S, Cohen MI, Albaro CA, Saarel EV, Bradley DJ. Long QT syndrome in children in the era of implantable defibrillators. J Am Coll Cardiol 2007; 50: 1335-1340.

155. Moore JP, Gallotti RG, Shannon KM, et al. Genotype predicts outcomes in fetuses and neonates with severe congenital long QT syndrome. JACC Clin Electrophysiol 2020; 6: 1561-1570.

156. Roston TM, Jones K, Hawkins NM, et al. Implantable cardioverter-defibrillator use in catecholaminergic polymorphic ventricular tachycardia: A systematic review. Heart Rhythm 2018; 15: 1791-1799.

157. Miyake CY, Webster G, Czosek RJ, et al. Efficacy of implantable cardioverter defibrillators in young patients with catecholaminergic polymorphic ventricular tachycardia: success depends on substrate. Circ Arrhythm Electrophysiol 2013; 6: 579-587.

158. Priori S, Napolitano C, Memmi M, et al. Clinical and molecular characterization of patients with catecholaminergic polymorphic ventricular tachycardia. Circulation 2002; 106: 69-74.

159. Roston TM, Haji-Ghassemi O, LaPage MJ, et al. Catecholaminergic polymorphic ventricular tachycardia patients with multiple genetic variants in the PACES CPVT registry. PLoS One 2018; 13: e0205925.

160. Hayashi M, Denjoy I, Extramiana F, et al. Incidence and risk factors of arrhythmic events in catecholaminergic polymorphic ventricular tachycardia. Circulation 2009; 119: 2426-2434.

161. Kannankeril PJ, Moore JP, Cerrone M, et al. Efficacy of Flecainide in the treatment of catecholaminergic polymorphic ventricular tachycardia: a randomized clinical trial. JAMA Cardiol 2017; 2: 759-766.

162. De Ferrari GM, Dusi V, Spazzolini C, et al. Clinical management of catecholaminergic polymorphic ventricular tachycardia: the role of left cardiac sympathetic denervation. Circulation 2015; 131: 2185-2193.

163. Olde Nordkamp LR, Postema PG, Knops RE. Implantable cardioverterdefibrillator harm in young patients with inherited arrhythmia syndromes: a systematic review and meta-analysis of inappropriate shocks and complications. Heart Rhythm 2016; 13: 443-454.

164. Roses-Noguer F, Jarman JW, Clague JR, et al. Outcomes of defibrillator therapy in catecholaminergic polymorphic ventricular tachycardia. Heart Rhythm 2014; 11: 58-66.
165. Gonzalez Corcia MC, de Asmundis C, Chierchia GB, et al. Brugada syndrome in the paediatric population: a comprehensive approach to clinical manifestations, diagnosis, and management. Cardiol Young 2016; 26: 1044-1055.

166. Gonzalez Corcia MC, Sieira J, Sarkozy A, et al. Brugada syndrome in the young: an assessment of risk factors predicting future events. Europace 2017; 19: 1864-1873.

167. Gonzalez Corcia MC, Sieira J, Pappaert G, et al. A clinical score model to predict lethal events in young patients ( $\leq 19$ years) with the Brugada syndrome. Am J Cardiol 2017; 120: 797-802.

168. Probst V, Denjoy I, Meregalli PG, et al. Clinical aspects and prognosis of Brugada syndrome in children. Circulation 2007; 115: 2042-2048.

169. Michowitz Y, Milman A, Andorin A, et al. Characterization and management of arrhythmic events in young patients with Brugada syndrome. J Am Coll Cardiol 2019; 73: 1756-1765.

170. Gonzalez Corcia MC, Sieira J, et al. Implantable cardioverter-defibrillators in children and adolescents with Brugada syndrome. J Am Coll Cardiol 2018; 71: 148-157.

171. Andorin A, Behr R, Denjoy I, et al. Impact of clinical and genetic findings on the management of young patients with Brugada syndrome. Heart Rhythm 2016; 13: 1274-1282.

172. Maron BJ, Rowin EJ, Casey SA, et al. Hypertrophic cardiomyopathy in children, adolescents, and young adults associated with low cardiovascular mortality with contemporary management strategies. Circulation 2016; 133: $62-73$.

173. Maron BJ, Spirito P, Ackerman MJ, et al. Prevention of sudden cardiac death with implantable cardioverter-defibrillators in children and adolescents with hypertrophic cardiomyopathy. J Am Coll Cardiol 2013; 61: 1527-1535.

174. Miron A, Lafreniere-Roula M, Steve Fan CP, et al. A validated model for sudden cardiac death risk prediction in pediatric hypertrophic cardiomyopathy. Circulation 2020; 142: 217-229.

175. Norrish G, Cantarutti N, Pissaridou E, et al. Risk factors for sudden cardiac death in childhood hypertrophic cardiomyopathy: a systematic review and meta-analysis. Eur J Prev Cardiol 2017; 24: 1220-1230.

176. Balaji S, DiLorenzo MP, Fish FA, et al. Risk factors for lethal arrhythmic events in children and adolescents with hypertrophic cardiomyopathy and an implantable defibrillator: an international multicenter study. Heart Rhythm 2019; 16: 1462-1467.

177. Norrish G, Ding T, Field E, et al. Development of a novel risk prediction model for sudden cardiac death in childhood hypertrophic cardiomyopathy (HCM Risk-Kids). JAMA Cardiol 2019; 1: 918-927.

178. Kaski J, Tomé Esteban MT, Lowe M. Outcomes after implantable cardioverter-defibrillator treatment in children with hypertrophic cardiomyopathy. Heart 2007; 93: 372-374.

179. Briasoulis A, Mallikethi-Reddy S, Palla M, et al. Myocardial fibrosis on cardiac magnetic resonance and cardiac outcomes in hypertrophic cardiomyopathy: a meta-analysis. Heart 2015; 101: 1406-1411.

180. Prinz C, Schwarz M, Ilic I, et al. Myocardial fibrosis severity on cardiac magnetic resonance imaging predicts sustained arrhythmic events in hypertrophic cardiomyopathy. Can J Cardiol 2013; 29: 358-363.

181. Vermeer AMC, Clur SB, Blom NA, et al. Penetrance of hypertrophic cardiomyopathy in children who are mutation positive. J Pediatr 2017; 188: 91-95.

182. Spinner JA, Noel CV, Denfield SW, et al. Association of late gadolinium enhancement and degree of left ventricular hypertrophy assessed on cardiac magnetic resonance imaging with ventricular tachycardia in children with hypertrophic cardiomyopathy. Am J Cardiol 2016; 117: 1342-1348.

183. Maron BJ, Maron MS, Semsarian C. Genetics of hypertrophic cardiomyopathy after 20 years: clinical perspectives. J Am Coll Cardiol 2012; 60: 705-715.

184. Muchtar E, Blauwet LA, Gertz MA. Restrictive cardiomyopathy: genetics, pathogenesis, clinical manifestations, diagnosis, therapy. Circulation Research 2017; 121: 819-837.

185. Walsh MA, Grenier MA, Jeffries LA, et al. Conduction abnormalities in pediatric patients with restrictive cardiomyopathies. Circ Heart Fail 2012; 5: 267-273. 
186. Webber SA, Lipshultz SE, Sleeper LA, et al. Outcomes of restrictive cardiomyopathy in childhood and the influence of phenotype: a report from the Pediatric Cardiomyopathy registry. Circulation 2012; 126: 1237-1244.

187. Wittekind SG, Ryan TD, Gao Z, et al. Contemporary outcomes of pediatric restrictive cardiomyopathy: a single-center experience. Pediatr Cardiol 2019; 40: 694-704.

188. Zangwill SD, Naftel D, L'Ecuyer T, et al. Outcomes of children with restrictive cardiomyopathy listed for heart transplant: a multi-institutional study. J Heart Lung Transplant 2009; 28: 1335-1340.

189. DeWitt ES, Chandler SF, Hylind RJ, et al. Phenotypic manifestations of arrhythmogenic cardiomyopathy in children and adolescents. J Am Coll Cardiol 2019; 74: 346-358.

190. Mazzanti A, Ng K, Faragli A, et al. Arrhythmogenic right ventricular cardiomyopathy: clinical course and predictors of arrhythmic risk. J Am Coll Cardiol 2016; 68: 2540-2550.

191. Te Riele A, James CA, Sawant AC, et al. Arrhythmogenic right ventricular dysplasia/cardiomyopathy in the pediatric population: clinical characterization and comparison with adult-onset disease. JACC Clin Electrophysiol 2015; $1: 551-560$.

192. Orgeron GM, James CA, Te Riele A, et al. Implantable cardioverter-defibrillator therapy in arrhythmogenic right ventricular dysplasia/cardiomyopathy: predictors of appropriate therapy, outcomes, and complications. J Am Heart Assoc 2017; 6: e006242.

193. Ortiz-Genga MF, Cuenca S, Dal Ferro M, et al. Truncating FLNC mutations are associated with high-risk dilated and arrhythmogenic cardiomyopathies. J Am Coll Cardiol 2016; 68: 2440-2451.

194. Dubin AM, Berul CI, Bevilacqua LM, et al. The use of implantable cardioverter-defibrillators in pediatric patients awaiting heart transplantation. J Card Fail 2003; 9: 375-379.

195. Bharucha T, Lee KJ, Daubeney PE, et al. Sudden death in childhood cardiomyopathy: results from a long-term national population-based study. J Am Coll Cardiol 2015; 65: 2302-2310.

196. Pahl E, Sleeper LA, Canter CE, et al. PCMR (Pediatric Cardiomyopathy Registry) Investigators. Incidence of and risk factors for sudden cardiac death in children with dilated cardiomyopathy: a report from the Pediatric Cardiomyopathy registry. J Am Coll Cardiol 2012; 59: 607-615.

197. Middlekauff HR, Stevenson WG, Stevenson LW, Saxon LA. Syncope in advanced heart failure: high risk of sudden death regardless of origin of syncope. J Am Coll Cardiol 1993; 21: 110-116.

198. Bardy GH, Lee KL, Mark DB, et al. Amiodarone or an implantable cardioverter-defibrillator for congestive heart failure. N Engl J Med 2005; 352: 225-237.

199. El-Assaad I, Al-Kindi SG, Oliveira G, et al. Implantable cardioverter-defibrillator and wait-list outcomes in pediatric patients awaiting heart transplantation. Heart Rhythm 2015; 12: 2443-2448.

200. Rhee EK, Canter CE, Basile S, et al. Sudden death prior to pediatric heart transplantation: would implantable defibrillators improve outcome? J Heart Lung Transplant 2007; 26: 447-452.

201. Jefferies JL, Wilkinson JD, Sleeper LA, et al. Cardiomyopathy phenotypes and outcomes for children with left ventricular myocardial noncompaction: results from the Pediatric Cardiomyopathy registry. J Card Fail 2015; 21: 877-884.

202. Brescia ST, et al. Mortality and sudden death in pediatric left ventricular noncompaction in a tertiary referral center. Circulation 2013; 127: 2202-2208.

203. van Waning JI, Caliskan K, Hoedemaekers YM, et al. Genetics, clinical features, and long-term outcome of noncompaction cardiomyopathy. J Am Coll Cardiol 2018; 71: 711-722.

204. Khairy P, Harris L, Landzberg MJ, et al. Implantable cardioverter-defibrillators in tetralogy of Fallot. Circulation 2008; 117: 363-370.

205. Silka MJ, Hardy BG, Menashe VD, et al. A population-based prospective evaluation of risk of sudden cardiac death after operation for common congenital heart defects. J Am Coll Cardiol 1998; 32: 245-251.

206. Nieminen HP, Jokinen EV, Sairanen HI. Causes of late deaths after pediatric cardiac surgery: a population-based study. J Am Coll Cardiol 2007; 50: 1263-1271.
207. Miyazaki A, Sakaguchi H, Ohuchi H, et al. Efficacy of hemodynamic-based management of tachyarrhythmia after repair of tetralogy of Fallot. Circ J 2012; 76: 2855-2862.

208. Zeppenfeld K, Schalij MJ, Bartelings MM, et al. Catheter ablation of ventricular tachycardia after repair of congenital heart disease: electroanatomic identification of the critical right ventricular isthmus. Circulation 2007; 116: 2241-2252.

209. Triedman JK. Should patients with congenital heart disease and a systemic ventricular ejection fraction less than $30 \%$ undergo prophylactic implantation of an ICD? Implantable cardioverter defibrillator implantation guidelines based solely on left ventricular ejection fraction do not apply to adults with congenital heart disease. Circ Arrhythm Electrophysiol 2008; 1: 307-316.

210. Silka MJ, Bar-Cohen Y. Should patients with congenital heart disease and a systemic ventricular ejection fraction less than $30 \%$ undergo prophylactic implantation of an ICD? Patients with congenital heart disease and a systemic ventricular ejection fraction less than $30 \%$ should undergo prophylactic implantation of an implantable cardioverter defibrillator. Circ Arrhythm Electrophysiol 2008; 1: 298-306.

211. Jordan CP, Freedenberg V, Wang Y, et al. Implant and clinical characteristics for pediatric and congenital heart patients in the national cardiovascular data registry implantable cardioverter defibrillator registry. Circ Arrhythm Electrophysiol 2014; 7: 1092-1100.

212. Dechert BE, Bradley DJ, Serwer GA, et al. Implantable cardioverter defibrillator outcomes in pediatric and congenital heart disease: time to system revision. Pacing Clin Electrophysiol 2016; 39: 703-708.

213. Krause U, Müller MJ, Wilberg Y, et al. Transvenous and non-transvenous implantable cardioverter-defibrillators in children, adolescents, and adults with congenital heart disease: who is at risk for appropriate and inappropriate shocks? Europace 2019; 21: 106-113.

214. Kalra Y, Radbill A, Johns JA, et al. Antitachycardia pacing reduces appropriate and inappropriate shocks in children and congenital heart disease patients. Heart Rhythm 2012; 9: 1829-1834.

215. Sandhu A, Ruckdeschel E, Sauer WH, et al. Perioperative electrophysiology study in patients with tetralogy of Fallot undergoing pulmonary valve replacement will identify those at high risk of subsequent ventricular tachycardia. Heart Rhythm 2018; 15: 679-685.

216. Alexander ME, Walsh EP, Saul JP, Epstein MR, Triedman JK. Value of programmed ventricular stimulation in patients with congenital heart disease. J Cardiovasc Electrophysiol 1999; 10: 1033-1044.

217. Khairy P, Landzberg MJ, Gatzoulis MA, et al. Value of programmed ventricular stimulation after tetralogy of fallot repair: a multicenter study. Circulation 2004; 109: 1994-2000.

218. Radbill AE, Triedman JK, Berul CI, et al. System survival of nontransvenous implantable cardioverter-defibrillators compared to transvenous implantable cardioverter-defibrillators in pediatric and congenital heart disease patients. Heart Rhythm 2010; 7: 193-198.

219. von Alvensleben Johannes C, Dechert Brynn, Bradley David J, et al. Subcutaneous implantable cardioverter-defibrillators in pediatrics and congenital heart disease: a pediatric and congenital electrophysiology society multicenter review. JACC Clin Electrophysiol 2020; 6: 1752-1761.

220. Steinberg JS, Varma N, Cygankiewicz I, et al. 2017 ISHNE-HRS expert consensus statement on ambulatory ECG and external cardiac monitoring/ telemetry. Heart Rhythm 2017; 14: e55-e96.

221. Moya A, Sutton R, Ammirati F, et al. Guidelines for the diagnosis and management of syncope. Eur Heart J 2009; 30: 2631-2671.

222. Macinnes M, Martin N, Fulton H, McLeod KA. Comparison of a smartphone-based ECG recording system with a standard cardiac event monitor in the investigation of palpitations in children. Arch Dis Child 2019; 104: 43-47.

223. Pradhan S, Robinson JA, Shivapour J, et al. Ambulatory arrhythmia detection with $\mathrm{ZIO}^{\circledast} \mathrm{XT}$ patch in pediatric patients: a comparison of devices. Pediatr Cardiol 2019; 40: 921-924.

224. Babikar A, Hynes B, Ward N, et al. A retrospective study of the clinical experience of the implantable loop recorder in a paediatric setting. Int $\mathrm{J}$ Clin Pract 2008; 62: 1520-1525. 
225. Bezzerides VJ, Walsh A, Martuscello M, et al. The real-world utility of the LINQ implantable loop recorder in pediatric and adult congenital heart patients. JACC Clin Electrophysiol 2019; 5: 245-251.

226. Placidi S, Drago F, Milioni M, et al. Miniaturized implantable loop recorder in small patients: an effective approach to the evaluation of subjects at risk of sudden death. Pacing Clin Electrophysiol 2016; 39: 669-674.

227. Avari Silva JN, Bromberg BI, Emge FK, et al. Implantable loop recorder monitoring for refining management of children with inherited arrhythmia syndromes. J Am Heart Assoc 2016; 5: e003632.

228. Brignole M, Moya A, de Lange FJ, et al. 2018 ESC Guidelines for the diagnosis and management of syncope. Eur Heart J 2018; 39: 1883-1948.

229. Brignole M, Vardas P, Hoffman E, et al. Indications for the use of diagnostic implantable and external ECG loop recorders. Europace 2009; 11: 671-687.

230. Rossano J, Bloemers B, Sreeram N, et al. Efficacy of implantable loop recorders in establishing symptom-rhythm correlation in young patients with syncope and palpitations. Pediatrics 2003; 112: e228-e233.

231. Edvardsson N, Garutti C, Rieger G, et al. Unexplained syncope: implications of age and gender on patient characteristics and evaluation, the diagnostic yield of an implantable loop recorder, and the subsequent treatment. Clin Cardiol 2014; 37: 618-625.

232. Al Dhahri KN, Potts JE, Chiu CC, et al. Are implantable loop recorders useful in detecting arrhythmias in children with unexplained syncope? PacingClin Electrophysiol 2009; 32: 1422-1427.

233. Frangini PA, Cecchin F, Jordao L, et al. How revealing are insertable loop recorders in pediatrics? Pacing Clin Electrophysiol 2008; 31: 338-343.

234. Kenny D, Chakrabarti S, Ranasinghe A, et al. Single-centre use of implantable loop recorders in patients with congenital heart disease. Europace 2009; 11: 303-307.

235. Serdyuk S, Davtyan K, Burd S, et al. Cardiac arrhythmias and sudden unexpected death in epilepsy: results of long-term monitoring. Heart Rhythm 2021; 18: 221-228.

236. Bongiorni MG, Burri H, Deharo JC, et al. 2018 EHRA expert consensus statement on lead extraction: recommendations on definitions, endpoints, research trial design, and data collection requirements for clinical scientific studies and registries: endorsed by APHRS/HRS/LAHRS. Europace 2018; 20: 1217.

237. Fu HX, Huang XM, Zhong L, et al. Outcome and management of pacemaker-induced superior vena cava syndrome. Pacing Clin Electrophysiol 2014; 37: 1470-1476.

238. Riley RF, Petersen SE, Ferguson JD, Bashir Y. Managing superior vena cava syndrome as a complication of pacemaker implantation: a pooled analysis of clinical practice. Pacing Clin Electrophysiol 2010; 33: 420-425.

239. Atallah J, Erickson CC, Cecchin F, et al. Multi-institutional study of implantable defibrillator lead performance in children and young adults: results of the Pediatric Lead Extractability and Survival Evaluation (PLEASE) study. Circulation 2013; 127: 2393-2402.

240. Cecchin F, Atallah J, Walsh EP, et al. Lead extraction in pediatric and congenital heart disease patients. Circ Arrhythmia Electrophysiol 2010; 3: 437-444.

241. Mah DY, Prakash A, Porras D, et al. Coronary artery compression from epicardial leads: more common than we think. Heart Rhythm 2018; 15: 1439-1447.

242. Fender EA, Killu AM, Cannon BC, et al. Lead extraction outcomes in patients with congenital heart disease. Europace 2017; 19: 441-446.

243. McCanta AC, Kong MH, Carboni MP, et al. Laser lead extraction in congenital heart disease: a case-controlled study. Pacing Clin Electrophysiol 2013; 36: 372-380.

244. Moak JP, Freedenberg V, Ramwell C, et al. Effectiveness of excimer laserassisted pacing and ICD lead extraction in children and young adults. Pacing Clin Electrophysiol 2006; 29: 461-466.

245. El-Chami MF, Sayegh MN, Patel A, et al. Outcomes of lead extracton in young adults. Heart Rhythm 2017; 14: 537-540.

246. Gourraud JB, Chaix MA, Shohoudie A, et al. Transvenous lead extraction in adults with congenital heart disease: insights from a 20-year singlecenter experience. Circ Arrhythm Electrophysiol 2018; 11: e005409.

247. Berul CI, Villafane J, Atkins DL, et al. Pacemaker lead prolapse through the pulmonary valve in children. Pacing Clin Electrohysiol 2007; 30: 1183-1189.

248. Webster RG, Margossian R, Alexander ME, Cecchin F, Triedman JK, Walsh EP, Berul CI. Impact of transvenous ventricular pacing leads on tricuspid regurgitation in children and congenital heart disease patients. J Interv Card Electrophysiol 2008; 21: 65-68.
249. Bar-Cohen Y, Berul CI, Alexander ME, et al. Age, size, and lead factors alone do not predict venous obstruction in children and young adults with transvenous lead systems. J Cardiovasc Electrophysiol 2006; 17: 754-759.

250. Joy PS, Kumar G, Poole JE, et al. Cardiac implantable electronic device infections: who is at greatest risk? Heart Rhythm 2017; 14: 839.

251. Sohal M, Williams S, Akhtar M, et al. Laser lead extraction to facilitate cardiac implantable electronic device upgrade and revision in the presence of central venous obstruction. Europace $2014 ; 16$ : 81-87.

252. Gula LJ, Ames A, Woodburn A, et al. Central venous occlusion is not an obstacle to device upgrade with the assistance of laser extraction. Pacing Clin Electrophysiol 2005; 28: 661-666.

253. Viganego F, O’Donoghue S, Eldadah Z, et al. Effect of early diagnosis and treatment with percutaneous lead extraction on survival in patients with cardiac device infections. Am J Cardiol 2012; 109: 1466-1471.

254. Baddour LM, Epstein AE, Erickson CC, et al. Update on cardiovascular implantable electronic device infections and their management: a scientific statement from the American Heart Association. Circulation 2010; 121: 458-477.

255. Janson CM, Patel AR, Bonney WJ, et al. Implantable cardioverter-defibrillator lead failure in children and young adults, a matter of lead diameter of lead design? J Am Coll Cardiol 2014; 63: 133-140.

256. Escudero CA, Mah DY, Miyake CY, et al. Riata lead failure in pediatric and congenital heart disease patients. J Cardiovasc Electrophysiol 2019; 30: 320-325.

257. Slotwiner D, Varma N, Akar J, et al. HRS Expert Consensus Statement on remote interrogation and monitoring for cardiovascular implantable electronic devices. Heart Rhythm 2015; 12: E69-E100.

258. Wilkoff BL, Auricchio A, Brugada J, et al. HRS/EHRA expert consensus on the monitoring of cardiovascular implantable electronic devices (CIEDs): description of techniques, indications, personnel, frequency and ethical considerations. Heart Rhythm 2008; 5: 907-925.

259. Dasgupta S, Madani S, Figueroa R, et al. Myocardial deformation as a predictor of right ventricular pacing -induced cardiomyopathy in the pediatric population. J Cardiovasc Electrophysiol 2020; 31: 337-344.

260. Song MK, Kim NY, Bae EJ, et al. Long term follow up of epicardial pacing and left ventricular dysfunction in children with congenital heart block. Ann Thorac Surg 2020; 109: 1913-1920.

261. Gebauer RA, Tomek V, Salameh A. Predictors of left ventricular remodelling and failure in right ventricular pacing in the young. Eur Heart J 2009; 30: 1097-1104.

262. Thambo JP, Bordachar P, Garrigue S, et al. Detrimental ventricular remodelling in patients with congenital complete heart block and chronic right ventricular apical pacing. Circulation 2004; 110: 3766-3772.

263. Tantengco MV, Thomas RL, Karpawich PP. Left ventricular dysfunction after long-term right ventricular apical pacing in the young. J Am Coll Cardiol 2001; 37: 2093-2100.

264. Gonzalez Corcia MC, Remy LS, Marchandise S, et al. Exercise performance in young patients with complete atrioventricular block: the relevance of synchronous atrioventricular pacing. Cardiol Young 2016: 261066-261071.

265. Ross B, Zeigler V, Zinner A, et al. The effect of exercise on the atrial electrogram voltage in young patients. Pacing Clin Electrophysiol 1991; 4: 2092-2097.

266. Chudzik M, Klimczak A, Wranicz JK. Ambulatory Holter monitoring in asymptomatic patients with DDD pacemakers - do we need ACC/AHA guideline revision? Arch Med Sci 2013; 9: 815-820.

267. Diemberger I, Gardini B, Martignani C, et al. Holter ECG for pacemaker/ defibrillator carriers: what is its role in the era of remote monitoring? Heart 2015; 101: 1272-1278.

268. Dechert BE, Sewer GA, Bradley DJ, et al. Cardiac implantable electronic device remote monitoring surveillance in pediatric and congenital heart disease: utility relative to frequency. Heart Rhythm 2015; 12: 117-122.

269. Malloy LE, Gingerich J, Olson MD, et al. Remote monitoring of cardiovascular implantable devices in the pediatric population improves detection of adverse events. Pediatr Cardiol 2014; 35: 301-306.

270. Nishii N, Miyoshi A, Kubo M, et al. Analysis of arrhythmic events is useful to detect lead failure earlier in patients followed by remote monitoring. J Cardiovasc Electrophysiol 2018; 29: 463-470. 
271. Piccini JP, Snell J, Prillinger JB, et al. Impact of remote monitoring on clinical events and associated health care utilization: a nationwide assessment. Heart Rhythm 2016; 13: 2279-2286.

272. Hummel JP, Leipold RJ, Amorosi SL, et al. Outcomes and costs of remote monitoring among patients with implanted cardiac defibrillators: an economic model based on the PREDICT RM database. J Cardiovasc Electrophysiol 2019; 30: 1066-1077.

273. Dechert BE, Sewer GA, Bradley DJ, et al. Frequency of CIED remote monitoring: a quality improvement follow-up study. Pacing Clin Electrophysiol 2019; 42: 959-962.

274. Boyer SL, Silka MJ, Bar-Cohen Y. Current practices in the monitoring cardiac rhythm devices in pediatrics and congenital heart disease. Pediatr Cardiol 2015; 36: 821-826.

275. Kadish AH, Buxton AE, Kennedy HL, et al. ACC/AHA clinical competence statement on electrocardiography and ambulatory electrocardiography: a report of the ACC/AHA/ACP-ASIM task force on clinical competence (ACC/AHA Committee to develop a clinical competence statement on electrocardiography and ambulatory electrocardiography) endorsed by the International Society for Holter and noninvasive electrocardiology. Circulation 2001; 104: 3169-3178.

276. Bricker JT, Garson A, Traweek M, et al. The use of exercise testing in children to evaluate abnormalities of pacemaker function not apparent at rest. Pacing Clin Electrophysiol 1985; 8: 656-660.

277. Sampio SMV, Craveiro NM, Darrieux F, et al. Accuracy of the pacemaker event recorder versus Holter-ECG to detect both symptomatic and asymptomatic ventricular arrhythmias. J Cardiovasc Electrophysiol 2018; 29: 154-159.

278. Munawar DA, Chan JEZ, Emami M, et al. Magnetic resonance imaging in non-conditional pacemakers and implantable cardioverter-defibrillators: a systematic review and meta-analysis. Europace 2020; 22: 288-298.

279. Bireley M, Kovach JR, Morton C, et al. Cardiac magnetic resonance imaging (MRI) in children is safe with most pacemaker systems, including those with epicardial leads. Pediatr Cardiol 2020; 41: 801-808.

280. Shah AD, Morris MA, Hirsh DS, et al. Magnetic resonance imaging safety in nonconditional pacemaker and defibrillator recipients: a meta-analysis and systematic review. Heart Rhythm 2018; 15: 1001-1008.

281. Gakenheimer-Smith L, Etheridge SP, Niu MC, et al. MRI in pediatric and congenital heart disease patients with CIEDs and epicardial or abandoned leads. Pacing Clin Electrophysiol 2020; 43: 797-804.

282. Schaller R, Brunker T, Riley MP, et al. Magnetic resonance imaging in patients with cardiac implantable electronic devices with abandoned leads. JAMA Cardiol 2021; 6: 549-556.

283. Nazarian S, Hansford R, Rahsepar AA, et al. Safety of magnetic resonance imaging in patients with cardiac devices. N Engl J Med 2017; 377: 2555-2564.

284. Padmanabhan D, Kella DK, Mehta R, et al. Safety of magnetic resonance imaging in patients with legacy pacemakers and defibrillators and abandoned leads. Heart Rhythm 2018; 15: 228-233.

285. Rahsepar AA, Zimmerman SL, Hansford R, et al. The relationship between MRI radiofrequency energy and function of nonconditional implanted cardiac devices: a prospective evaluation. Radiology 2020; 295: 307-313.

286. Balmer C, Gass M, Dave H, et al. Magnetic resonance imaging of patients with epicardial leads: in vitro evaluation of temperature changes at the lead tip. J Interv Card Electrophysiol 2019; 56: 321-326.

287. Langman DA, Goldberg IB, Finn JP, et al. Pacemaker lead tip heating in abandoned and pacemaker-attached leads at 1.5 Tesla MRI. J Magn Reson Imaging 2011; 33: 426-431.

288. Mattei E, Calcagnini G, Censi F, et al. Role of the lead structure in MRIinduced heating: in vitro measurements on 30 commercial pacemaker/ defibrillator leads. Magn Reson Med 2012; 67: 925-935.

289. Higgins JV, Gard JJ, Sheldon SH, et al. Safety and outcomes of magnetic resonance imaging in patients with abandoned pacemaker and defibrillator leads. Pacing Clin Electrophysiol 2014; 37: 1284-1290.

290. Saarel EV, Pilcher TA, Etheridge SP. Safety of sports for pediatric and congenital ICD and pacemaker patients. Heart Rhythm 2013; 10 (5S): 211.

291. Lampert R, Olshansky B, Heidbuchel H, et al. Safety of sports for athletes with implantable cardioverter-defibrillators: results of a prospective, multinational registry. Circulation 2013; 127: 2021-2030.
292. Lampert R, Olshansky B, Heidbuchel H, et al. Safety of sports for athletes with implantable cardioverter defibrillators: long-term results of a prospective multinational registry. Circulation 2017; 135: 2310-2312.

293. Saarel EV, Law I, Berul CI, et al. Safety of sports for young patients with implantable cardioverter-defibrillators: long-term results of a prospective multinational registry. Circ Arrhythm Electrophysiol 2018; 11: e006305.

294. Maron BJ, Udelson JE, Bonow RO, et al. Eligibility and disqualification recommendations for competitive athletes with cardiovascular abnormalities: task force 3: hypertrophic cardiomyopathy, arrhythmogenic right ventricular cardiomyopathy and other cardiomyopathies, and myocarditis. Circulation 2015; 132: e273-e280.

295. Zipes DP, Link MS, Ackerman MJ, et al. Eligibility and disqualification recommendations for competitive athletes with cardiovascular abnormalities: task force 9: arrhythmias and conduction defects. Circulation 2015; 132: e315-e325.

296. Maron BJ, Zipes DP. Introduction: eligibility recommendations for competitive athletes with cardiovascular abnormalities-general considerations. J Am Coll Cardiol 2005; 45: 1318-1321.

297. Pelliccia A, Fagard R, Bjørnstad HH, et al. Recommendations for competitive sports participation in athletes with cardiovascular disease: a consensus document from the Study Group of Sports Cardiology of the Working Group of Cardiac Rehabilitation and Exercise Physiology and the Working Group of Myocardial and Pericardial Diseases of the European Society of Cardiology. Eur Heart J 2005; 26: 1422-1445.

298. Mitchell JH, Haskell W, Snell P, et al. Task Force 8: classification of sports. J Am Coll Cardiol 2005; 45: 1364-1367.

299. Lampert R, Cannom D, Olshansky B. Safety of sports participation in patients with implantable cardioverter defibrillators: a survey of heart rhythm society members. J Cardiovasc Electrophysiol 2006; 17: 11-15.

300. The World Bank. Country and Lending Groups, 2021. Retrieved January 2021, http://data.worldbank.org/about/country-classifications/countryand-lending-groups.

301. Bonny A, Mgantcha M, Jeilan M, et al. Statistics on the use of cardiac electronic devices and interventional electrophysiological procedures in Africa from 2011 to 2016: report of the Pan African Society of Cardiology (PASCAR) Cardiac Arrhythmias and Pacing Task Forces. Europace 2018; 1 : 1513-1526.

302. Murray LE, Smith AH, Flack EC, et al. Genotypic and phenotypic predictors of complete heart block and recovery of conduction after surgical repair of congenital heart disease. Heart Rhythm 2017; 14: 402-409.

303. Paech C, Dahnert I, Kostelka M, et al. Association of temporary complete AV block and junctional ectopic tachycardia after surgery for congenital heart disease. Ann Pediatr Cardiol 2015; 8: 14-19.

304. Batra AS, Wells WJ, Hinoki KW, et al. Late recovery of atrioventricular conduction after pacemaker implantation for complete heart block associated with surgery for congenital heart disease. J Thorac Cardiovasc Surg 2003; 125: 1291-1293.

305. Bruckheimer E, Berul CI, Kopf GS, et al. Late recovery of surgicallyinduced atrioventricular block in patients with congenital heart disease. J Interv Card Electrophysiol 2002; 6: 191-195.

306. Khairy T, Lupien MA, Nava S, et al. Infections associated with resterilized pacemakers and defibrillators. N Engl J Med 2020; 382: 1823-1831.

307. Baman TS, Meier P, Romero J, et al. Safety of pacemaker reuse: a metaanalysis with implications for underserved nations. Circ Arrhythm Electrophysiol 2011; 4: 318-323.

308. Kapoor A, Vora A, Nataraj G, Mishra S, et al. Guidance on reuse of cardiovascular catheters and devices in India: a consensus document. Indian Heart J 2017; 69: 357-363.

309. Roberts PR, El Refai MH. The use of App-based follow-up of cardiac implantable electronic devices. Card Fail Rev 2020; 6: e03.

310. Elwyn G, Frosch D, Thomson R, et al. Shared decision making: a model for clinical practice. J Gen Intern Med 2012; 27: 1361-1367.

311. Greenfield S, Kaplan S, Ware Jr. JE. Expanding patient involvement in care. Effects on patient outcomes. Ann Intern Med 1985; 102: 520-528.

312. Legare F, Adekpedjou R, Stacey D, et al. Interventions for increasing the use of shared decision making by healthcare professionals. Cochrane Database Syst Rev 2018; 7: CD006732. 
313. Khairy P, Dore A, Poirier N, et al. Risk stratification in surgically repaired tetralogy of Fallot. Expert Rev Cardiovasc Ther 2009; 7: 755-762.

314. Goette A, Auricchio A, Boriani G, et al. EHRA White paper: knowledge gaps in arrhythmia management—status 2019. Europace 2019; 21: 993-994.

315. Burns KM, Evans F, Kaltman JR. Pediatric ICD utilization in the United States from 1997-2006. Heart Rhythm 2011; 8: 23-28.
316. Breatnach CR, Dunne L, Al-Alawi K, et al. Leadless Micra pacemaker use in the pediatric population: device implantation and short-term outcomes. Pediatr Cardiol 2020; 41: 683-686.

317. Lyon S, Dandamudi G, Kean AC. Permanent His-bundle pacing in pediatrics and congenital heart disease. J Innov Card Rhythm Manag 2020; 11: $4005-4012$. 


\section{Appendix A1}

Author relationships with industry

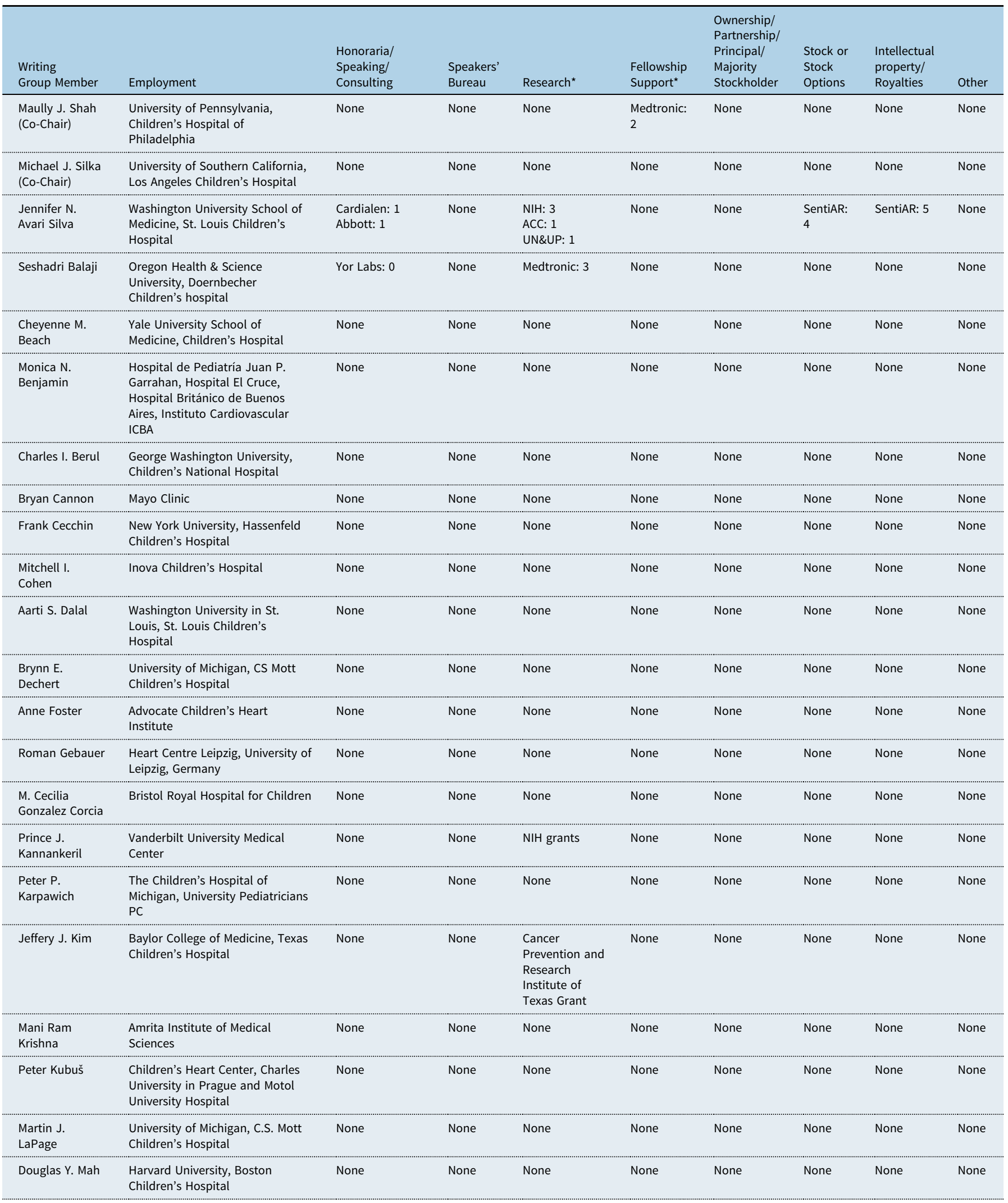




\begin{tabular}{|c|c|c|c|c|c|c|c|c|c|}
\hline $\begin{array}{l}\text { Writing } \\
\text { Group Member }\end{array}$ & Employment & $\begin{array}{l}\text { Honoraria/ } \\
\text { Speaking/ } \\
\text { Consulting }\end{array}$ & $\begin{array}{l}\text { Speakers' } \\
\text { Bureau }\end{array}$ & Research* $^{\star}$ & $\begin{array}{l}\text { Fellowship } \\
\text { Support* }\end{array}$ & $\begin{array}{l}\text { Ownership/ } \\
\text { Partnership/ } \\
\text { Principal/ } \\
\text { Majority } \\
\text { Stockholder }\end{array}$ & $\begin{array}{l}\text { Stock or } \\
\text { Stock } \\
\text { Options }\end{array}$ & $\begin{array}{l}\text { Intellectual } \\
\text { property/ } \\
\text { Royalties }\end{array}$ & Other \\
\hline $\begin{array}{l}\text { Lindsey Malloy- } \\
\text { Walton }\end{array}$ & Children's Mercy Hospital & None & None & None & None & None & None & None & None \\
\hline Aya Miyazaki & $\begin{array}{l}\text { Mt. Fuji Shizuoka Children's } \\
\text { Hospital }\end{array}$ & None & None & None & None & None & None & None & None \\
\hline $\begin{array}{l}\text { Kara S. } \\
\text { Motonaga }\end{array}$ & $\begin{array}{l}\text { Stanford University, Lucile } \\
\text { Packard Children's Hospital }\end{array}$ & None & None & None & None & None & None & None & None \\
\hline Mary C. Niu & $\begin{array}{l}\text { University of Utah Health } \\
\text { Sciences Center/Primary } \\
\text { Children's Hospital }\end{array}$ & None & None & None & None & None & None & None & None \\
\hline Melissa Olen & Nicklaus Children's Hospital & None & None & None & None & None & None & None & None \\
\hline Thomas Paul & $\begin{array}{l}\text { Georg-August-University Medical } \\
\text { Center }\end{array}$ & $\begin{array}{l}\text { AOP Orphan } \\
\text { Pharmaceuticals }\end{array}$ & & & & & & & \\
\hline Eric Rosenthal & $\begin{array}{l}\text { Evelina London Children's } \\
\text { Hospital, Guy's \& St Thomas' NHS } \\
\text { Trust, St Thomas' Hospital }\end{array}$ & None & None & None & None & None & None & None & None \\
\hline $\begin{array}{l}\text { Elizabeth V. } \\
\text { Saarel }\end{array}$ & St. Luke's Health System & None & None & None & None & None & None & None & None \\
\hline $\begin{array}{l}\text { Massimo } \\
\text { Stefano Silvetti }\end{array}$ & $\begin{array}{l}\text { Bambino Gesù Children's Hospital } \\
\text { IRCCS }\end{array}$ & None & None & None & None & None & None & None & None \\
\hline $\begin{array}{l}\text { Elizabeth A. } \\
\text { Stephenson }\end{array}$ & The Hospital for Sick Children & None & None & None & None & None & None & None & None \\
\hline Reina B. Tan & $\begin{array}{l}\text { New York University Langone } \\
\text { Health, Hassenfeld Children's } \\
\text { Hospital }\end{array}$ & None & None & None & None & None & None & None & None \\
\hline John Triedman & $\begin{array}{l}\text { Harvard Medical School, Boston } \\
\text { Children's Hospital }\end{array}$ & $\begin{array}{l}\text { Biosense } \\
\text { Webster, } \\
\text { SentiAR }\end{array}$ & None & None & None & None & None & None & None \\
\hline $\begin{array}{l}\text { Nicholas H. Von } \\
\text { Bergen }\end{array}$ & $\begin{array}{l}\text { The University of Wisconsin- } \\
\text { Madison }\end{array}$ & None & None & None & None & $\begin{array}{l}\text { Atrility } \\
\text { Medical: } 5\end{array}$ & $\begin{array}{l}\text { Atrility } \\
\text { Medical: } \\
1\end{array}$ & None & None \\
\hline Philip L. Wackel & Mayo Clinic & None & None & None & None & None & None & None & None \\
\hline
\end{tabular}

Number value: $\mathbf{0}=\$ 0 ; \mathbf{1}=\leq \$ 10,000 ; \mathbf{2}=>\$ 10,000$ to $\leq \$ 25,000 ; \mathbf{3}=>\$ 25,000$ to $\leq \$ 50,000 ; \mathbf{4}=>\$ 50,000$ to $\leq \$ 100,000 ; \mathbf{5}=>\$ 100,000$.

${ }^{\star}$ Research and fellowship support are classed as programmatic support. Sources of programmatic support are disclosed but are not regarded as a relevant relationship with industry for writing group members or reviewers. 


\section{Appendix A2}

Reviewer relationships with industry

\begin{tabular}{|c|c|c|c|c|c|c|c|c|c|c|}
\hline Peer Reviewer & Representation & Employment & $\begin{array}{l}\text { Honoraria/ } \\
\text { Speaking/ } \\
\text { Consulting }\end{array}$ & $\begin{array}{l}\text { Speakers' } \\
\text { Bureau }\end{array}$ & Research* & $\begin{array}{l}\text { Fellowship } \\
\text { Support* }\end{array}$ & $\begin{array}{l}\text { Ownership/ } \\
\text { Partnership/ } \\
\text { Principal/ } \\
\text { Majority } \\
\text { Stockholder }\end{array}$ & $\begin{array}{l}\text { Stock } \\
\text { or } \\
\text { Stock } \\
\text { Options }\end{array}$ & $\begin{array}{l}\text { Intellectual } \\
\text { Property/ } \\
\text { Royalties }\end{array}$ & Other \\
\hline Philip M. Chang & $\mathrm{ACC}$ & $\begin{array}{l}\text { University of Florida } \\
\text { Health/Shands } \\
\text { Children's Hospital }\end{array}$ & None & None & None & None & None & None & None & None \\
\hline Fabrizio Drago & AEPC & $\begin{array}{l}\text { Bambino Gesù } \\
\text { Children's Hospital } \\
\text { IRCCS }\end{array}$ & None & None & None & None & None & None & None & None \\
\hline Anne M. Dubin & PACES & $\begin{array}{l}\text { Stanford University, } \\
\text { Lucile Packard } \\
\text { Children's Hospital }\end{array}$ & None & None & None & None & None & None & $\begin{array}{l}\text { UpToDate } \\
\text { royalties: } 1\end{array}$ & None \\
\hline $\begin{array}{l}\text { Susan P. } \\
\text { Etheridge }\end{array}$ & $\mathrm{AHA}$ & $\begin{array}{l}\text { University of Utah } \\
\text { Health Sciences Center/ } \\
\text { Primary Children's } \\
\text { Hospital }\end{array}$ & None & None & None & None & None & None & None & None \\
\hline $\begin{array}{l}\text { Apichai } \\
\text { Kongpatanayothin }\end{array}$ & APHRS & $\begin{array}{l}\text { Bangkok General } \\
\text { Hospital }\end{array}$ & None & None & None & None & None & None & None & None \\
\hline Jose M. Moltedo & LAHRS & Sanatorio Finochietto & $\begin{array}{l}\text { Abbott/ } \\
\text { Biomarkers: } \\
1\end{array}$ & None & None & None & None & None & None & None \\
\hline Ashish A. Nabar & IHRS & $\begin{array}{l}\text { Lilavati Hospital, } \\
\text { Jupiter Hospital }\end{array}$ & None & None & None & None & None & None & None & None \\
\hline $\begin{array}{l}\text { George F. Van } \\
\text { Hare }\end{array}$ & HRS & $\begin{array}{l}\text { Washington University } \\
\text { in St. Louis, St. Louis } \\
\text { Children's Hospital }\end{array}$ & None & None & None & None & None & None & None & None \\
\hline
\end{tabular}

Number value: $\mathbf{0}=\$ 0 ; \mathbf{1}=\leq \$ 10,000 ; \mathbf{2}=>\$ 10,000$ to $\leq \$ 25,000 ; \mathbf{3}=>\$ 25,000$ to $\leq \$ 50,000 ; \mathbf{4}=>\$ 50,000$ to $\leq \$ 100,000 ; \mathbf{5}=>\$ 100,000$.

${ }^{*}$ Research and fellowship support are classed as programmatic support. Sources of programmatic support are disclosed but are not regarded as a relevant relationship with industry for writing group members or reviewers. 